University of Redlands

\title{
Connected Global Learning
}

\author{
A Major Individual Project submitted in partial satisfaction of the requirements \\ for the degree of Master of Science in Geographic Information Systems \\ by \\ Shawn Kan \\ Ruijin Ma, Ph.D., Committee Chair \\ Douglas M. Flewelling, Ph.D.
}

August 2016 
Connected Global Learning

Copyright (C) 2016

by

Shawn Kan 
The report of Shawn Kan is approved.
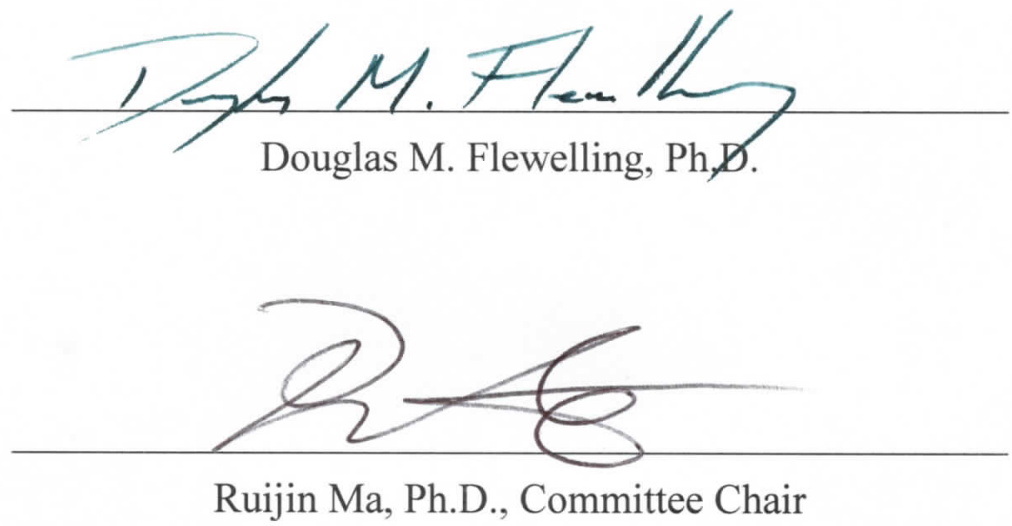

August 2016 



\section{Acknowledgements}

I would first like to acknowledge and thank the MS GIS faculty for your instruction and deep dedication to helping the students. I would like to thank Dr Ruijin Ma for the guidance that you have shown as my adviser, for taking the time to help me frame my thoughts better, and for the help that you've given to make my project a better one. Thanks Andrea Barrios for sorting out our administrative issues and ensuring the smooth running of the program, even dealing with untimely requests. Thanks Matthew

Flewelling for helping with JavaScript and styling. Thanks Lynn Flewelling for the time you've put into editing and the advice you've given for writing.

I would like to thank members of Cohort 28 for their friendship and support through the last 12 months. Thank you for the memorable time at the program especially the outings and learning together.

A big thanks to my family for their continuous support back home, helping me sort out issues there so that I could have a worry-free time going through the program. Thank you for all the prayers and the words of encouragement as I went through the program. Thanks Robyn Heng for your prayers as well. 



\author{
Abstract \\ Connected Global Learning \\ by \\ Shawn Kan
}

Internationalization is becoming an increasingly important topic at institutions worldwide due to its scale and effects. The University of Redlands Council for Comprehensive Internationalization wanted to consolidate various datasets about internationalization into a streamlined interface for users to access according to their needs. The information was consolidated and imported into a geodatabase. The datasets were published as feature services in ArcGIS Online. A web GIS application was developed using HTML, CSS, Dojo Toolkit and Esri's ArcGIS JavaScript API to depict internationalization at the university. The content panes in the application consists international students, study abroad programs, faculty research, and teaching at the university. Each pane has its own functionality and shows its respective aspect of internationalization in the map viewer so that students, faculty members and planners are able to visualize and use the information. 



\section{Table of Contents}

Chapter 1 - Introduction ................................................................................................ 1

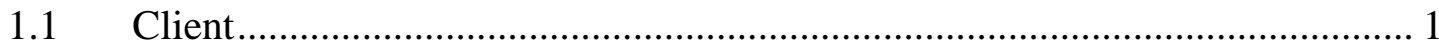

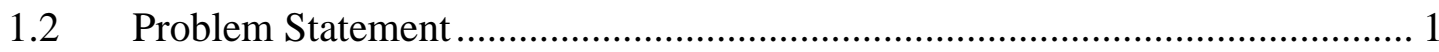

$1.3 \quad$ Proposed Solution ............................................................................... 1

1.3.1 Goals and Objectives ........................................................................... 2

1.3.2 Scope

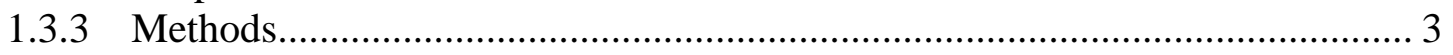

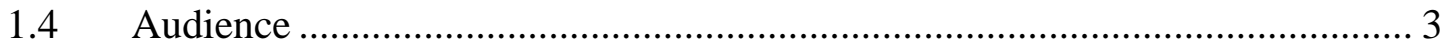

1.5 Overview of the Rest of this Report ........................................................... 3

Chapter 2 - Background and Literature Review ............................................................. 5

$2.1 \quad$ Introduction to Internationalization ...................................................... 5

2.2 Promoting Internationalization ............................................................ 6

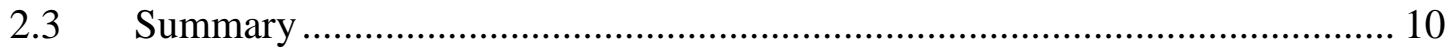

Chapter 3 - Systems Analysis and Design............................................................. 13

$3.1 \quad$ Problem Statement ................................................................................. 13

3.2 Requirements Analysis ………………………..................................... 13

3.2.1 Functional Requirements .......................................................................... 13

3.2.2 Non-Functional Requirements .............................................................. 14

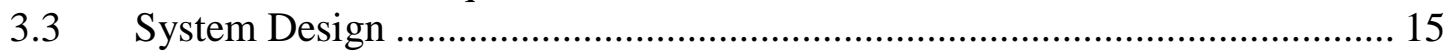

3.4 Project Plan ...................................................................................... 16

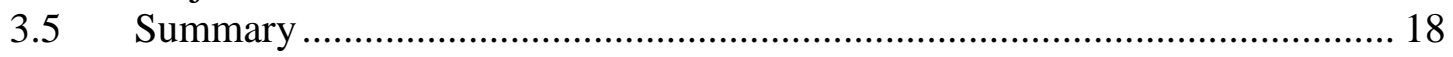

Chapter 4 - Database Design..................................................................................................... 19

4.1 Conceptual Data Model ..................................................................... 19

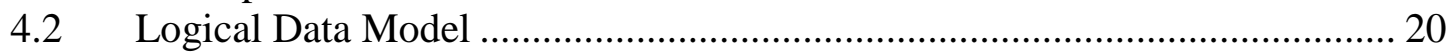

4.2.1 International Students Dataset ............................................................... 20

4.2.2 Study Abroad Programs Dataset .................................................................. 22

4.2.3 Faculty Research Dataset..................................................................... 22

4.2.4 Faculty Teaching Dataset..................................................................... 24

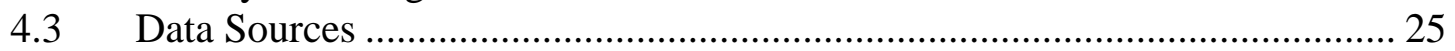

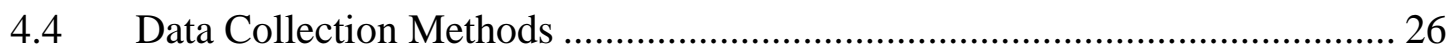

4.5 Data Scrubbing and Loading …………………….................................. 29

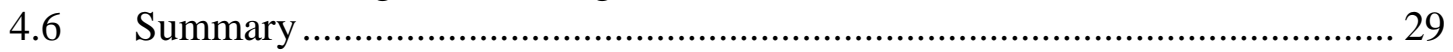

Chapter 5 - Implementation.................................................................................................. 31

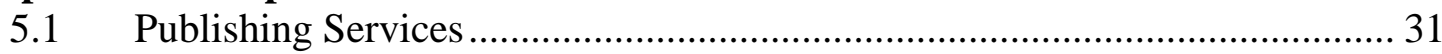

5.2 Graphical User Interface (GUI) of Web Application ...................................... 32

5.2.1 Map Viewer and Graphic Visualization ..................................................... 34

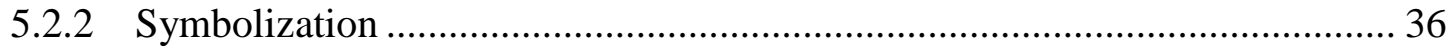

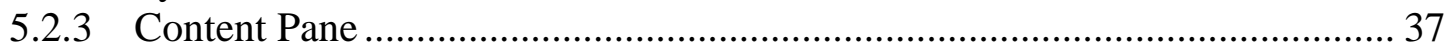

5.2.4 Navigation Tools and User Interaction ......................................................... 40

5.2.5 Search Widget Implementation..................................................................... 44

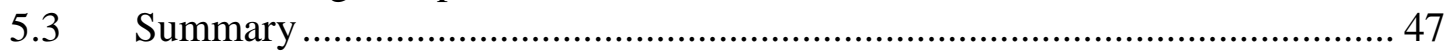


Chapter 6 - Use Cases................................................................................................................ 49

6.1 Use Case: Students Planning to Come to the University and Looking for

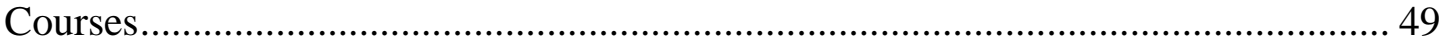

6.2 Use Case: Faculty Looking for Resources and Collaboration ........................ 52

6.3 Use Case: Planning for Students, Faculty and Programs................................. 55

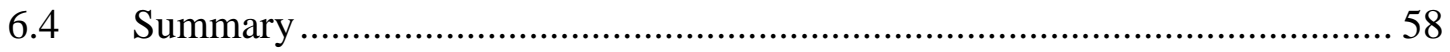

Chapter 7 - Conclusions and Future Work ....................................................................... 59

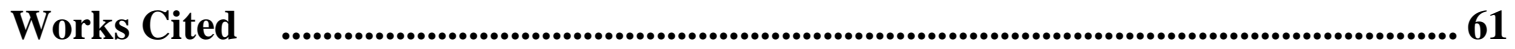

Appendix A. HTML Code.................................................................................................... 63

Appendix B. JavaScript Code......................................................................................... 64

Appendix C. CSS Code......................................................................................................... 89 


\section{Table of Figures}

Figure 2-1: $\quad$ Faculty Survey Story Map Template. ............................................... 9

Figure 2-2: $\quad$ An Example of Radial Flow Web Map.......................................... 10

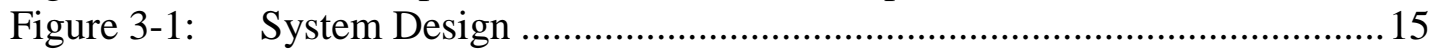

Figure 4-1: Conceptual Data Model ............................................................... 19

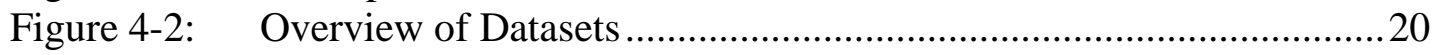

Figure 4-3: International Student Dataset ........................................................ 21

Figure 4-4: Study Abroad Programs Dataset....................................................... 22

Figure 4-5: $\quad$ Faculty Research Dataset Overview ................................................. 23

Figure 4-6: Research Country of Interest ....................................................... 23

Figure 4-7: Research Region of Interest .......................................................24

Figure 4-8: Faculty Teaching Dataset............................................................2 24

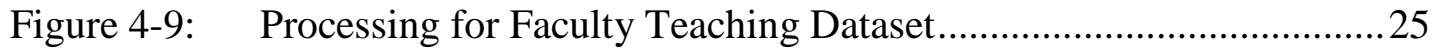

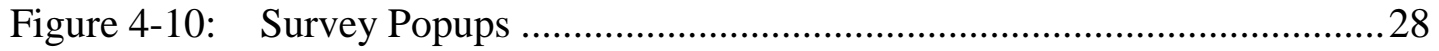

Figure 4-11: Faculty Survey Story Map Template .............................................28

Figure 5-1: $\quad$ Feature Services From Datasets ..................................................... 31

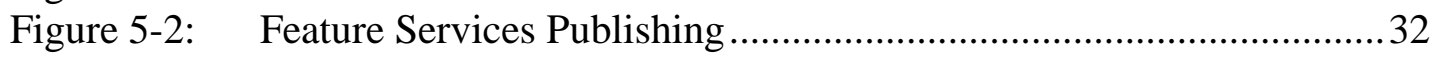

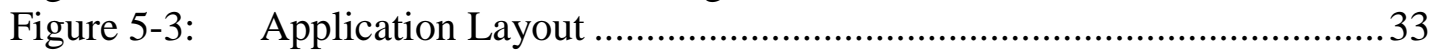

Figure 5-4: Showing Data on Map Viewer..................................................... 34

Figure 5-5: Layers Linked to the International Students Pane ............................. 35

Figure 5-6: $\quad$ Example of Programmatically Displaying Layers ............................ 35

Figure 5-7: $\quad$ Examples of Using Proportional Symbols and Color Ramps for

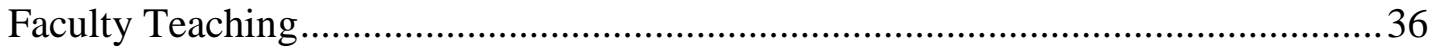

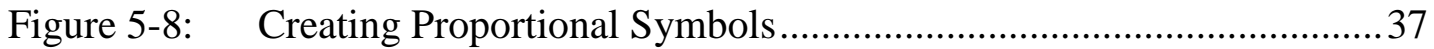

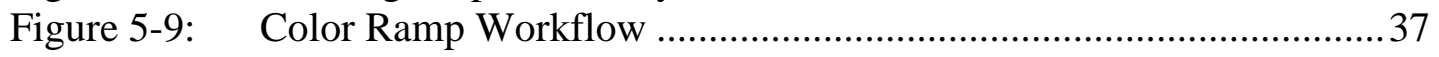

Figure 5-10: Content Pane Example .............................................................. 38

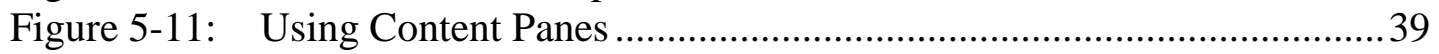

Figure 5-12: Horizontal Bar Chart for Top International Student Countries .........39

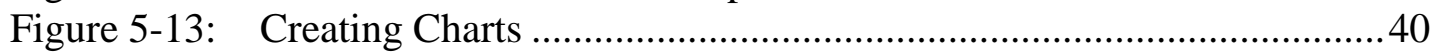

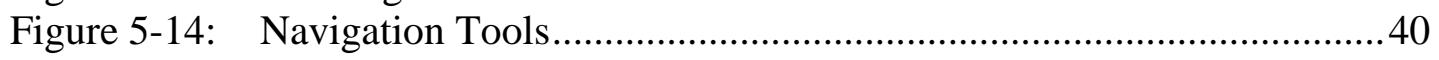

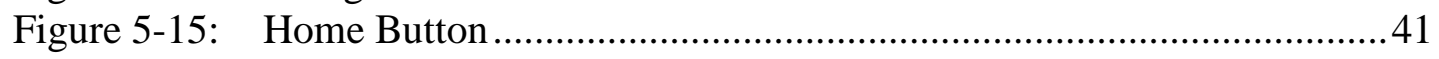

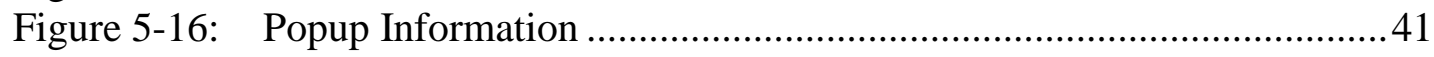

Figure 5-17: Creating and Setting Popup Windows ........................................ 41

Figure 5-18: Selecting Country Point or Region Polygon .................................... 42

Figure 5-19: Flow for Implementing Related Query in JavaScript ........................43

Figure 5-20: Return from Relationship Class .................................................. 43

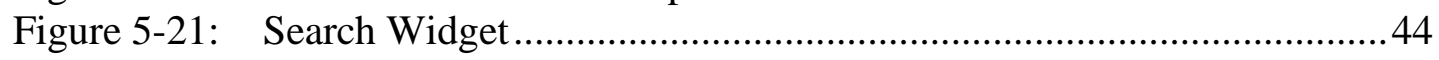

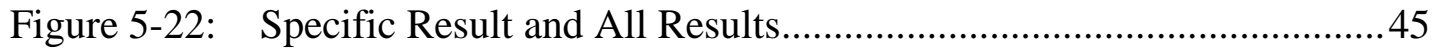

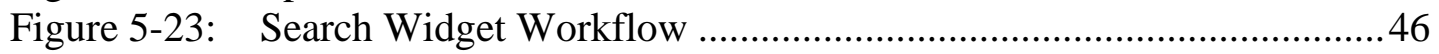

Figure 5-24: Search Results Returned ............................................................ 47

Figure 6-1: Internationalization at the University of Redlands ..........................49

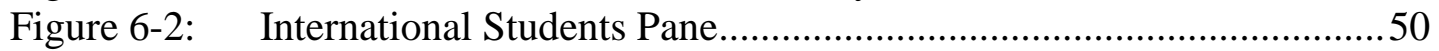

Figure 6-3: $\quad$ Popups and Home Button .............................................................50

Figure 6-4: Study Abroad Programs Offered Related to China............................51 
Figure 6-5: Courses Taught With Relation to China........................................ 52

Figure 6-6: Number of Students from Austria ................................................. 53

Figure 6-7: The Search Tool in Various Forms (A) Collapsed (B) Expanded with

Hints (C) Showing Search Suggestions.............................................................. 53

Figure 6-8: $\quad$ Comparison Between (A) General and (B) Specific Search Results 54

Figure 6-9: $\quad$ Select By Region in Faculty Research ....................................... 54

Figure 6-10: Using Country Count and Charts ............................................... 55

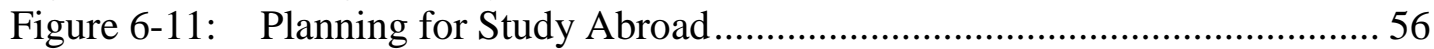

Figure 6-12: Planning for Faculty Hiring........................................................ 57

Figure 6-13: Color Ramps and Number of Points in an Area Help in

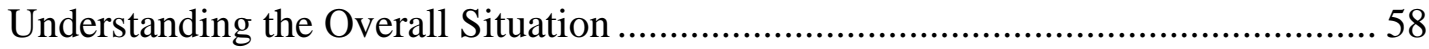




\section{List of Tables}

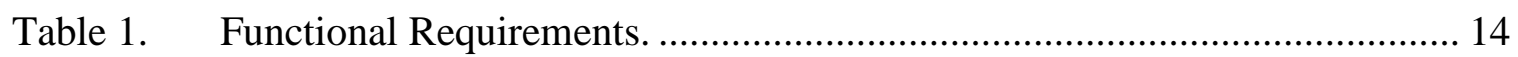

Table 2. Non Functional Requirements. ............................................................. 15

Table 3. Initial Planned Project Activities and Timeline ........................................ 16

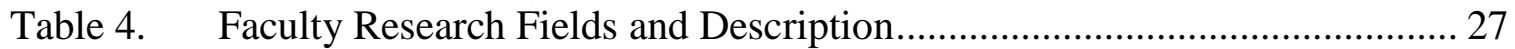

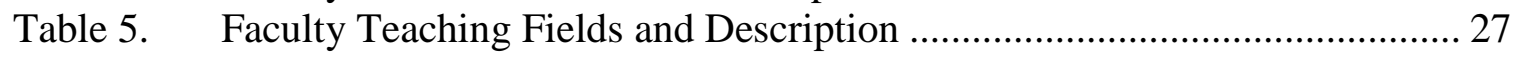





\section{List of Acronyms and Definitions}

$\begin{array}{ll}\text { API } & \text { Application Programming Interface } \\ \text { CCI } & \text { Council for Comprehensive Internationalization } \\ \text { CITI } & \text { Collaborative Institutional Training Initiative } \\ \text { CSS } & \text { Cascading Style Sheets } \\ \text { GIS } & \text { Geographic Information System } \\ \text { GUI } & \text { Graphical User Interface } \\ \text { HTML } & \text { Hyper Text Markup Language } \\ \text { IRB } & \text { Institutional Review Board } \\ \text { OECD } & \text { Organization for Economic Co-operation and Development } \\ \text { REST } & \text { Representational State Transfer } \\ \text { SQL } & \text { Structured Query Language } \\ \text { UN } & \text { United Nations } \\ \text { UNESCO } & \text { United Nations Educational, Scientific and Cultural Organization } \\ \text { URL } & \text { Uniform Resource Locator }\end{array}$





\section{Chapter 1 - Introduction}

In 2013, the University of Redlands, California, announced the creation of the Council for Comprehensive Internationalization (CCI) to develop plans to shape and guide internationalization for the university. The CCI adopted "the process of integrating an international, intercultural or global dimension into the purpose, functions or delivery of postsecondary education" (Knight, Updated definition of internationalization, 2003, p. 2) as the definition of internationalization to guide its thinking and actions. Following an internal study conducted in 2014, the CCI made recommendations to strengthen its position regarding internationalization. One of the key areas for the university to leverage on was its strengths in the study abroad programs. In turn, one of the key weaknesses targeted was the lower percentage of undergraduate international student enrollment as compared to institutes of similar size in California (Wingenbach, et al., 2014).

\subsection{Client}

The client for this project was Dr. Steve Wuhs, an Associate Professor of Government, Chair of the Department of Political Science at the University of Redlands and a member of the CCI. The CCI report made detailed recommendations in areas which the CCI believed should be of immediate focus. The client wanted to address the issues of creating international resources for faculty to integrate into their existing teaching curriculum, positioning the university as a global institute to attract prospective international students, and preparing students who are embarking on exchange or study abroad programs with the requisite knowledge and cultural understanding. He felt that the way to do this was to utilize GIS in creating a web application that could be integrated with the Global Opportunities page at the university website.

\subsection{Problem Statement}

The key problem the CCI faced was that various departments within the university currently held disparate data sets representing multiple facets of internationalization such as faculty teaching, faculty research, international student, and study abroad data. Users have a difficult time locating the data since they need to query through the different department databases to piece the data together.

The university lacks a comprehensive platform to consolidate the existing datasets of internationalization into a streamlined interface that allows a user to query these datasets according to their respective needs. The CCI needed the query results displayed in a more useful format so as to aid decision making. They also wanted this functionality to be integrated into their existing web page on internationalization and global opportunities.

\subsection{Proposed Solution}

Following discussions with the client, it was decided that the final project would be a web application that would make use of international student data, study abroad data, and faculty research and teaching data to evaluate internationalization at the university. This 
application needed to be interactive and would allow users to click each country, which then displayed popup information such as the number of students at or from a country and the programs offered within that country. It also allowed the query of specific information such as faculty that taught or conducted research over a particular country, the topics they covered and a synopsis of the research or teaching subjects. The page also provided some summary information such as total international students or study abroad students and countries involved.

\subsubsection{Goals and Objectives}

The goal of this project was to develop a proof of concept web application that depicts internationalization at the university through the aforementioned aspects of international students, study abroad programs, faculty teaching, and faculty research. This web application can be embedded into an existing web page and is used to display underlying tabular data spatially.

This web application provided a consolidation of resources and was targeted towards four key groups. The first group is comprised of prospective students, who need more information about the university, including facts such as the current composition of international students and the courses with international content offered by the university. The second group is comprised of current students, who need to identify study abroad programs to attend, as well as the corresponding faculty and courses which would aid them in preparing for these programs. The third group is comprised of faculty, who need to identify resources for teaching and to also identify potential areas of further collaboration with other faculty. The final group is comprised of planners and shows the overall distribution of curriculum, student recruitment, and study abroad popularity by country. This allowed them the ability to better make plans for the recruitment of faculty and students, as well as to adjust the scope of curriculum and study abroad programs.

\subsubsection{Scope}

The scope of this project entailed producing a web application for the client and a set of instructions of how to update the application with recent data. The data would be represented at country level.

The client was responsible for providing the data about the number of international students and their countries, the study abroad countries and the programs involved. Due to privacy reasons, the data collected previously on international teaching subjects and international research areas could not be used for this project. The project team had to go through Collaborative Institutional Training Initiative (CITI) training and submit an application to the university's Institutional Review Board (IRB) to collect and use faculty teaching and research data, and to design the survey to collect the necessary data from the faculty at university.

The project team had to design a model for converting tabular data into spatial data to be represented on the map. They were also responsible for designing a geodatabase for the converted data. The team was responsible for developing the web application to display the data, enable the correct popups, and create the query for users to search for countries, regions or faculty names. The web application and data would be hosted on the projects team's servers during development and transferred to the university's servers 
upon completion. The team also developed a set of instructions to facilitate future usage and updating of the system.

\subsubsection{Methods}

A number of methods were used in this project. Since the different departments generated data in tabular form, Microsoft Excel was used to manage the initial tabular data and process it into the proper format for use in a Geographic Information System (GIS). Esri's ArcGIS Online, Application Templates, and Story Maps Templates were used to construct the survey that collected the data about faculty teaching and research. The required tables were created as comma-separated value files and uploaded as feature layers into a web map. Symbols were selected for countries and regions representing faculty research and teaching. The Edit template was used to create a web application that collects survey data, which was added to a Story Maps Template. The story map provided background information and instructions on how to complete the survey. Domains were used to ensure that the countries and regions the users entered were constrained to those used in the project.

Esri's ArcGIS for Desktop was used to import the tables and convert them into feature classes that could be displayed spatially, and to create the geodatabases for containing them. ModelBuilder was used to build the models needed to streamline the workflows. Once the feature classes were created, these were then published as feature services to ArcGIS Online.

The web application was developed making use of the ArcGIS JavaScript Application Programming Interface (API) and the Dojo Toolkit. JetBrains WebStorm was used as the programming Integrated Development Environment (IDE).

\subsection{Audience}

The intended audience of this paper includes developers of GIS web applications who have a basic understanding of JavaScript and GIS. It could also be useful to educators and planners interested in using GIS for visualization of educational resources.

\subsection{Overview of the Rest of this Report}

Chapter 2 provides an overview of the importance of internationalization, how it is communicated and an explanation of web application development. Chapter 3 covers system, analysis and design and the project plan. Chapter 4 discusses the conceptual and logical data models required for the project and how data were prepared for the project. Chapter 5 discusses the models to process the data and the implementation of the Web Application. Chapter 6 describes the testing and use cases of the project and Chapter 7 describes the project summary, conclusions and possible future works. 



\section{Chapter 2 - Background and Literature Review}

This chapter introduces how internationalization is defined and measured, its importance, and the factors that affect it. The chapter also examines how internationalization is promoted through responses at different levels and how it can be represented and mapped. Section 2.1 looks at the introduction to internationalization. Section 2.2 examines how it is promoted. Section 2.3 summarizes the chapter.

\subsection{Introduction to Internationalization}

Internationalization is not a new term but has different meanings when applied to different fields. Specifically in education, an early working definition was proposed by De Wit (1999) as "the process of integrating an international/intercultural dimension into the teaching, research, and service functions of the institution" (p. 2). This definition has been refined over the years. Due to its applicability to many levels of society, Knight (2015) proposed an updated, more focused working definition to be "internationalization at the national, sector, and institutional levels is defined as the process of integrating an international, intercultural or global dimension into the purpose, functions or delivery of postsecondary education" (p. 2). Because internationalization is commonly confused with globalization, Knight (2015) also differentiated globalization as: "the flow of technology, economy, knowledge, people, values, and ideas... across borders" (p. 3). Internationalization is important because of the quantity of people affected both locally and internationally, the effects that it has on institutes, and on the employability of students after their studies.

A growing number of people are affected by internationalization. For example, according to the UNESCO Institute for Statistics (2014) website, in 2014 "over 4.1 million students went abroad to study, up from 2 million in 2000, representing $1.8 \%$ of all tertiary enrolments or 2 in 100 students globally" (UNESCO Institute for Statistics, 2016). The Organization for Economic Co-operation and Development (OECD) projected that international student mobility will reach eight million by 2025 (Tremblay, Lalancette, \& Roseveare, 2013). Luo and Jamieson-Drake (2013) found that with more international students at an institution, the local students benefit from the exchange of ideas, gain the opportunity to interaction, are more open to diverse views, and have an increase in skill development. This changes the nature of the institution, potentially making it more open and well-rounded in its education. Institutions would have to plan the support system necessary to handle the intake of students, including language courses and other international interaction programs.

Institutions with more international students often benefit financially as international students are often charged higher fees hence more revenue is generated. In addition, international students also spend a substantial amount of money on tuition, accommodations, and living expenses. An example is given by the OECD (2013) where students contributed 8 billion Canadian dollars to the economy in 2010 which is more than the Canadian export of aluminum which contributed six billion, or helicopters, airplanes, and spacecraft which contributed 6.9 billion. Therefore, it is in the best interests of institutes to be able to attract international students. 
Internationalization also positively affects the employability of students after graduation. In a study by the European Commission, Brandenburg et al. (2014) found that "skills gained abroad were a factor in acquiring one"s first and subsequent jobs for over $70 \%$ of respondents, a significant factor for over 30\%, and the determining factor for about $10 \%$ " (p. 69) and these skills were useful at work for nine out of ten graduates. Additionally, $61 \%$ of employers that the European Commission study group surveyed considered international experience important for employability. Hence it is important that institutes respond appropriately to internationalization considering both its effects and scale.

Although the number of institutes that support the internationalization has increased, there is sometimes a gap between the institutional rhetoric and the reality of internationalization. The reactions to internationalization have been mixed. A report published by the American Council on Education (2012) found that for many institutes in the US, "although many institutions indicated that the curriculum has been a particular focus of internationalization efforts in recent years, overall this is not reflected in the general education requirements that apply to all students" (p. 23). However, the same report also showed that the percentage of institutions with a campus-wide internationalization plan increased from $23 \%$ to $26 \%$. Even if institutes have a plan, their implementation of the plan might still be sub-optimal.

Different institutes have different responses to internationalization. One typical response is that of the University of Redlands, which set up a campus-wide committee to study and measure internationalization on the campus, to set goals for the university, to make recommendations, and to oversee and coordinate internationalization efforts among various departments (Wingenbach, et al., 2014). In Gopal's (2011) study, other responses by campuses include having transnational education initiatives whereby branch campuses are set up and faculty members fly in from the home country to teach students in a foreign country. However Gopal asserted that not all faculty are prepared for the task of teaching about the foreign country. It would therefore make sense for institutes to have a database to track faculty members with experience and for faculty members to find international resources, building their knowledge in preparation to teach.

\subsection{Promoting Internationalization}

Internationalization can be affected by a large variety of factors, ranging governmental policy level to policies and decisions made at institutes, down to changes in demographics and changes in the world view of students. At a national level, governments recognizing the importance of internationalization have delivered policies that encourage it, such as in Germany where there are plans for up to half of all degree students to experience study abroad by 2020 and to increase international student intake by $17 \%$ by the same year (Grove, 2014). The Association of South East Asian Nations (ASEAN) has worked toward creating a shared "Common Space of Higher Education" which allows qualifications and standards to be accepted and shared at universities, colleges and academies across the region, fostering increased student mobility (ASIC News, 2015).

At an institutional level, Olson, Green and Hill (2005) suggested that the environment for internationalization was affected by three important trends which brought about challenges and opportunities for the implementation of comprehensive 
internationalization at campuses. The first trend was an intensified interest in international and global matters on many campuses with a greater need for campuses to assess the progress of their international education efforts. The second was an increased emphasis on learner-centered pedagogy with the challenge of providing resources to help the students learn and to find methods of measuring this learning. The third trend was the growing presence of a new profile of students who were more mobile, attending different colleges before graduation, and who had diverse cultural backgrounds. The challenge was to provide learning opportunities for students and to ensure good curriculum delivery.

At the individual student level, when studying push-pull factors that affect international student destination choice, Mazzarol and Soutar (2002) defined five factors that were important influences on the decision to study overseas. They found that places with high international profiles, easily available education services information, an exciting learning environment with quality staff, and a large international student population were more attractive to international students. These factors are important considerations for institutions when developing marketing strategies to attract students. The biggest difficulties that institutions would face are how to communicate and promote the above information to prospective students.

De Witt (2010) provided an overview of internationalization strategies that can be used in higher education. At that time, efforts were underway to provide frameworks to measure the amount the internationalization at institutes in order to provide indicators and to benchmark them against desired outcomes. Projects such as "Accessing Best Practices in Internationalization" by the Association of International Educators NAFSA, and instruments such as MINT (Mapping Internationalization) by the Netherlands Organization for International Cooperation in Higher Education were developed to measure internationalization quantitatively and qualitatively. Most of the methods suggested seemed to be at a very broad institutional level without going down to very detailed information about internationalization.

According to Hudzik and Stohl (2009), developing methods for assessing internationalization are not trivial and these assessments must meet the dual purposes of referencing an institutions overall missions and goals and relating to outside forces and their expectations. They proposed looking at inputs, outputs, and outcomes as assessment dimensions. Inputs were resources available to support the efforts, outputs were the amount and types or work undertaken, and outcomes were the impact or end results. Examples of inputs included number of options to study abroad and extent of campus curriculum that incorporated global content. Examples of outputs included the number and diversity of students studying abroad or the number of faculty delivering the content. Outcomes could be institutional reputation or students achieving measurable levels of competency. Other common indicators of internationalization include "the number of international students, the number of education abroad programs offered, or the proportion of students engaged in education abroad programs" (Green, 2012, p. 4) and the presence of international students at an institute (University of Oxford, 2015). These factors are important when designing systems that capture data and how to quantify or represent the data.

Green (2012) stated that mapping internationalization at an institute provides insights into its performance, measures the effectiveness of its strategy, and gives a comparison against similar institutes, thus providing it with information with which to improve itself. 
Factors that an institution can map include the number of courses with an international focus, the number and proportion of faculty and researchers with international experience, and the number of research projects with international partners.

Most of the methods of mapping internationalization appear to be collecting data and presenting them in tabular, graphical or textual form. For example, in Connecticut the George R. Muirhead Center for International Education (2012) built a web page to show information regarding number of international students at universities there. These data were presented in tabular form, showing countries, institutes and the number of students at each institute. Although the information might be important and useful, its presentation is not easy for people to make sense of which country or region are the most students from or to make comparisons between the institutes.

Other internationalization mapping methods enables the sharing of information about programs abroad. The UNC Eshelman School of Pharmacy (2016) built a site to share information about its Global Pharmacy Scholars Program. The site enables students to find practice opportunities in each country with which the university has a connection. Clicking on each country brings up information about the programs in the country. The grouping by country is useful as it enables students to decide which country they would like to go for programs. It might be even more useful if this information was shown on a map that enables students to visualize it geographically and would also be better for university planners as they would be able to consolidate all other programs by country to study linkages that the institute had with various countries.

Since internationalization seems to indicate a spatial component as it deals with international or global dimensions, a map might be a good medium to represent data concerning it. Tyner (2010) asserted that maps are a graphical representation that enables both visualization, which reveals the spatial order and organization of a geographic phenomenon, and communication, where the findings are presented to an audience. In the case of internationalization, maps can enable both better visualization of the current situation by depicting spatial linkages to the reader and better communication of the data by integrating with other visual representations such as graphs or symbols.

Flow maps are an example of maps that can be used to show one aspect of internationalization. Writing in Esri's blog, Akella (2011) stated that "flow maps show the movement of some phenomenon, normally goods or people, from one place to another. Lines are used to symbolize the flow, typically varied in width to represent differences in the quantity of the flow" (para 1). She explained that there were three types of flow maps: radial, network, and distributive. Radial flows have a spoke-like pattern which shows a node and origin. Network flows show interconnectivity; and distributive flows show from origin to multiple destinations. She demonstrated in the blog that Esri used radial flow maps to depict people all over the world travelling to its user conference, as shown in Figure 2-1. These radial flows may be useful in communicating the movement of students to study as well as students going from the institute to study abroad. The map presented so far was static and good for visualization on where most of the participants come from, but more underlying information can be communicated utilizing web technologies. 


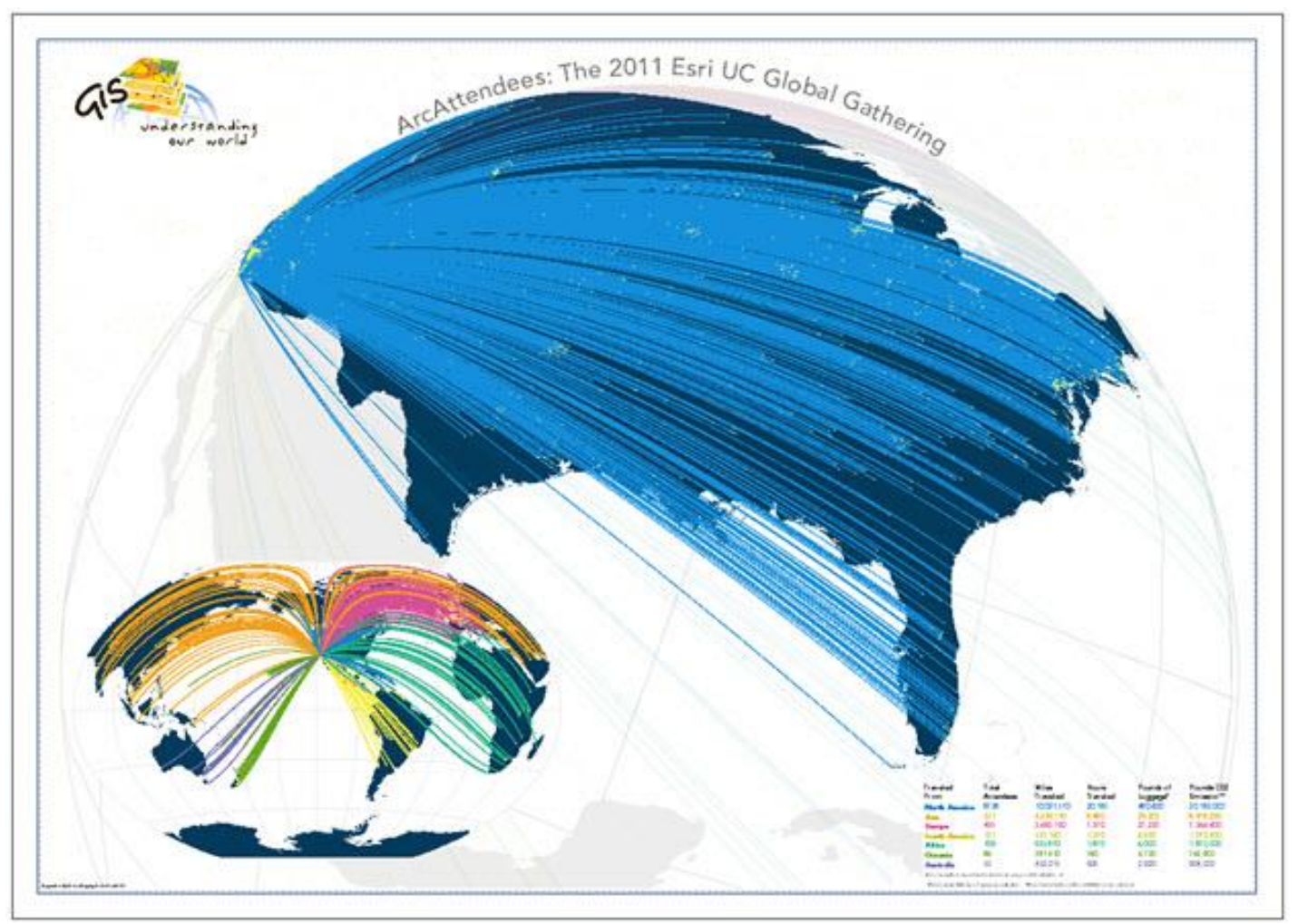

Figure 2-1: Faculty Survey Story Map Template. Reprinted from "Creating radial flow maps with ArcGIS", by M. Akella, 2011, ArcGIS Blog. Retrieved July 14, 2016, from https://blogs.esri.com/esri/arcgis/2011/09/06/creating-radial-flowmaps-with-arcgis. Map image is the intellectual property of Esri and is used herein under license. Copyright $($ C Esri and its licensors. All rights reserved. Reprinted with permission.

As an example why the web has better information delivery, Dempsey (2013) created an interactive radial flow map of cardinals that were eligible to vote for the next Pope. The map in Figure 2-2 showed where each cardinal originated from based on their office with a line connecting to Rome. Clicking on each radial line provides more information on the specific cardinal. Contrasting with the earlier radial flow map, this makes the map much more useful as there can be a wealth of data hidden in related layers beneath it. 


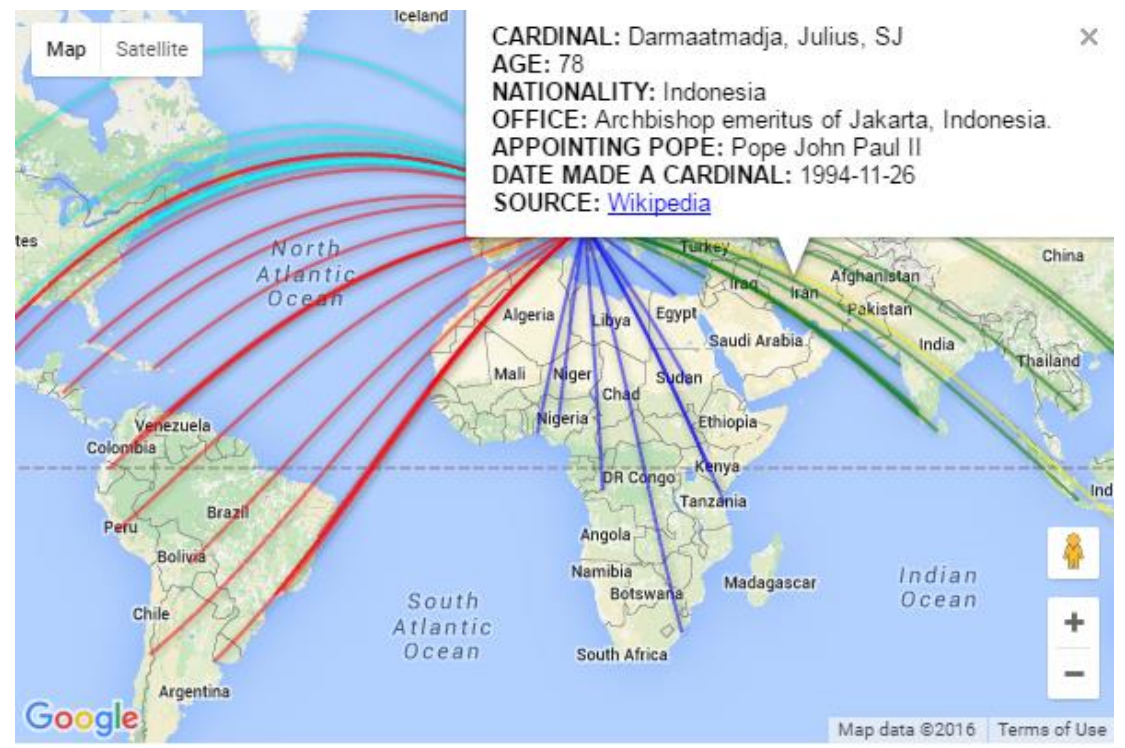

Figure 2-2: An Example of Radial Flow Web Map. Reprinted from Map of Cardinals, In GIS Lounge, 2013 by C. Dempsey, Retrieved July 14, 2016, from https://www.gislounge.com/map-of-cardinals. Copyright 2013 by C. Dempsey. Reprinted with permission.

Caution, however, is needed when designing web maps. Muehlenhaus (2013) stated that, living in a data rich environment, there is a need to decide what data are worth mapping and that a web map needs to be interactive as it is designed for users rather than for readers. However, he also argued that a balance between interaction and communication is required since designers are commonly distracted from delivering the main message by incorporating "cool' interactive features. There is a wealth of information collected at each institute about internationalization, hence there is a need for careful consideration of what information should be presented for public consumption and how an interface can be built around it to make it both interactive and informative. For example, the State University of New York (n.d.) built a web page that allows a students to click on a country to find out more about study abroad programs. Arguably, the web map communicates its data to the user. However, the interaction is not smooth since the user needs many clicks to be able to retrieve programs about a country. In addition, all the study abroad program links appears in a tiny popup and do not contain any additional information about the programs, which may not be the best way to communicate the programs to users.

\subsection{Summary}

This chapter examined past and current definitions of internationalization. It looked at how countries, institutes, and students are impacted by internationalization and also the response that institutes have to internationalization. The chapter also explores how internationalization is affected by actions at governmental, institutional, and individual levels, providing an overview of how internationalization is measured and mapped by various institutes. Examples are provided of how web mapping is used to share 
internationalization in webpages and the difficulty in ensuring a balance between communication of information and interactivity.

The following chapters will utilize the existing literature to show how internationalization was measured at the University of Redlands. It will map internationalization using web maps and to create a balance between information delivery and interactivity within the application. 



\section{Chapter 3 - Systems Analysis and Design}

This chapter examines the system design and requirements of the Council for Comprehensive Internationalization (CCI). Section 3.1 reiterates the problem statement. Section 3.2 describes the project functional and non-functional requirements. Section 3.3 examines the system design that was used in the project. Section 3.4 outlines the project plan and the changes that occurred during the project.

\subsection{Problem Statement}

The University of Redlands lacked a comprehensive platform that consolidated the existing datasets of internationalization into a streamlined interface so that a user can access and use these datasets according to their needs. The CCI needed query results displayed in a format so as to aid decision making. They also wanted this functionality to be integrated into their existing web page of internationalization and global opportunities.

\subsection{Requirements Analysis}

The client was interested in how GIS could be used to depict internationalization and portray the university as being internationally connected. At the same time he foresaw the need for a resource that people can use to make decisions regarding internationalization questions. Following more in-depth discussions with the client, it was agreed that this would be best accomplished with a web mapping application that would integrate with the "Global Landing" page that the university was building. The following functional and non-functional requirements were agreed upon for the project.

\subsubsection{Functional Requirements}

Functional requirements specify behaviors or functions of the project. Considerations for these requirements included the client's goals and objectives that could be completed in the allocated time. Table 1 below outlines the functional requirements that are required for this project. 
Table 1. Functional Requirements.

\begin{tabular}{|c|c|}
\hline Requirement & Description \\
\hline $\begin{array}{l}\text { Display where Students Come } \\
\text { From }\end{array}$ & $\begin{array}{l}\text { Shows which home countries of international } \\
\text { students, including total countries as well as total } \\
\text { number of students from these countries }\end{array}$ \\
\hline $\begin{array}{l}\text { Display top countries for } \\
\text { international students }\end{array}$ & $\begin{array}{l}\text { Shows the top } 5 \text { countries from where international } \\
\text { students come }\end{array}$ \\
\hline $\begin{array}{l}\text { Display where students study } \\
\text { abroad }\end{array}$ & $\begin{array}{l}\text { Displays the countries where students go for study } \\
\text { abroad programs }\end{array}$ \\
\hline $\begin{array}{l}\text { Display study abroad } \\
\text { information }\end{array}$ & $\begin{array}{l}\text { Displays the appropriate information such as } \\
\text { program name, synopsis and link for study abroad } \\
\text { programs related to a particular country }\end{array}$ \\
\hline $\begin{array}{l}\text { Display areas and regions of } \\
\text { faculty teaching }\end{array}$ & $\begin{array}{l}\text { Shows which countries and regions that faculty } \\
\text { teach about or have taught about }\end{array}$ \\
\hline $\begin{array}{l}\text { Display areas and regions of } \\
\text { faculty research }\end{array}$ & $\begin{array}{l}\text { Shows which countries and regions more faculty } \\
\text { focus on in their research }\end{array}$ \\
\hline $\begin{array}{l}\text { Display relevant faculty } \\
\text { research and information when } \\
\text { selected }\end{array}$ & $\begin{array}{l}\text { Allows users to select a country or region and see } \\
\text { related information regarding title, faculty first and } \\
\text { last name, synopsis and link to a page }\end{array}$ \\
\hline $\begin{array}{l}\text { Query faculty research or } \\
\text { teaching }\end{array}$ & $\begin{array}{l}\text { Allows users to key in a search term for individual } \\
\text { faculty by his or her name or countries of research } \\
\text { and teaching, displaying the information in a } \\
\text { sidebar }\end{array}$ \\
\hline Popups for data & $\begin{array}{l}\text { Displays the information of number of students } \\
\text { coming from a particular country when clicked }\end{array}$ \\
\hline $\begin{array}{l}\text { Change viewing layers } \\
\text { automatically }\end{array}$ & $\begin{array}{l}\text { Changes the viewing layers automatically } \\
\text { according to the aspect of internationalization } \\
\text { viewed by the users. }\end{array}$ \\
\hline
\end{tabular}

\subsubsection{Non-Functional Requirements}

The non-functional requirements define how the system should work and refer to the tools and methods to achieve the goals and objectives in the project. These requirements are listed in Table 2. 
Table 2. Non Functional Requirements.

\begin{tabular}{|l|l|}
\hline Requirement & Description \\
\hline Data organization & $\begin{array}{l}\text { Data should be consolidated and stored in a form } \\
\text { assessable by the application and that can be } \\
\text { updated }\end{array}$ \\
\hline Intuitive user interface & $\begin{array}{l}\text { User interface for the web application should be } \\
\text { intuitive for non-GIS users. }\end{array}$ \\
\hline $\begin{array}{l}\text { Supports Mozilla Firefox, } \\
\text { Internet Explorer and Apple } \\
\text { Safari Browsers }\end{array}$ & The application will work in these browsers. \\
\hline $\begin{array}{l}\text { ArcMap 10.3 } \\
\text { ArcGIS JavaScript API 3.16 } \\
\text { and Dojo Toolkit 1.10 }\end{array}$ & $\begin{array}{l}\text { The toolbox, models and geodatabase should be } \\
\text { compatible with this version of ArcMap. }\end{array}$ \\
\hline
\end{tabular}

\subsection{System Design}

To meet the client's requirements, the system was based on an Esri ArcGIS environment. The system consisted four major components: data processing and storage, online GIS, Web Server and Desktop Browser. Figure 3-1 illustrates the overall system design.
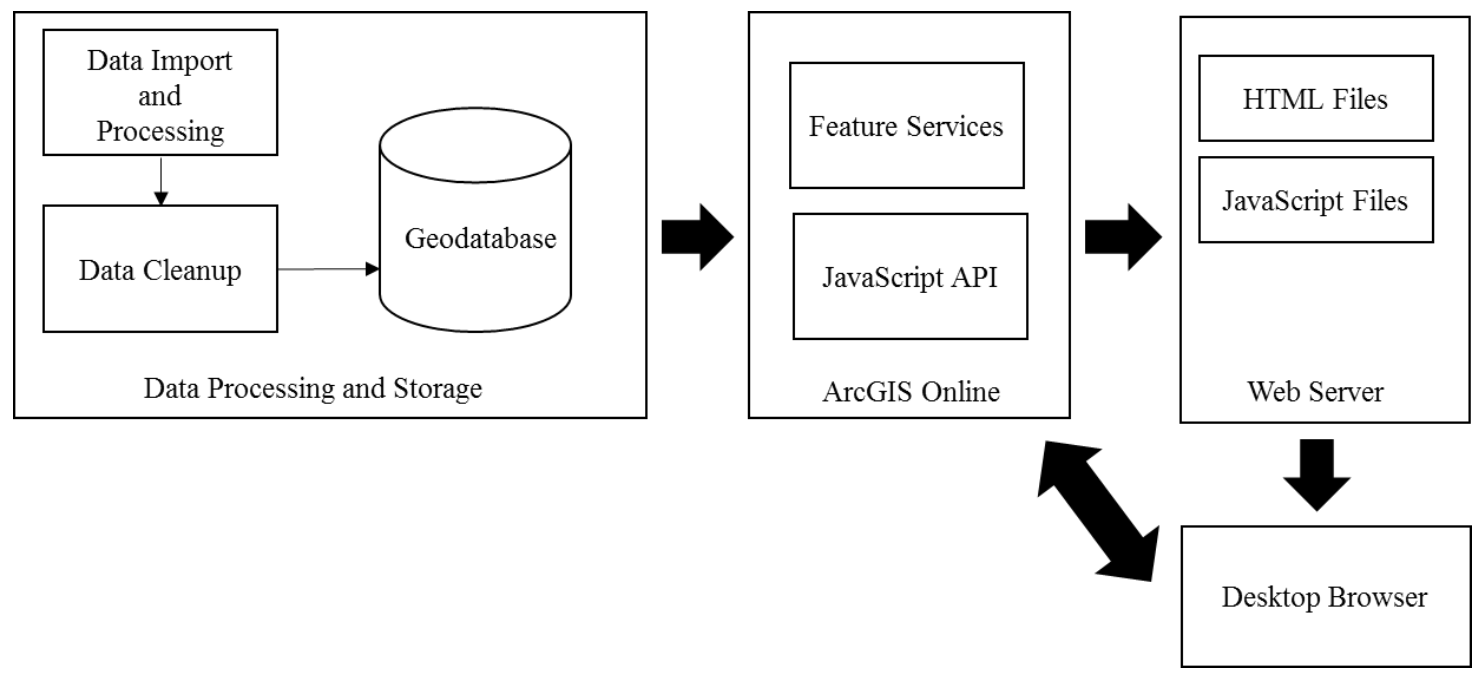

Figure 3-1: System Design

The first component is data processing and storage, and focusses on preparing the data for publication. The datasets provided by the client comes in various forms, 
including tables and feature classes. In this component, models are built to import the data into the project geodatabase. The models also summarize the data and prepare them to be plotted on a map for display and query. Data cleanup needed to be done before the data could be finalized in the geodatabase.

The second component consists an online GIS which, in this case, was ArcGIS Online maintained by Esri. ArcGIS Online is a web GIS used to create and share maps, scenes, apps, layers and data. The layers needed for this project were published to and hosted at https://univredlands.maps.arcgis.com. Each group of layers is published to its own feature service and is accessed through representational state transfer (REST) endpoints for use in the web application. In addition, arcgis.com also contains the JavaScript API and the Dojo toolkit needed to implement the functions of the web application.

The third component consists of a web server, which hosts the related HTML and JavaScript project files. These files contain the information needed for the web map to display and the web application to run correctly. During the trial phase, the team used its own servers to test the application. In the final implementation, the HTML and JavaScript files were handed over to the client for embedding on their webpage and hosted on the client's servers.

The last component consists of a desktop browser to view and use the web application. This browser accesses the HTML and JavaScript files on the web server. When the browser has downloaded the files, it communicates with the online GIS for the necessary data and then formats it for display for the user.

\subsection{Project Plan}

When the project was first started, due to the optimistic nature of the project team and the earlier belief of data availability at the client end, more time was given to the development phase rather than data collection. The forecasted activities and the expected timeline are outlined in Table 3 below.

Table 3. Initial Planned Project Activities and Timeline

\begin{tabular}{|l|l|l|l|l|l|l|l|l|l|l|l|}
\hline Activity & Oct & Nov & Dec & Jan & Feb & Mar & Apr & May & Jun & Jul & Aug \\
\hline $\begin{array}{l}\text { Project } \\
\text { Finalization }\end{array}$ & $\mathrm{x}$ & $\mathrm{x}$ & & & & & & & & & \\
\hline Project Design & & $\mathrm{x}$ & $\mathrm{x}$ & $\mathrm{x}$ & & & & & & & \\
\hline Data Collection & & & $\mathrm{x}$ & $\mathrm{x}$ & & & & & & & \\
\hline GIS Training & & & & $\mathrm{x}$ & $\mathrm{x}$ & $\mathrm{x}$ & $\mathrm{x}$ & & & & \\
\hline $\begin{array}{l}\text { Web App } \\
\text { Development }\end{array}$ & & & & & & & & & & & \\
\hline Testing & & & & & & & & $\mathrm{x}$ & $\mathrm{x}$ & & \\
\hline Documentation & & & & & & & & & $\mathrm{x}$ & $\mathrm{x}$ & \\
\hline $\begin{array}{l}\text { Public } \\
\text { Presentation }\end{array}$ & & & & & & & & & & & \\
\hline Poster & & & & & & & & & $\mathrm{x}$ & & \\
\hline Defense & & & & & & & & & & & $\mathrm{x}$ \\
\hline
\end{tabular}


There were several changes to the timeline and activities within the plan. In the beginning, project finalization was on time, leading the team to believe that the rest of the project would be on track. This phase culminated in the submission of a project proposal outlining the project, its scope and the methods taken towards it resolution.

In the project design phase, it was anticipated that the overall design layout and the database design would be completed by January 31, 2016. The overall design was initially completed by December 15 and a sample layout was decided upon. The sample layout was predicated on the usage of existing story map and web mapping application templates for its development, with minor customization as needed. However, after discussions with the client, the functions required were determined to be beyond those of the templates. Therefore, a re-design was necessary, using JavaScript to build a customized web application. Progress was delayed to February 16 as the iterative design process for the look and feel of the project was completed.

Data collection was initially given less time due to the belief that data were readily available for the project. The data were to come from earlier surveys conducted by the client and were also available from the respective offices at the University of Redlands. However, there were delays in data collection due to rules dictating that the data from the surveys could not be reused for this project. It was then necessary to design a separate survey to collect the necessary data. This survey involved attending additional CITI training on data sensitivity and privacy and an application being submitted to the university IRB for permission to conduct the survey. The survey was done using story map templates and the ArcGIS Edit web application templates to mitigate the time spent cleaning up the data afterwards. Receiving data from the university offices also required approval from the IRB. This culminated in a delay of 3 months to April 16 before the survey data on faculty research and teaching was received. Some data regarding study abroad programs were never received. Instead, the team created a trial dataset to ensure that the framework was in place for loading the data when they become available.

GIS training was necessary for the completion of the project. Training in databases and geodatabases were necessary to give an overview of the structured query language for the web application and to build the geodatabase for the project. Training in Web GIS allowed an understanding of the usage of ArcGIS Online, the story map templates and application templates available, which were essential in building the faculty survey to collect data. Additional Esri JavaScript API instructor-led training courses allowed knowledge in scripting to build the actual application.

Due to the delay in receiving the data, web application development began before the entire data were delivered by the client. The team created a fictitious dataset used to build the ideal framework; the real data can be added easily at a later time. The web application development actually ended slightly earlier than expected, due to the team solving bugs earlier than anticipated, being self-taught in certain areas of scripting and through the support of the Center for Spatial Studies, University of Redlands.

Testing and documentation occurred at the end of the development to ensure that the client was satisfied with the functionality of the project and that all the functional and non-functional requirements were delivered as promised. The documentation was created for the client to take over the project. Discussions and demonstrations were also held with the client's team to enable them to continue to maintain the project in future. 
Despite deviations from the original plan due to client and project team expectations, the project was still completed on time. Some extra time was taken in preparation to collect the data, but this was offset by the survey design that minimized data cleanup.

\subsection{Summary}

This chapter covered the problem, the analysis of requirements, the system design and the project plan. The requirements analyses included both functional and non-functional requirements agreed upon by the project team and the client. The project had four major blocks in the system design that served different purposes. The project plan consists of both the expected activities and timeline as well as a description of unforeseen deviations to the plan. 


\section{Chapter 4 - Database Design}

This project relied on a properly formatted database to support the feature services that are essential for the web application. This chapter describes the database needed for the project and how data were transformed from their raw form into the datasets needed for the project.

Section 4.1 outlines the conceptual model for the project. Section 4.2 describes the logical model of the database. Section 4.3 details the data sources required for the project. Section 4.4 describes how the data were collected for the Faculty Research and Teaching datasets. Section 4.5 communicates how the data were scrubbed and loaded into the database, and Section 4.6 presents the chapter summary.

\subsection{Conceptual Data Model}

The conceptual data model outlines the various entities of interest symbolizing internationalization and their relationships. Figure 4-1 below provides the overview of the project's conceptual model.

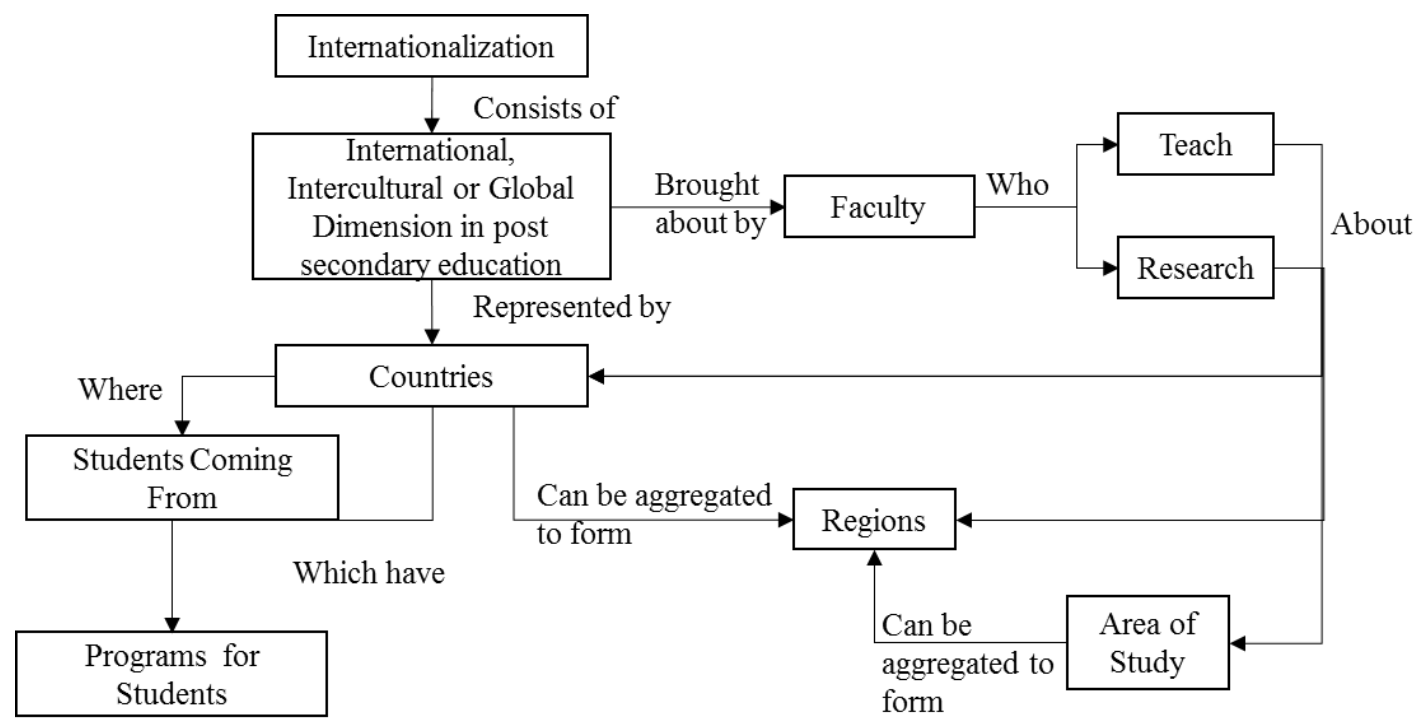

\section{Figure 4-1: Conceptual Data Model}

From the definition in Chapter 1, internationalization is the "process of integrating an international, intercultural or global dimension into the purpose, functions or delivery of postsecondary education" (Knight, Updated definition of internationalization, 2003, p. 2). This international, intercultural, and global dimension refers to countries where students come from to study at the University of Redlands or countries where they go to for Study Abroad Programs.

This international dimension is also seen through the faculty who teach subjects with international content, whether it is about countries or regions. The faculty also conduct research where the subject matter may be international in nature such as religion, business, or music. Specifically, the research should relate to a particular country, region or study area. 
For this project, countries form the basis of linking and representing aspects of internationalization at the University of Redlands. When the faculty research or teaching span multiple countries or areas of study, these countries and areas can be aggregated to form regions through established systems such as the UN classification system.

\subsection{Logical Data Model}

The conceptual model established the macro elements and their relationship. The logical model delves into the actual data representation of these elements and how they were organized in the database. The database used was an Esri geodatabase and the data were held as feature classes and tables within it.

Corresponding to the four aspects of internationalization that were described, four datasets were used to hold the data on internationalization. These were the international students' dataset, the study abroad dataset, the faculty research dataset, and the faculty teaching dataset. Figure 4-2 provides an overview. More details are given in the following sub-sections.

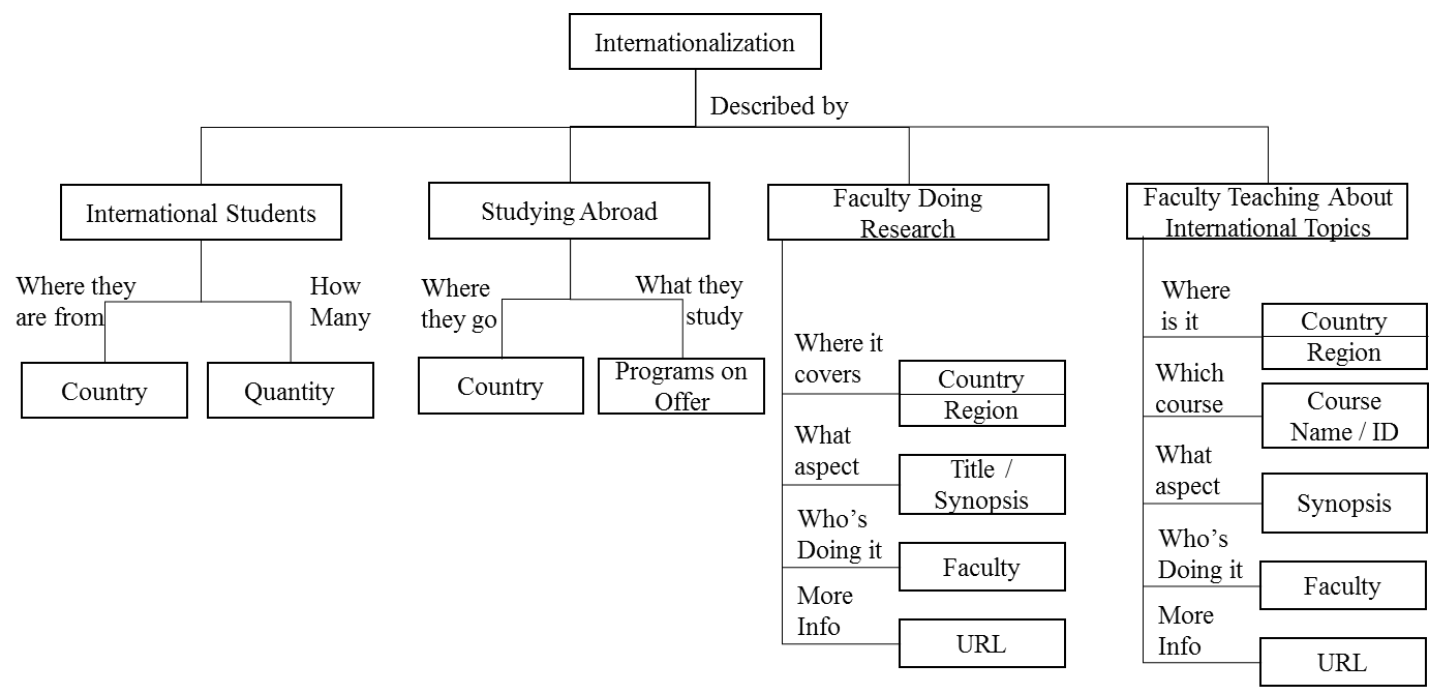

Figure 4-2: Overview of Datasets

A country point feature class was used as a master list to provide coordinates for country centroids to plot the data on a map. Country centroids were selected because they represent a geometrically close approximation of a country. This could be misleading because most of the students do not come from the country centroid locale, which for countries like Russia may be sparsely populated. The team considered using the largest population centers to represent a country but the difficulty in finding authoritative sources on population centers and their location, as well as the possibility that some countries may have numerous or competing population centers, precluded this.

\subsubsection{International Students Dataset}

The International Students Dataset contained information about numbers of students coming to the university to study from each country. It consisted of two feature classes 
and one table. StuFr2015 was the raw data table provided by the university and imported into the geodatabase, StuFr2015_Point was the derived point feature class and StuFr2015_XY was the lines feature class. The fields in the feature classes can be seen in Figure 4-3.

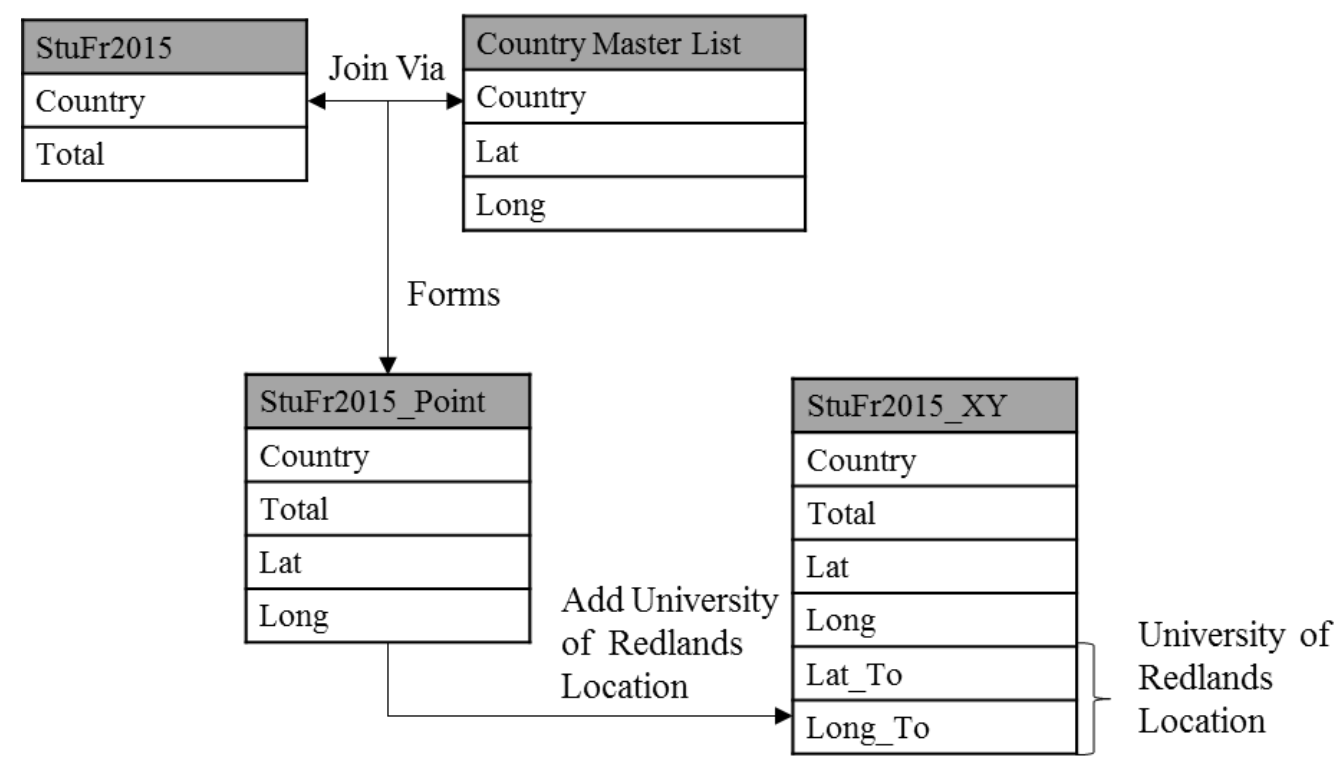

\section{Figure 4-3: International Student Dataset}

StuFr2015 was imported from Microsoft Excel format. The "country" field referred to the home country of the international students and the "total" field indicated the number of students in the particular year; a new table was generated every year. StuFr2015_Point was generated from the StuFr2015 table. The "country" field in StuFr2015 was joined with the country master list, hence providing the "Lat" and "Long" fields in the feature class. Where the countries in StuFr2015 were spelled differently than in the master list, the country centroid coordinates had to be manually entered. These points were then plotted using the "Display XY Data" function in ArcGIS and exported as a point feature class to create StuFr2015_Point.

StuFr2015_XY consisted of lines linking the centroid of the home countries of international students to the University of Redlands. This was plotted using the "XY to Line" function in ArcGIS. This function required a starting and an ending set of coordinates. Working from the StuFr2015_Point feature class, which already had country coordinates, there was a need to add "Lat_To" and "Long_To" fields for the lines to be plotted. These fields were populated using a field calculator with the coordinates of the University of Redlands.

An alternative approach that would support future growth would have been to join the number of students from StuFr2015 to the Country Master List instead. This would allow the number of students to be added yearly as new fields. However, this would have resulted in longer loading times for the web application and the project requirements were tightly scripted. This could be implemented in future. 


\subsubsection{Study Abroad Programs Dataset}

The Study Abroad Programs Dataset contained information about student study abroad programs in two feature classes and two tables. The fields in the feature classes and tables are presented in Figure 4-4.

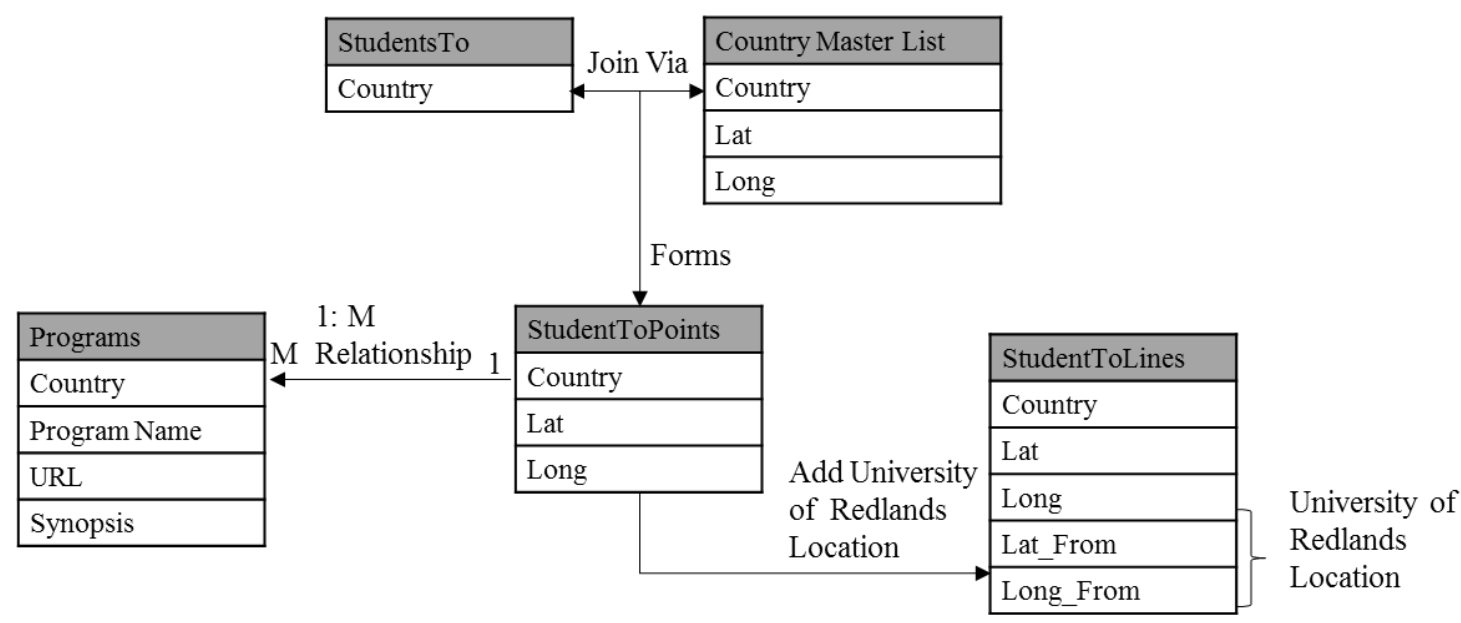

\section{Figure 4-4: Study Abroad Programs Dataset}

StudentsTo and Programs were provided by the university in Microsoft Excel format. StudentsTo table contained only the countries that students go to for study abroad programs. The Programs table was comprised of a list of study abroad programs sorted by country and was used to perform a relate operation to the list of countries in the StudentToPoints feature class for the web application in a one-to-many relationship.

StudentToPoints was generated in a similar manner as that of StudentFr2015_Points above via joining with the country field. This feature class was then plotted using the "Display XY Data" function in ArcGIS and exported as a point feature class. StudentToLines was created from StudentToPoints in a similar manner and exported as a line feature class. The data should be repaired in a similar manner if there are countries that have been spelled differently.

Although StudentToPoints was related to the Programs table, there was no requirement to create a relationship class in the geodatabase as the data could be retrieved via JavaScript Query. However, to ensure that the data could be queried, the project team performed quality control by summarizing the "country" field in the Programs table. The number and spelling of the summarized fields were then compared with the list of countries in StudentToPoints. Misspelled countries in the Programs table were amended.

\subsubsection{Faculty Research Dataset}

The faculty research dataset contained information about faculty research with international elements. It consisted of four feature classes, two of which described research countries of interest and their summarized point feature class and the other two described research regions of interest and their summarized polygon feature class. The feature classes and their fields can be seen in the Figure 4-5 below. 


\begin{tabular}{|l|}
\hline RC_Sum_Pt \\
\hline Country \\
\hline Frequency \\
\hline Lat \\
\hline Long \\
\hline
\end{tabular}

\begin{tabular}{|l|}
\hline Research_Country_of_Interest \\
\hline Country \\
\hline Faculty First Name \\
\hline Faculty Last Name \\
\hline Research Title \\
\hline Synopsis \\
\hline URL \\
\hline
\end{tabular}

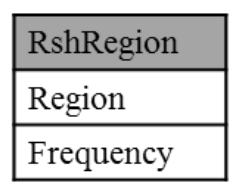

\begin{tabular}{|l|}
\hline Research_Region_of_Interest \\
\hline Region of Study \\
\hline Faculty First Name \\
\hline Faculty Last Name \\
\hline Research Title \\
\hline Synopsis \\
\hline URL \\
\hline
\end{tabular}

\section{Figure 4-5: Faculty Research Dataset Overview}

The Research_Country_of_Interest was a point feature class extracted from a faculty survey. This survey is addressed in Section 4.4 below. Each record in it represented one topic per faculty per country. The "country" field was used as a summary field to look at the number of research topics concerning a particular country. The summarized fields were used to create the point feature class RC_Sum_Pt, which was then related to Research_Country_of_Interest by country in a one-to-many relationship. The process is shown in Figure 4-6 below. The subsequent processes are similar to those of the Study Abroad Programs and International Student Datasets where they are joined by country to obtain country centroid coordinates, displayed as XY data on the map, and exported as feature classes.

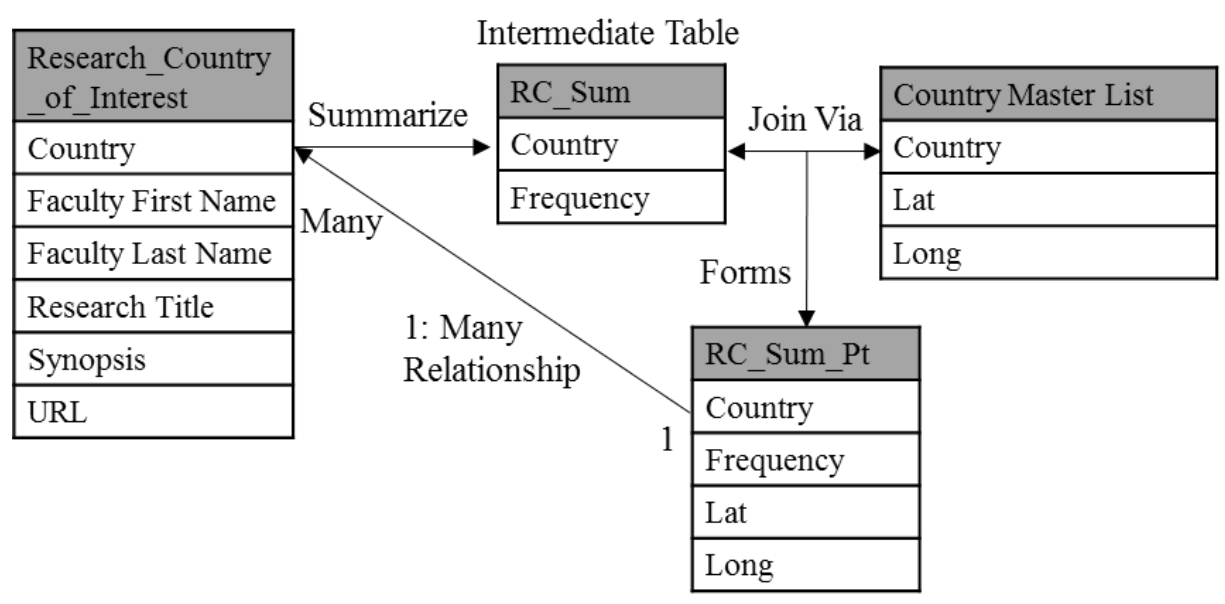

\section{Figure 4-6: Research Country of Interest}

Research_Region_of_Interest was a polygon feature class extracted from the same faculty survey as Research_Country_of_Interest. Each record in it represented one topic per faculty per region. The "regions" field was summarized to examine the number of research topics in each region. The summarized fields were joined to a copy of the world regions feature class to create a new polygon feature class, RshRegion, which is related to the Research_Region_of_Interest by regions in a one to many relationship. The process is shown in Figure 4-7 below. 


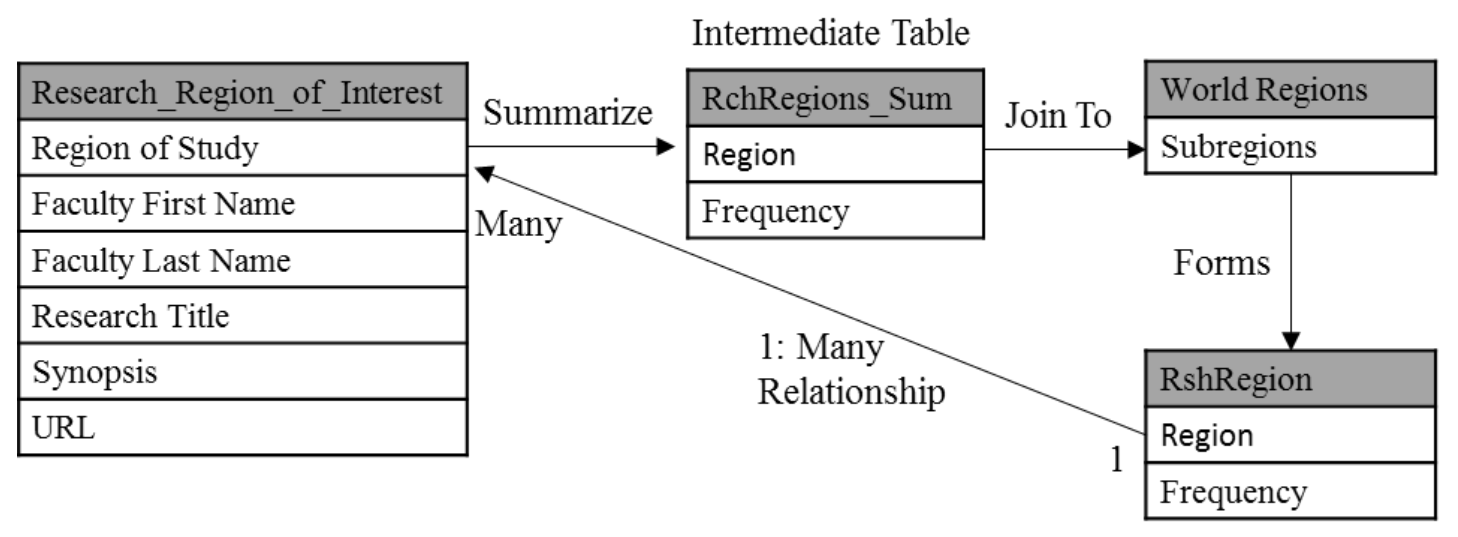

Figure 4-7: Research Region of Interest

Similar to the Study Abroad Programs Dataset, all the relationships between the feature classes were created using JavaScript Query. This reduced the need to create a new relationship class every time new layers are created. However, to ensure that the JavaScript works, the field naming should be consistent.

\subsubsection{Faculty Teaching Dataset}

The faculty teaching dataset contained information about faculty teaching subjects with international elements. It consisted of four feature classes. This is similar to the faculty research dataset with the main difference being that the information in this dataset have a course ID. The dataset components are shown in Figure 4-8 below.

\begin{tabular}{|l|}
\hline TC_Sum_Pt \\
\hline Country \\
\hline Frequency \\
\hline Lat \\
\hline Long \\
\hline
\end{tabular}

\begin{tabular}{|l|}
\hline Teaching_Country \\
\hline Country \\
\hline Instructor First Name \\
\hline Instructor Last Name \\
\hline Course Name \\
\hline Course ID \\
\hline Synopsis \\
\hline URL \\
\hline
\end{tabular}

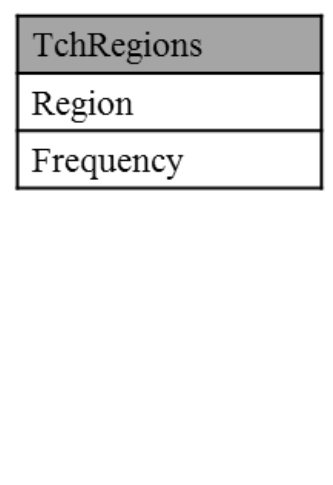

\begin{tabular}{|l|}
\hline Teaching_Region \\
\hline Region of Teaching \\
\hline Instructor First Name \\
\hline Instructor Last Name \\
\hline Course Name \\
\hline Course ID \\
\hline Synopsis \\
\hline URL \\
\hline
\end{tabular}

\section{Figure 4-8: Faculty Teaching Dataset}

The initial feature classes extracted from the survey were Teaching_Country and Teaching_Region. Their treatment and processing were similar to that of the faculty research dataset with the extracted feature classes being summarized by countries and regions and then joined with the master lists and exported to be represented on the map. Similarly the relationships are a one-to-many relationship. This is shown in Figure 4-9 below. 
Intermediate Table

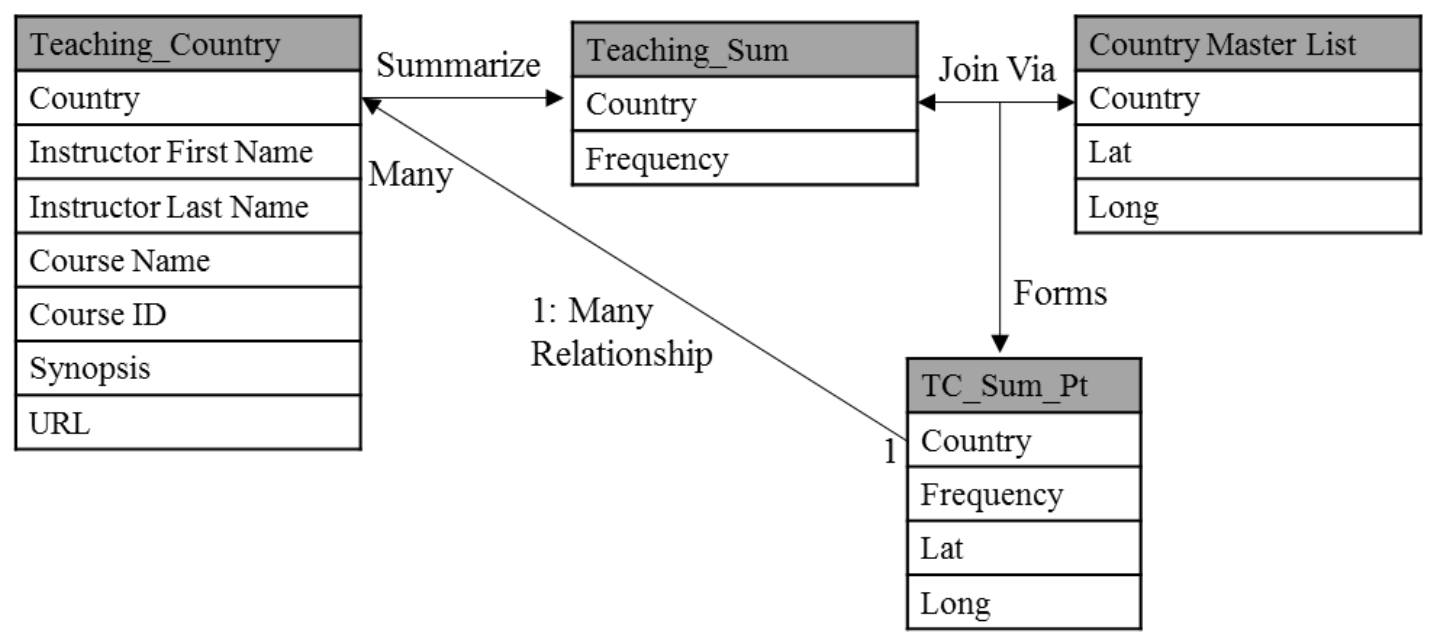

Intermediate Table

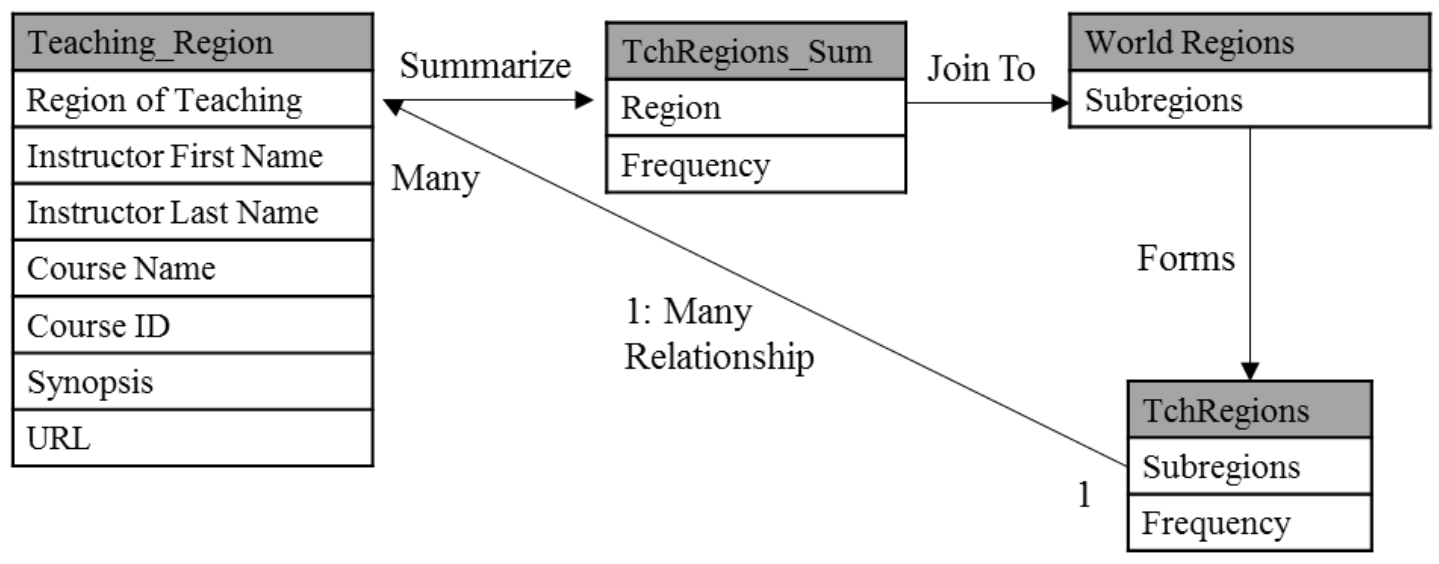

Figure 4-9: Processing for Faculty Teaching Dataset

\subsection{Data Sources}

There were a variety of data sources for this project. For the international students' dataset, the list of countries and number of students for Fall 2015 was provided by the University of Redlands Provost Office through the assistant provost for institutional research.

The list of countries in the study abroad program dataset, was provided by the Director of Study Abroad's Office. The programs table in that dataset was synthetic data for purposes of testing and building the database schema.

The faculty research and faculty teaching datasets, containing the four source layers of faculty research countries, faculty research regions, faculty teaching countries, and faculty teaching regions, were collected via a survey of the faculty, addressed in the following Section 4.4 .

The regions layer used was initially based on the 25 commonly used world regions layer provided by Esri, but was eventually amended to country data taken from Natural 
Earth and dissolved by sub-regions based on the UN grouping of countries. This was due to the UN being the more authoritative source for world regions.

The country master list used for the joining and plotting of country centroid coordinates was taken from Gothos. Information from the site indicate that the data were extracted from the National Geospatial-Intelligence Agency GEOnet Names Server and the USGS Geographic Names Information System in February 2012.

\subsection{Data Collection Methods}

The CCI originally conducted a faculty survey on international teaching and research. However, the earlier results from the CCI survey could not be used for this web application due to privacy concerns and the data being classified as officially collected for a different study. Hence a new survey was needed to collect the data.

Due to the university being a public institution and the data concerning human subjects, there was a need to undergo Collaborative Institutional Training Initiative training and certification to learn about the laws, rules, and ethics governing such research. There was also a need to submit an application to the University of Redland's IRB for approval to receive the international students and study abroad data as well as to be able to collect and use the faculty research and teaching data for the purpose of this web application

Initially, the team considered using survey tools such as Survey Monkey or Excel to collect data, but eventually it was decided to use Esri's tools instead. This provided certain advantages. First, Esri's tools allowed the use of domains, whereby the entire list of countries and regions can be input to allow users a drop down list of choices. This facilitated the processing of data subsequently as the join fields would match perfectly. Second, the survey was already created as a series of feature classes, hence there was no additional processing needed to bring it into an Esri geodatabase or export it to a variety of formats as needed, with topology already in place. Third, it allowed users to keep adding data in the future as they continue to do research or teaching concerning countries. Fourth, any correction to the data could be easily done.

The faculty research and teaching survey was created as four point feature classes in Arc Desktop that contained the necessary fields for their final representation as in Sections 4.2.3 and 4.2.4 above. The feature classes were uploaded as feature services to ArcGIS online. The survey was created using the ArcGIS Web Application Edit Template to minimize development time. The faculty research country and region fields and description are listed in Table 4. 
Table 4. Faculty Research Fields and Description

\begin{tabular}{|c|c|c|c|}
\hline & \multicolumn{2}{|c|}{ Feature Classes } & \multirow[t]{2}{*}{ Description } \\
\hline & $\begin{array}{l}\text { Research Country } \\
\text { of Interest }\end{array}$ & $\begin{array}{l}\text { Research Region of } \\
\text { Interest }\end{array}$ & \\
\hline \multirow[t]{6}{*}{ Fields } & Country & Region of Study & $\begin{array}{l}\text { Text Field of } 50 \text { characters. Created } \\
\text { using domains in Arc Desktop. } \\
\text { Countries and regions are those used } \\
\text { from the reference list. }\end{array}$ \\
\hline & Faculty First Name & Faculty First Name & Text field of 50 characters \\
\hline & Faculty Last Name & Faculty Last Name & Text field of 50 characters \\
\hline & Research Title & Research Title & Text field of 200 characters \\
\hline & Synopsis & Synopsis & Text field of 256 characters \\
\hline & URL & URL & Text field of 256 characters \\
\hline Symbol & $\begin{array}{c}\text { Ti } \\
\begin{array}{c}\text { Research } \\
\text { Country }\end{array}\end{array}$ & $\underset{\substack{\text { Research } \\
\text { Region }}}{\text { O) }}$ & \\
\hline
\end{tabular}

Similar to faculty research portion of the survey, faculty teaching portion was created using two feature classes. The key difference being the naming of the fields as well as the addition of a Course ID field. The faculty teaching country and region fields and descriptions are found in Table 5 .

Table 5. Faculty Teaching Fields and Description

\begin{tabular}{|c|c|c|c|}
\hline & \multicolumn{2}{|c|}{ Feature Classes } & \multirow[t]{2}{*}{ Description } \\
\hline & Teaching Country & Teaching Region & \\
\hline \multirow[t]{8}{*}{ Fields } & Country & Region of Study & $\begin{array}{l}\text { Text Field of } 50 \text { characters. Created } \\
\text { using domains in Arc Desktop. } \\
\text { Countries and regions are those } \\
\text { used from the reference list. }\end{array}$ \\
\hline & Instructor First Name & Instructor First Name & Text field of 256 characters \\
\hline & Instructor Last Name & Instructor Last Name & Text field of 50 characters \\
\hline & Course Name & Course Name & Text field of 256 characters \\
\hline & Course ID & Course ID & Text field of 256 characters \\
\hline & Synopsis & Synopsis & Text field of 256 characters \\
\hline & URL & URL & Text field of 256 characters \\
\hline & $\begin{array}{c}\text { Tall } \\
\text { Teaching } \\
\text { country }\end{array}$ & $\underset{\substack{\text { Tazching } \\
\text { Region }}}{(1)}$ & \\
\hline
\end{tabular}

Each faculty member was asked to place points on the web map according to the country or region that they teach about or research in and key in the relevant details in the resulting popup. The "country" or "region" fields were created as a drop down for selection and not automatically populated because survey participants might not zoom in enough to their country and so misplace the points, or could have mistakenly placed it at a wrong country. The example of the popups are shown in Figure 4-10 


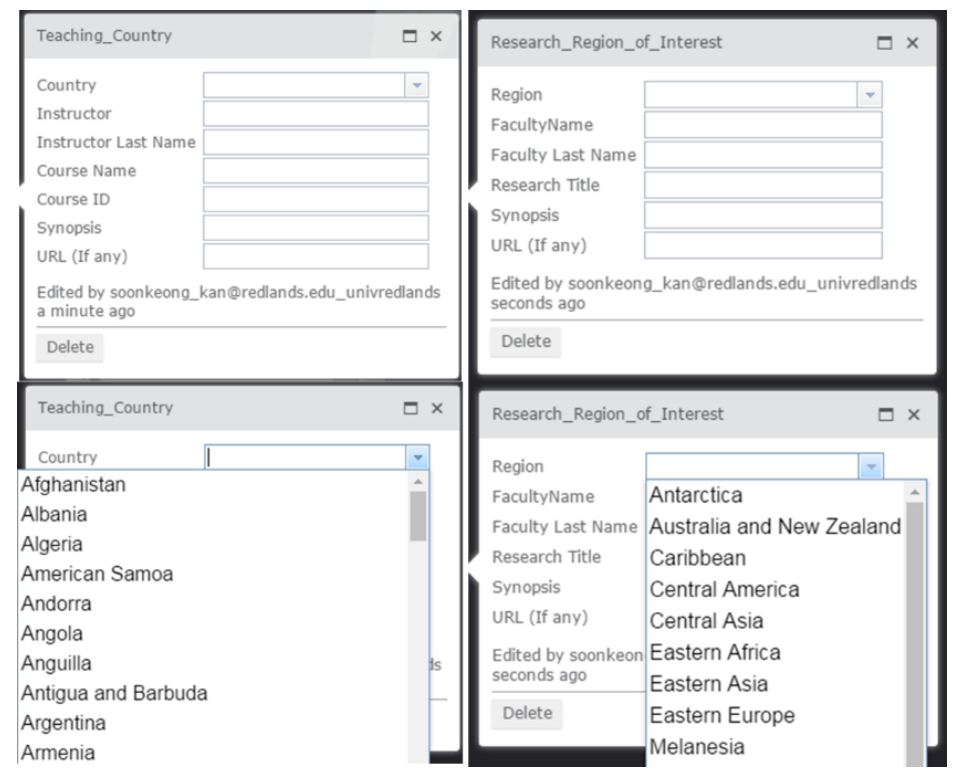

Figure 4-10: Survey Popups

Esri's Story Map Journal template was used to encapsulate the survey created using the Edit template because it allowed the team to provide an explanation of the survey and instructions on how to place the points in the survey. Similar to the Edit template, it facilitated development by providing a ready-made template and not requiring an entire interface and HTML web page be built for the survey. It is shown in Figure 4-11 below.

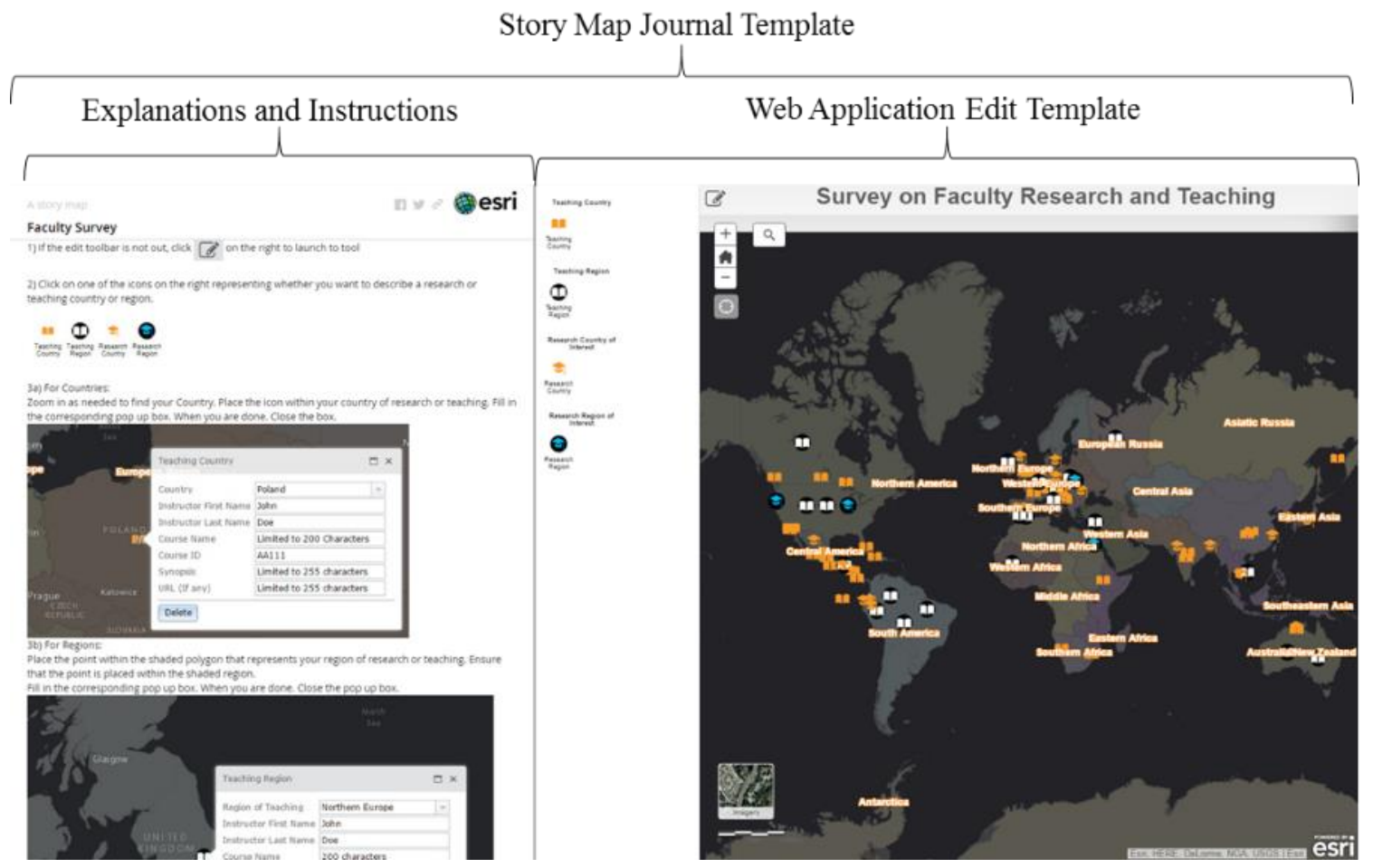

Figure 4-11: Faculty Survey Story Map Template 
When the survey was completed the results were exported as a geodatabase so that they could be easily imported into the existing working geodatabase for processing. The client will continue to maintain the feature services and can add or subtract from the research and teaching points as needed.

\subsection{Data Scrubbing and Loading}

Some data cleanup was required. The first, major part of the cleanup fixed the spellings of countries for the Provost Office and the Study Abroad Office that were different from the fields used in the country master-list which was used to join for the country centroid. Examples of this included, "Atlantic Ocean" for the study abroad program which did not exist in the country master-list, and "England", which was listed under "United Kingdom". In these cases, after the data were joined, the project team manually keyed in the coordinates for these locations.

In addition to these two datasets provided by the client, the other data cleanup occurred for the faculty survey. There were several reasons for this. Some faculty did not $\log$ in with their ArcGIS online account, and so were unable to edit or delete the points they had created. Hence there were some points that needed to be deleted for the faculty, especially some points that were blank because the person started the survey but did not complete it. Other areas of clean-up occurred when the person taking the survey forgot to select the drop down for their country interest. This cleanup was done after the feature service had been downloaded to the geodatabase.

\subsection{Summary}

This chapter covered the database design conceptual model, logical model, data sources, data collection methods and data scrubbing and loading. The key method of plotting the data on the map was through the use of the master list for country and region as all the coordinates of the points and polygons were joined from there. Efforts were made at every step of the process to ensure that the names used for country and region conformed to that list, whether in the design of the survey for data collection or for repairing the datasets that were given by the client. 



\section{Chapter 5 - Implementation}

This chapter discusses the tasks, tools and processes used in the development of the web application to achieve project functional and non-functional requirements. It references the database created in earlier chapters to describe the services that are published and how the various functions are implemented to meet the requirements. Section 5.1 addresses how the feature services are published from the database. Section 5.2 describes the application development in terms of the various layouts and functionalities of the web application. Section 5.3 provides the summary for this chapter.

\subsection{Publishing Services}

Following the processing of the tables to form the various datasets and feature classes mentioned in the previous chapter, the datasets needed to be published as feature services before they could be consumed by the application. This was done using Arc Desktop to publish to ArcGIS Online. Each dataset maps to one feature service, with the exception of an additional feature service containing the University of Redlands location and logo. This additional feature service showed where international students came to study, as well as the starting point for students going to study abroad programs. Figure 5-1 below shows the publishing of the feature services.

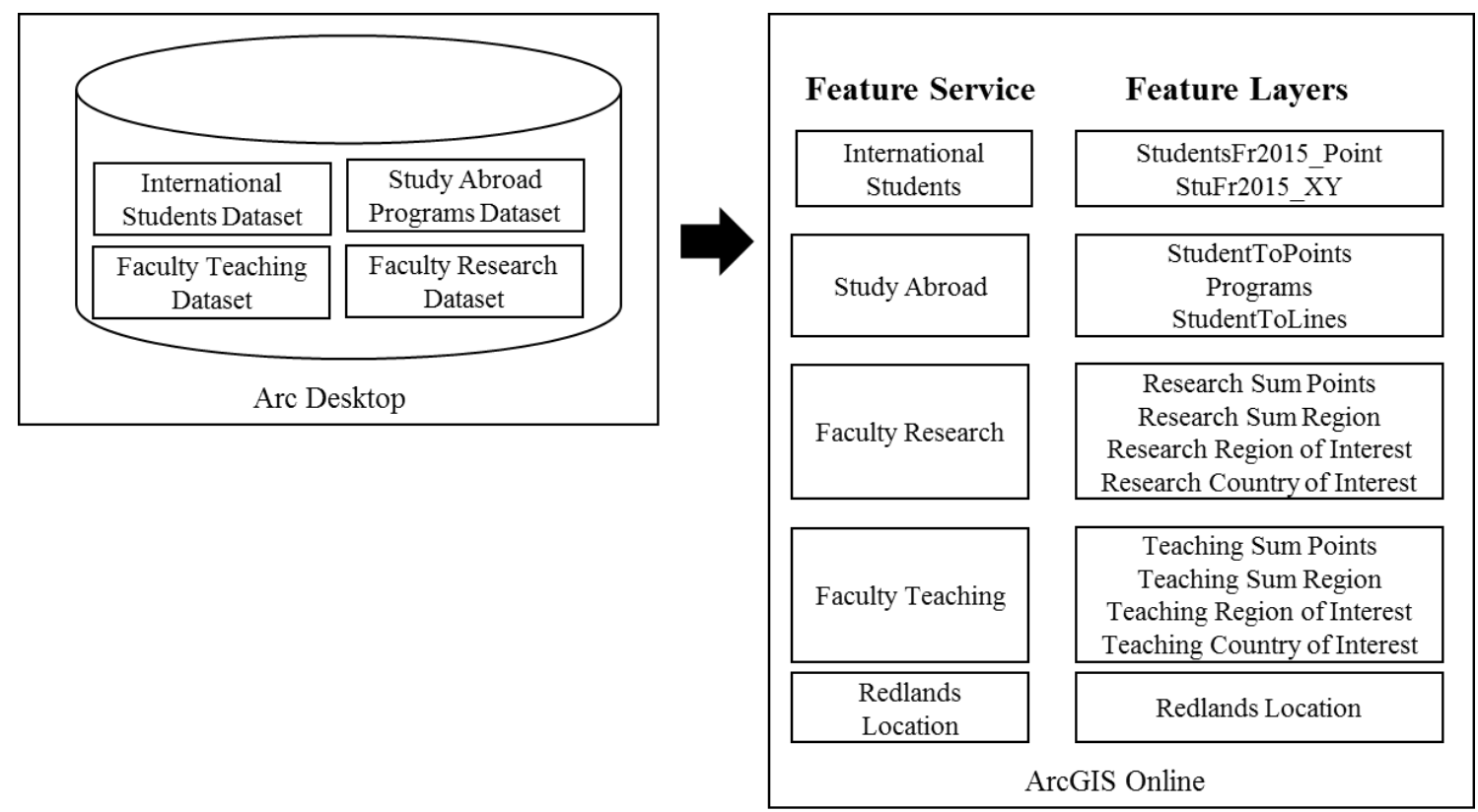

Figure 5-1: Feature Services From Datasets

All the feature services were initially published as a single large service with all the feature layers inside it. This was later split and each dataset was published as a separate feature service due to two factors. First, the datasets had different rates of update. Datasets such as the International Student Dataset and the Study Abroad Dataset changed 
from semester to semester, whereas those of Faculty Research and Faculty Teaching might not change at all during the year. The Redlands Location would not change at all. Hence, multiple services made it easier for a user to update the necessary feature classes, arrange them to form a dataset, and publish the updated feature classes instead of publishing all the layers together.

The second factor was due to intermittent problems publishing the entire set of layers into one feature service. When overwriting existing feature services or creating new services, there were times when not all the features were properly published to the ArcGIS Online server, which resulted in missing features within the layers. Publishing as multiple services ensured that only one service was affected at a time, making it easier for the user to debug and perform checks in future

Feature services are published when there are changes to any of the feature classes in any of the datasets. The team started a new map document and added the layers into it. It is recommended to order the layers by their intended display order. The team then shared the map document as a service to ArcGIS Online. The settings to configure the service included the following three steps. The first step was setting the maximum number of records returned by the server. This number should be high enough to accommodate returning all the records from feature layers or else some features might not be displayed correctly. Second, the feature access to allow query was set, so that the records can be searched or queried. Finally, permissions to "everyone" were set so that the public can view and access the service.

When the service had been published, the team updated the links to the new services in the web application code accordingly. It is recommended that new service are published instead of overwriting an existing one. Although this was more labor intensive because the links in the code needed updates, this ensured that the old services were still available if anything went wrong during publication and the team could revert to the existing services as a backup. Figure 5-2 shows the process flow for users to publish features and make changes to the web application.

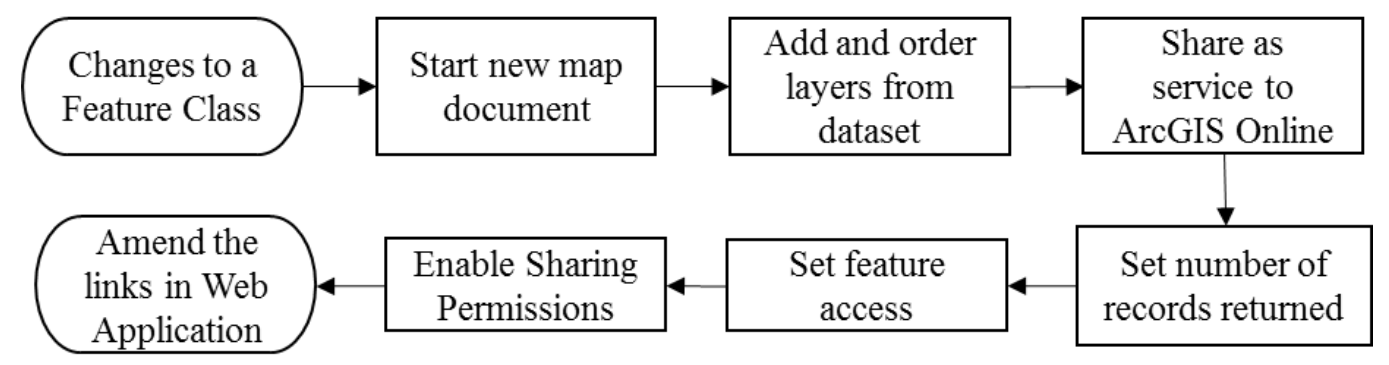

Figure 5-2: Feature Services Publishing

\subsection{Graphical User Interface (GUI) of Web Application}

The script for the application made use of HTML for the layout, Cascading Style Sheets (CSS) for the styling of the page, Dojo toolkits for functionality such as the panes, and ArcGIS JavaScript API 3.16 for the map and other widgets. During project development, Esri had just launched its JavaScript API 4.0. An official blog post in Esri's developer blog described it as enabling support for both 2D and 3D, as well as a redesign for ease of 
coding (Heberlie, Powell, \& Svensson , 2016). The team chose to work with API 3.16 instead because it had the functions needed for this project, had a proven record of stability, and there was a large existing user base where help and troubleshooting were readily available.

The layout of the application was created using HTML. HTML uses div elements to define a division or section in the HTML document, and these div elements were used to reserve space for the various panes, viewers, and functions of the application. To left of the application was the Accordion container. It contained content panes where each pane represented different topics for internationalization and provided space to display additional information. The right side of the application contained the map viewer where the various feature services were symbolized and displayed. Space was also reserved for the search widget and the navigation tools on the map viewer. The overall layout of the web application is shown in Figure 5-3 below. The original basemap is published in dark gray, but for illustrative purposes, the light gray basemaps will be used in some figures for better interpretation.
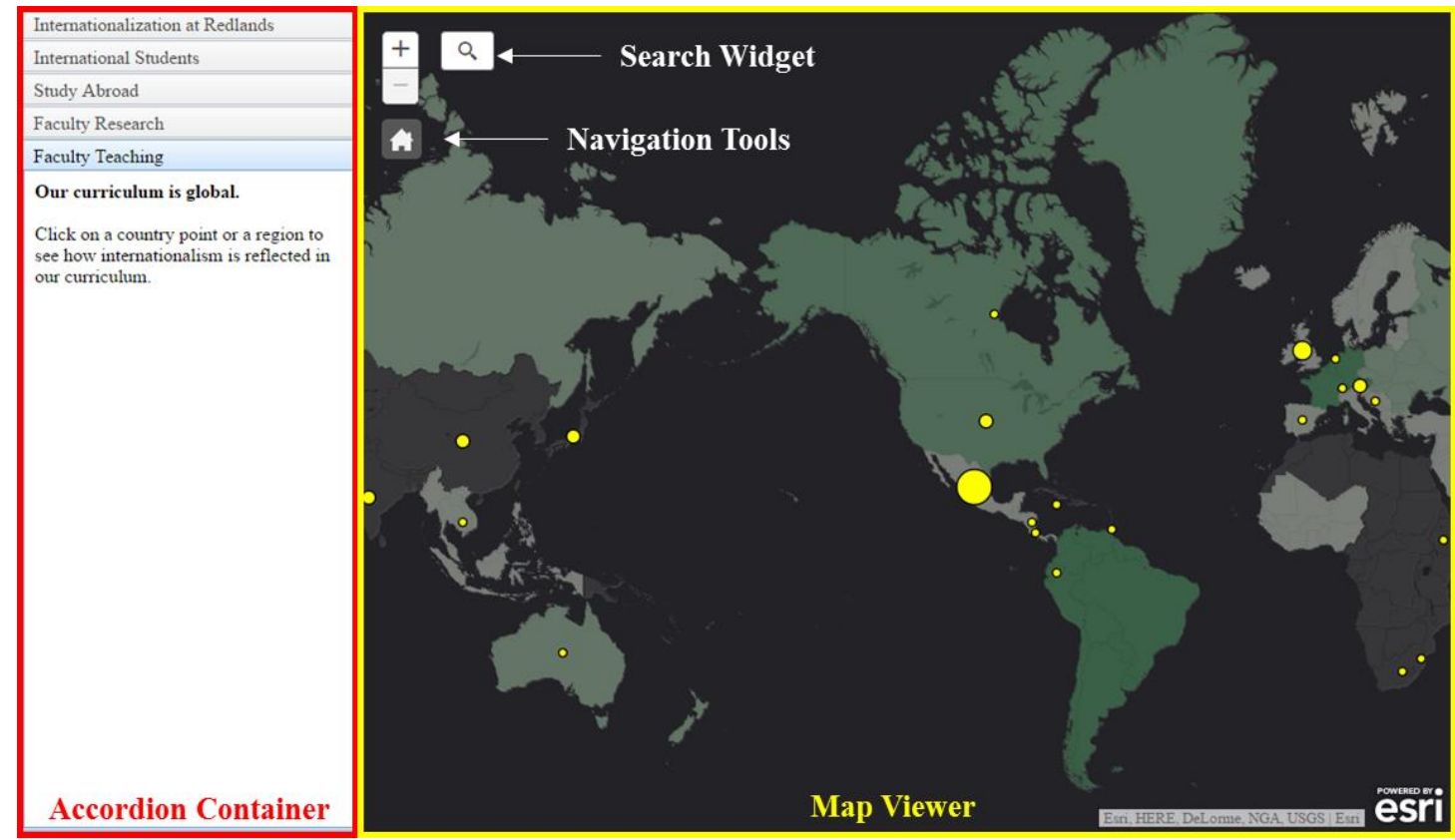

\section{Figure 5-3: Application Layout}

This section describes the design of the graphical user interface (GUI) of the web application. It details the layout, tools and functions that were incorporated into the web application and discusses the background considerations behind their selection and implementation. It also outlines the processes involved in the implementation. For more information on the underlying code, refer to Appendix A. Section 5.2.1 will describe the map viewer and graphic visualization of the feature services according to the topic of the content pane. Section 5.2.2 presents the symbolization of the feature services for display. Section 5.2.3 explains the functionality and the process for creating the content panes, information windows, and navigation tools. Section 5.2.4 discusses enabling the user 
interaction of the web application. Section 5.2.5 details the implementation of the search widget to enable users to find information.

\subsubsection{Map Viewer and Graphic Visualization}

Graphic visualization enables users to view and interact with the data in a form that makes sense and enables decision making. The map viewer was placed in the space to the right in the layout, occupying the largest portion of the GUI. This was where the different feature layers were symbolized for users to view the extent of internationalization at the University of Redlands and interact with the data. The workflow to create the map viewer and represent the data is shown in Figure 5-4 below.

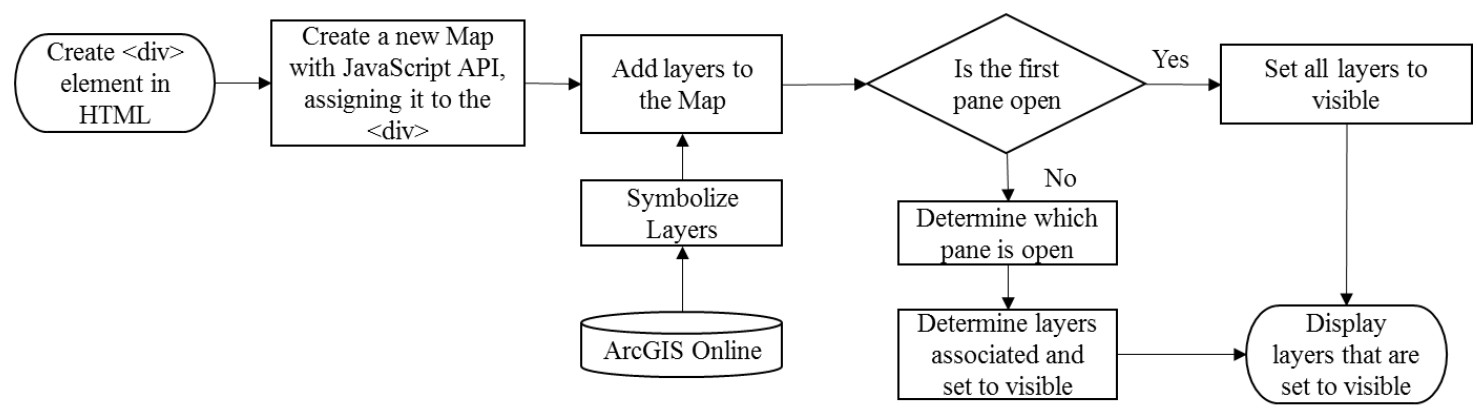

Figure 5-4: Showing Data on Map Viewer

Space for the map viewer was configured using a div tag in HTML. CSS was used to style the space and adjust settings such as height, width, and position. The map was then created using the Esri JavaScript API 3.16. The feature services published previously consisted of features that were symbolized before adding to the base map. The base map used was a dark gray one offered by Esri.

In order to meet the functional requirement of changing viewing layers automatically, the layers were linked to their respective content panes and displayed according to the topic of the pane that the user was viewing. This is also described as programmatically displaying layers as this is done through code. For example, if the user is on the international student's pane, the layers displayed would be StudentsFr2015_points, StudentsFr2015_XY, and the University of Redlands logo, as shown in Figure 5-5. 


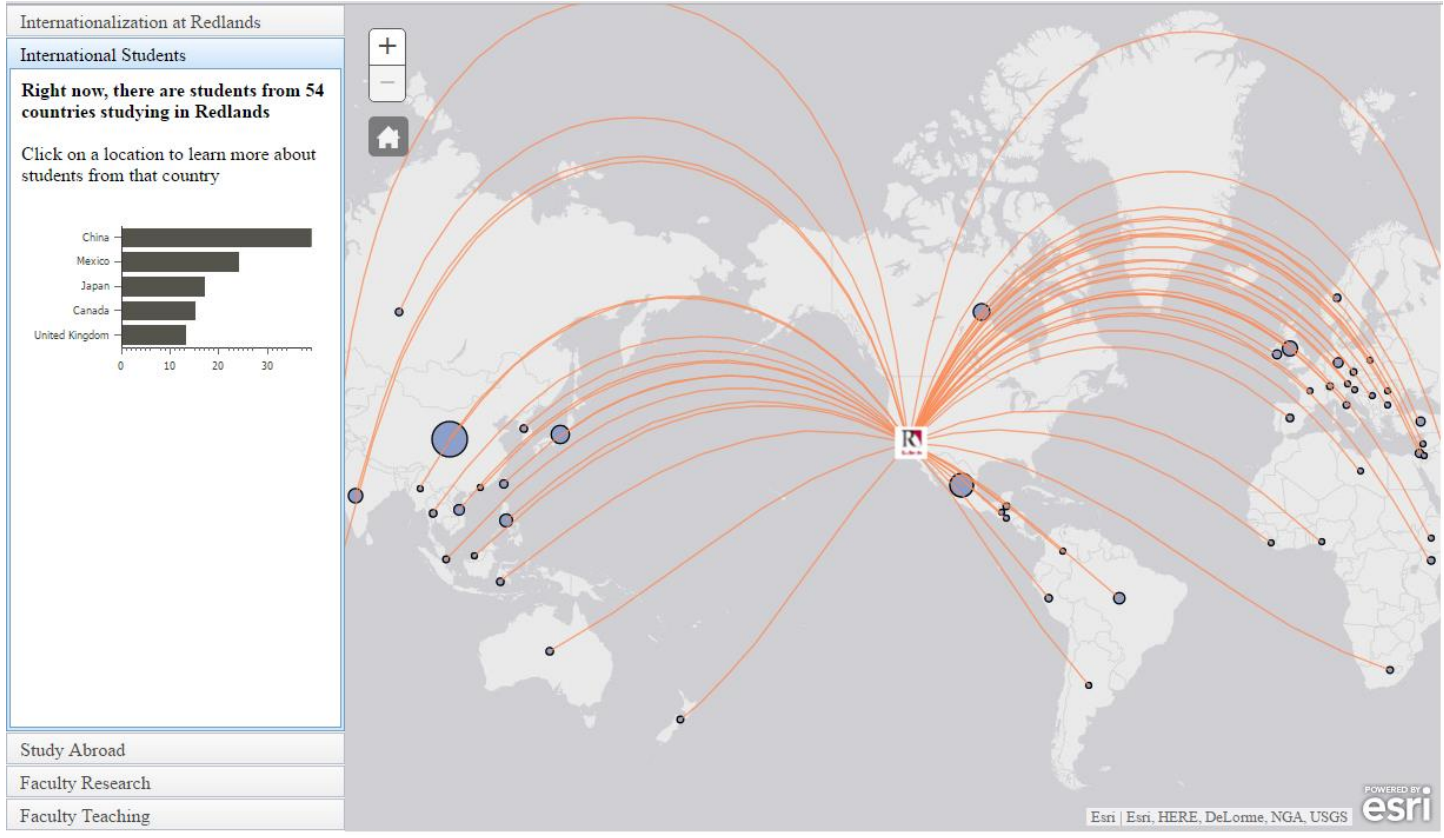

Figure 5-5: Layers Linked to the International Students Pane

Layers are denoted by their URL, also called REST end points. These addresses were first assigned to a recognizable layer name variable. This allowed the variable to be used throughout the rest of the program within other functions and saved the user the trouble of editing addresses throughout the code. The feature layers were then added to an array of layers. Each layer's position or index within the array was noted. Each content pane was then given a string which told the pane which layers were associated with it. The string contained the layers position in the array. For example International Students might have had " $1,2,3$ " as its string, indicating that layers one, two, and three were associated with it. A function parsed through all the layers in the array and compared the layer position with the string. If the layer position matched the string, the layer display property was set to be "on" and other layers were turned off. This is illustrated in Figure 5-6.

\begin{tabular}{|l|c|c|}
\hline \multicolumn{1}{|c|}{ Layer Name } & $\begin{array}{c}\text { Layer List } \\
\text { Position }\end{array}$ & Visibility \\
\hline Redlands Location & 1 & On \\
\hline StuFr2015Point & 2 & On \\
\hline StuFr2015_XY & 3 & On \\
\hline StudentToPoints & 4 & Off \\
\hline StudentToLines & 5 & Off \\
\hline
\end{tabular}

Figure 5-6: Example of Programmatically Displaying Layers 


\subsubsection{Symbolization}

According to the Esri's (2015) help page for JavaScript "symbols define graphic's appearance, including fill color or pattern, border width and transparency". The feature services published had symbols that were assigned at time of publishing. These symbols did not fit the application theme or represent the data in a way easy for the user to interpret. Hence renderers, which define the set of symbols, were used to change the symbols according to what needed to be displayed.

In this project, graduated symbols and color ramps were used to represent data variations and give users visual cues to their quantity relative to other objects in the map. With the International Students pane open, the country point's size represented the number of students that came from the country. Similarly, in the Faculty Research and Faculty Teaching panes, the size of the points represented the amount of research and teaching respectively concerning a given country. In addition, a color ramp was used to represent regions, where the shade of the color represented the amount of research and teaching within a region: lighter shades for less and darker shades for more. An example is shown in Figure 5-7 below. For illustrative purposes, the basemap has been changed to a light gray basemap.

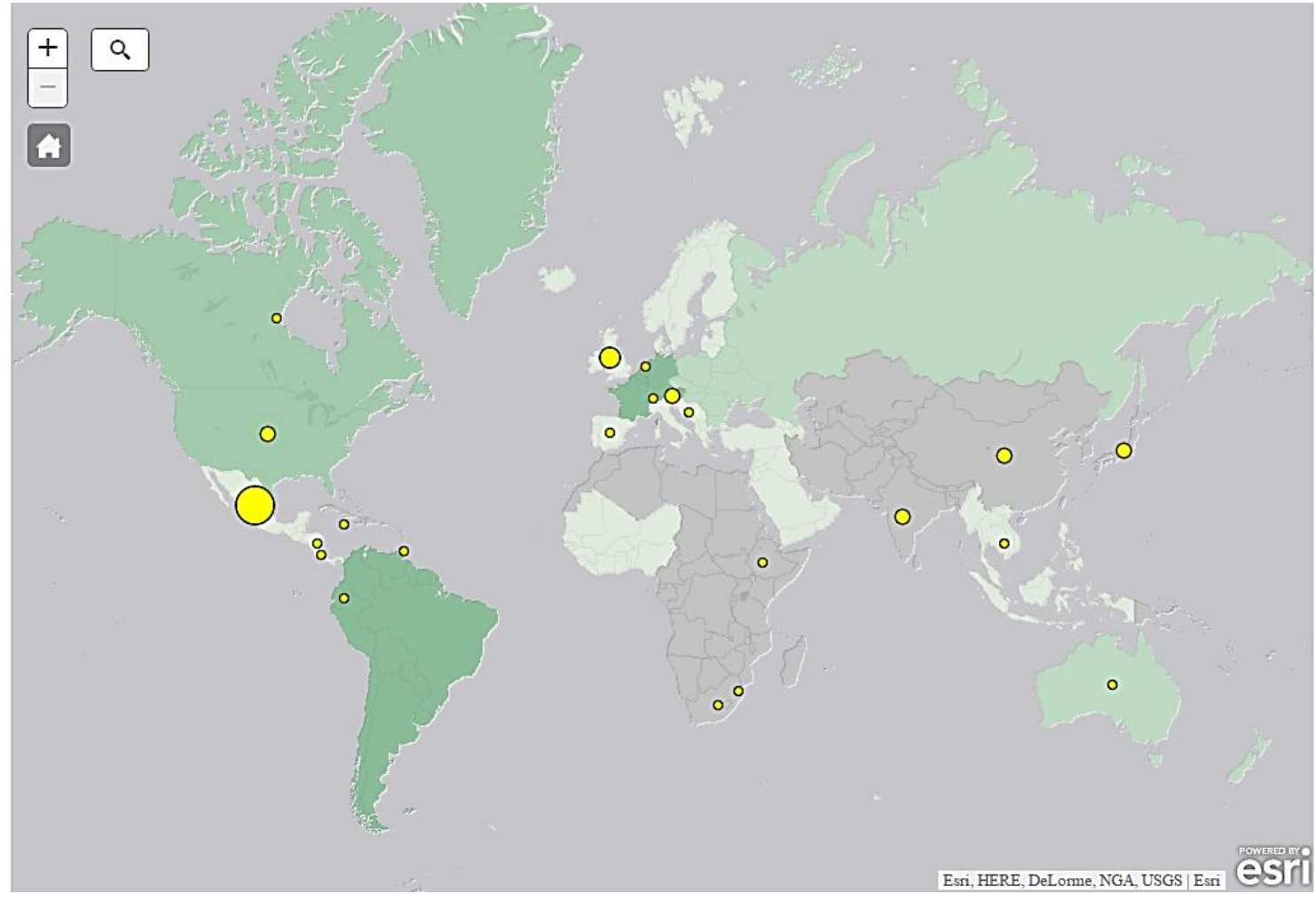

Figure 5-7: Examples of Using Proportional Symbols and Color Ramps for Faculty Teaching

The yellow circles in Figure 5-7 above were implemented using Esri's simple marker symbols and simple renderer in the JavaScript API. First, the size information was set; 
this consisted of telling the API which data field was used to adjust the symbol size, the maximum and minimum symbol size desired, and the range of data being represented. The size information displayed proportional symbol size, which was suitable because the numbers represented were continuous and relative to one another.

Next, a new simple marker symbol was created and the color to be rendered was set. Simple marker symbols can be circles, crosses, diamonds, squares or paths. If a picture icon is required a picture marker symbol is used instead, like in the case of the University of Redlands Location. The created marker symbol was then passed to the renderer, following which an event listener was set. Event listeners are functions that wait for an event to occur. The event listener waits for the layer that needs to be symbolized to load. When the layer is loaded, the event listener calls a function to set the new renderer for the layer. The workflow to do this is shown in Figure 5-8 below.

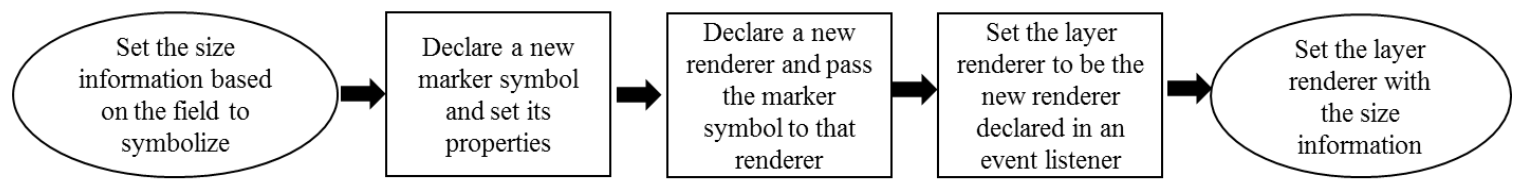

\section{Figure 5-8: Creating Proportional Symbols}

The methodology was similar for the color ramp used on the regions polygons. First, the color ramp information such as the field to symbolize and the range of expected data values were set. At least two colors, representing the start and end color for the data range were selected. A continuous range of a single color was used because the amount of research and teaching can take on a wide range of values. Users can also use multiple stops if there are distinct classes of data to render.

Next, a new fill symbol was created and its properties such as outline color and line thickness were set. Similar to the marker symbol, a new renderer was declared and the new fill symbol was assigned. The difference compared to graduated symbols was that the color information was set on the renderer before the renderer was assigned to the layer that it symbolized. Again, this was encapsulated in an event listener that listens when the layer to be symbolized has loaded. The workflow is shown in Figure 5-9 below.

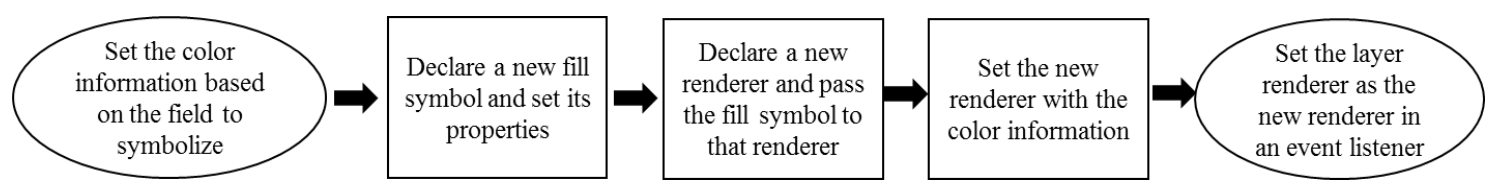

Figure 5-9: Color Ramp Workflow

\subsubsection{Content Pane}

The content panes were located in the accordion container on the left side of the web application. Each tabbed topic on the accordion container was its own content pane. Clicking on a new topic caused the currently displayed pane to slide away and the new topic to be displayed. An accordion container was selected so that users could view at a glance the various topics of internationalization. It also provided space below it to display 
pertinent related information to the user. The content pane turned out to be ideal because it could display a variety of different textutal and graphical information, allowed sufficient space for users to navigate, and performed automatic resizing of widgets when the pane size is adjusted. An example of the accordion container and information displayed on a content pane is shown in Figure 5-10 below.

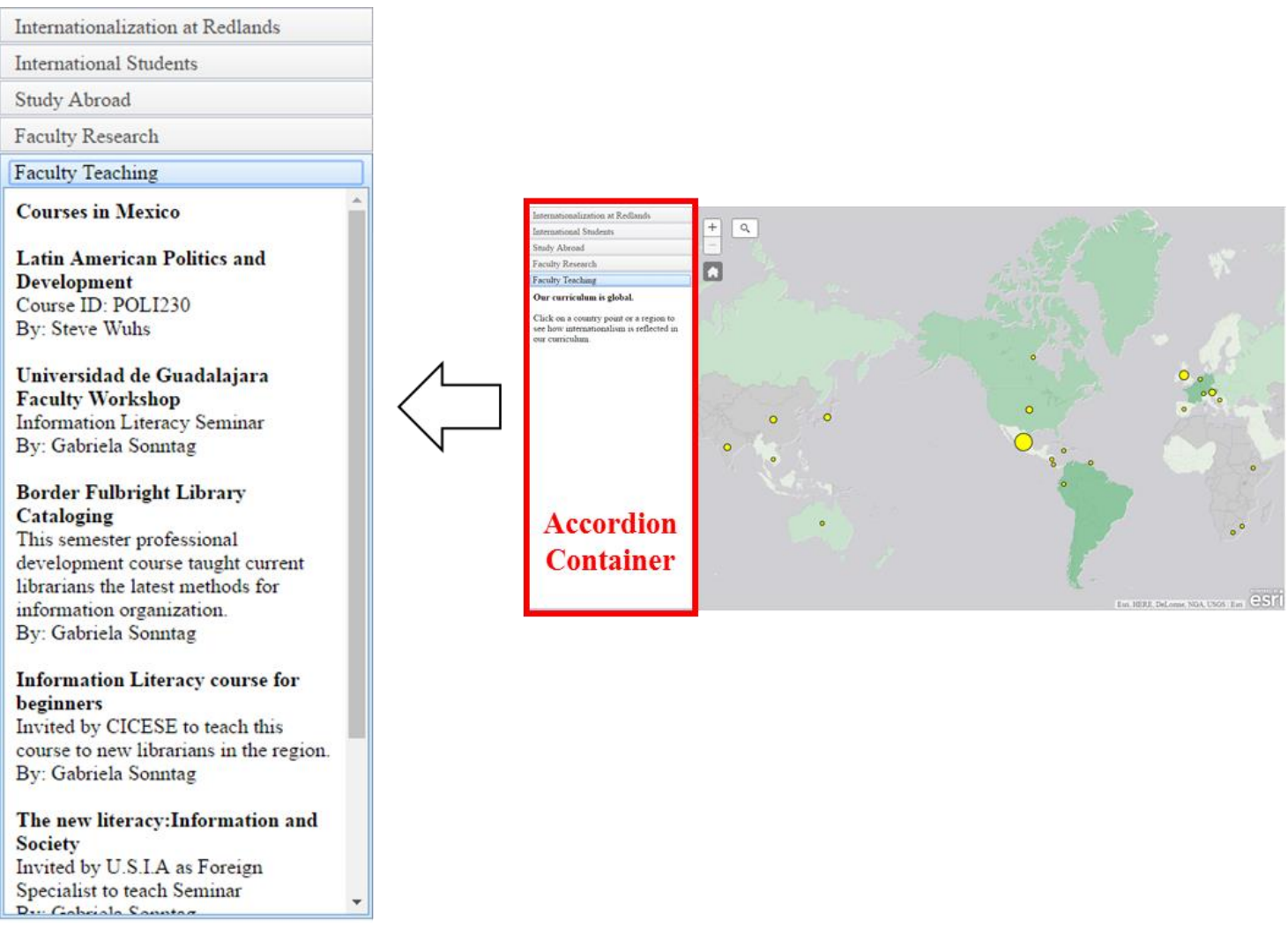

\section{Figure 5-10: Content Pane Example}

Accordion containers and content panes were implemented using the Dojo toolkit. They were part of the Dojo user interface library and were sometimes termed as dijits. To use content panes, an accordion container was first created and its settings such as height and position in the main application layout were assigned. A new content pane instance was then created. Third, the layers to display in the map viewer and the functions to execute when the content pane was shown were assigned. Examples of functions were: turning on popups, or enabling search. Fourth, the content displayed when users first opened that content pane was initialized and added to the pane. More information on the user interaction, information retrieval and display results can be found in Section 5.2.4 below. Fifth, the content pane was added to the accordion container. Finally an accordion container dijit was started. This workflow is shown in Figure 5-11 below. 


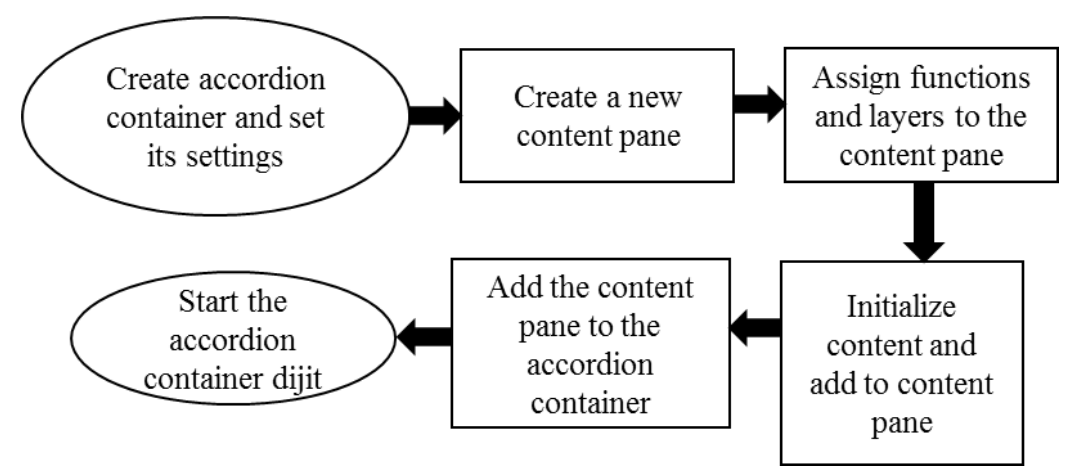

Figure 5-11: Using Content Panes

Content panes are versatile because a variety of information such as textual, graphical, and even widgets such as charts can be added to them. A horizontal bar chart was used in the International Students pane to display the top five countries where international students were from and the number of students from each country. This chart was selected because of the usable space for display. An example is given in Figure 5-12 below. The chart was dynamically created using data from the StuFr2015_Points layer using the Charting Widget within the Dojo toolkit. The chart updates itself when there are new data within the layer, assuming that the same field names were used. It provides configurable settings for the browser to draw the charts and automatically resizes when the browser window is moved. Similarly, if data are available, charts can be implemented to depict other forms of numerical data such as top countries for faculty research and teaching.

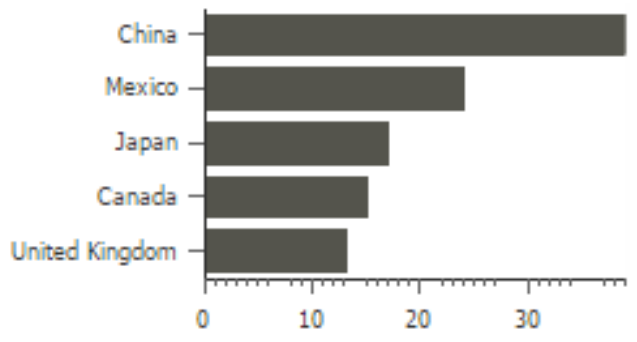

\section{Figure 5-12: Horizontal Bar Chart for Top International Student Countries}

To create the chart, the process was initiated when the International Student pane appeared. A query was then created using Esri's Query in the JavaScript API and a QueryTask was used to retrieve information from the database. Structured Query Language (SQL) was used to define the query. Next, the QueryTask was sent to the ArcGIS Online database which processed the request, retrieved the records, sorted them and returned them via an object to the program. When the records were returned, a function was called to extract the top five countries and add them to an array in order. This array contained key-value pairs of country and number of students that needed to be plotted. A new chart widget was declared using the Dojo toolkit and the configurable settings such as chart title, color, font, axes data and chart type were set. The country and number of students were then plotted onto the chart from the array. Finally, the entire 
chart was appended as a node onto the International Students content pane to be displayed. The workflow is shown below in Figure 5-13.

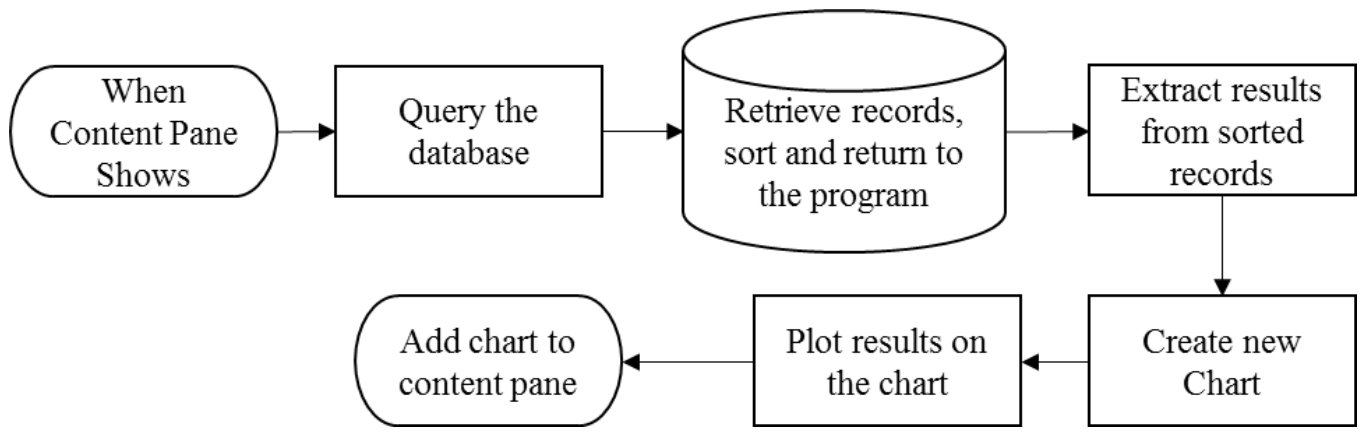

Figure 5-13: Creating Charts

\subsubsection{Navigation Tools and User Interaction}

Once the map viewer, symbolization of the features, setting up of the accordion container and the individual content panes were configured, users could now interact with the map and navigate through it in various ways. The primary tool for navigation within the map viewer is the mouse. Users are able to zoom in and out to countries of interest using either the mouse scroll wheel or through the in-built icons in the map viewer. To reset a map to its original extent, the user uses the home button. The original extent refers to the zoom scale and map center that the user first encountered when the application is loaded. These icons and the home button are found in the upper left hand corner of the map as shown in Figure 5-14 below.

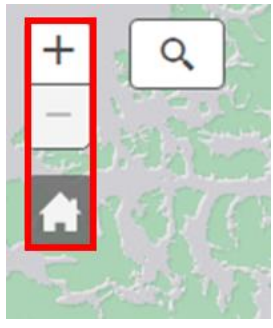

\section{Figure 5-14: Navigation Tools}

While the zoom in and out buttons are a part of Esri's map viewer, meaning they do not have to be explicitly created, the home button was an Esri widget that needed to be added in separately. First, a div was created using HTML to reserve space for the home button. CSS was used to ensure the correct positioning and space size were reserved for the button and that its position was dynamically adjusted as the window was resized. Second, a new instance of the home button widget was declared using Esri's JavaScript API. Third, the widget was assigned to map viewer and the div space that had been reserved for it. Lastly, the widget was started up. The process of adding a new home button is shown in Figure 5-15 below. 


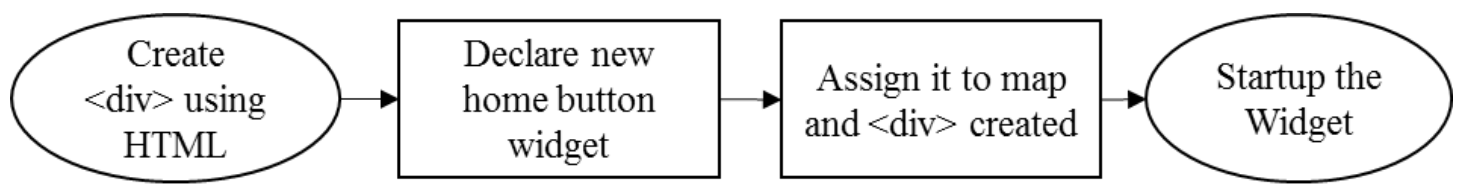

\section{Figure 5-15: Home Button}

Other user interaction included selecting features in the map viewer to get more information regarding that feature. There are two responses for that action. Within the International Students pane, selecting a country point provided the number of students from that country via a popup as shown in Figure 5-16 below.

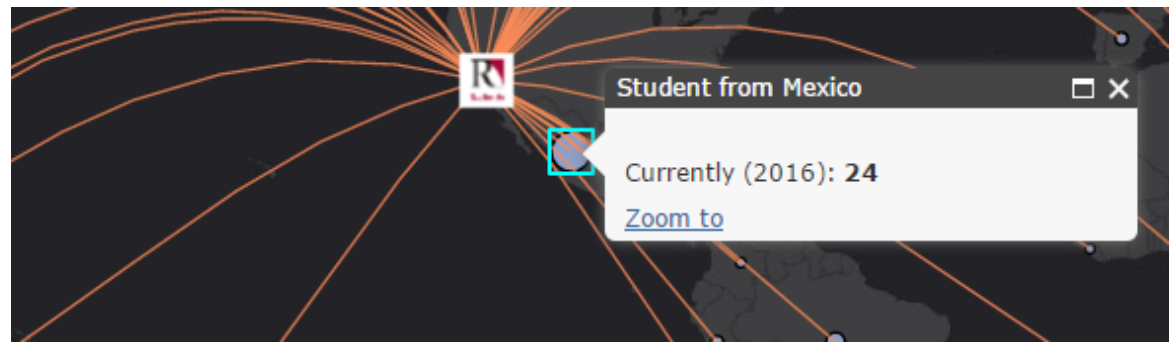

\section{Figure 5-16: Popup Information}

The popups were implemented using Esri's Info Template in the JavaScript API. To do this, a new instance of an info template was first declared. The popup information, such as the title and the content that was to appear within the window, was then configured. While this uses the JavaScript API, HTML tags were used to control the output format. Next, this new info template was assigned to the feature layer and the output fields when a feature was selected were set. Lastly, it was set to be shown or hidden with its respective content pane. The flow for this is summarized in Figure 5-17 below.

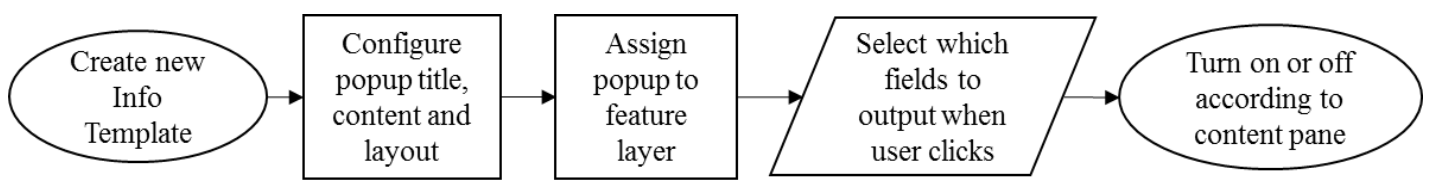

\section{Figure 5-17: Creating and Setting Popup Windows}

Within the other panes, selection of a country point or a region polygon resulted in the related information being displayed in the content pane on the left, shown in Figure 5-18 below. For example, when a user selected a country point in the faculty research pane, they get the list of faculty doing research within that country, the research topics associated with that country, and a link directing them to the faculty's page if there is one. As mentioned in Chapter 4, the relationship between features and records was a oneto-many relationship, meaning that every feature selected by the user on the map corresponded with many records within a separate table. 

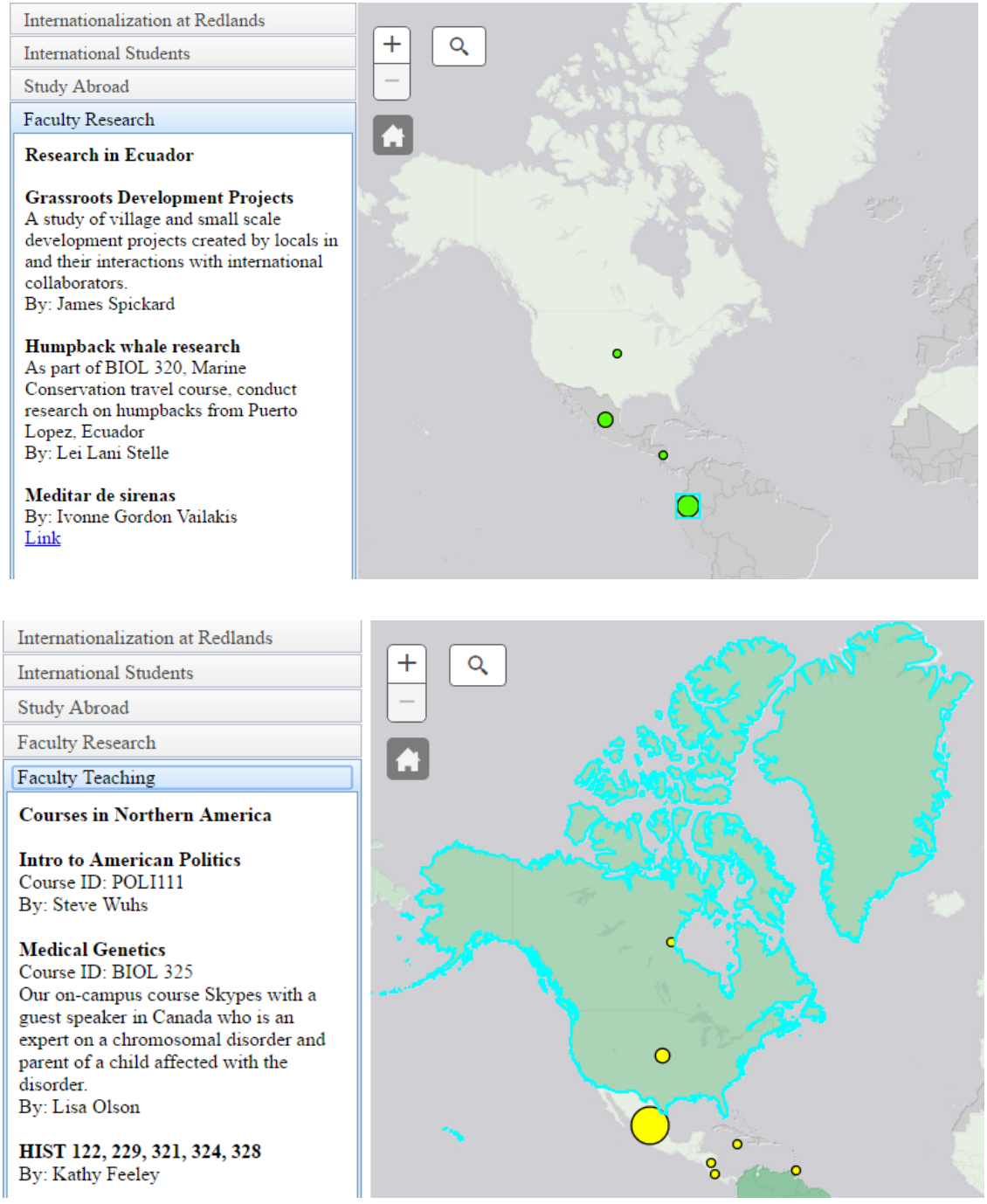

\section{Figure 5-18: Selecting Country Point or Region Polygon}

To enable this, the application waits for the pane mentioned in Section 5.2.3 to open. The application then initializes the content in the pane and the event listener, which attaches a handler to a specified event. The event is when a user clicks on a country or region. The function or handler is called to determine if the user clicked on a country point or region polygon. The name of the country or region from the layer which the user clicked is then extracted. A Query is created using SQL to find records where the country or region name matched the one extracted. The QueryTask executes the Query on the related country or region of interest table in ArcGIS Online and returns the results. After the results are returned from the QueryTask, a callback function is executed. Callback functions are executed within another function and are passed as a parameter to the other functions. In this case, when the QueryTask is successful, the callback function is executed to handle the returned results, which are then formatted for display in the form of a string. This string is then pushed into the content pane node for display. The flow is depicted in below in Figure 5-19. 


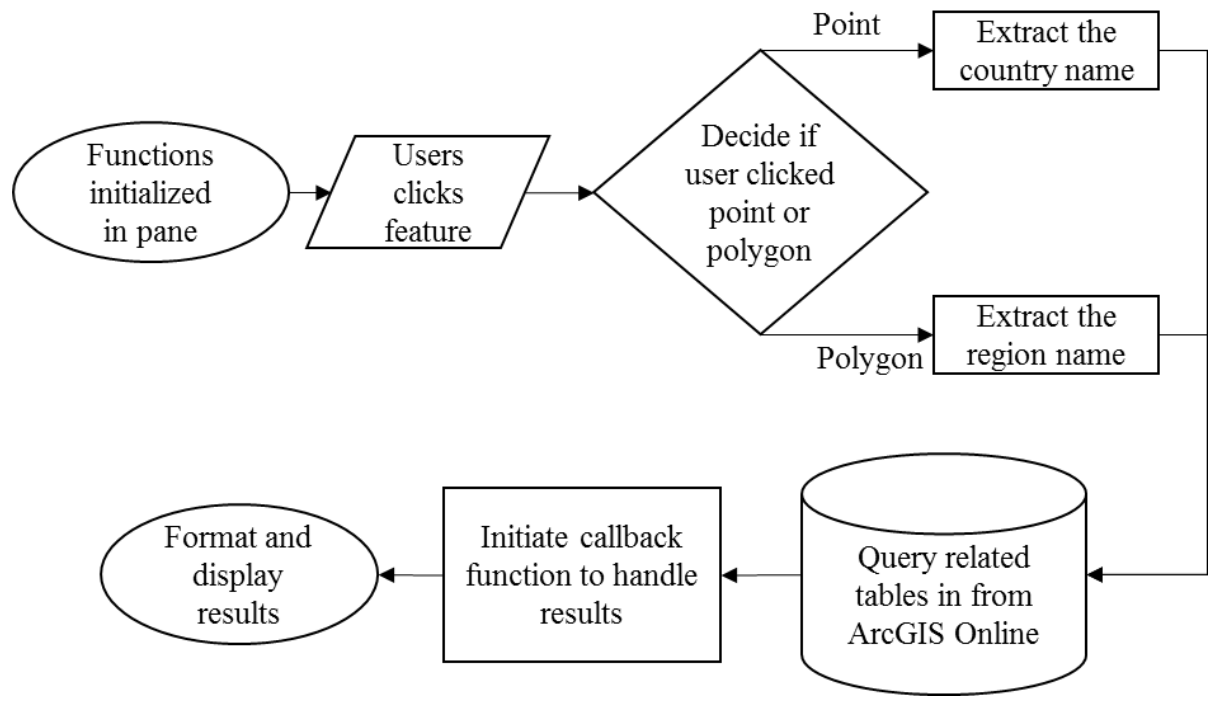

Figure 5-19: Flow for Implementing Related Query in JavaScript

The Query and QueryTask methods are within the JavaScript API and were used in place of the relationship class. This provided more flexibility to the user since multiple tables can be searched at the same time. Initially, building relationship classes in Arc Desktop, uploading these relationships to ArcGIS online, and displaying the information using popups was considered. However there were two reasons not to do this. The first was that for a one-to-many relationship, Esri's API only returns a summary of the number of related features and not the actual features. The actual features are returned in a separate table, as shown in Figure 5-20. The second reason was that, an additional relationship class needed to be created every time a new dataset was created, causing extra work for the team maintaining the database. Hence the query from related tables was created using JavaScript instead.

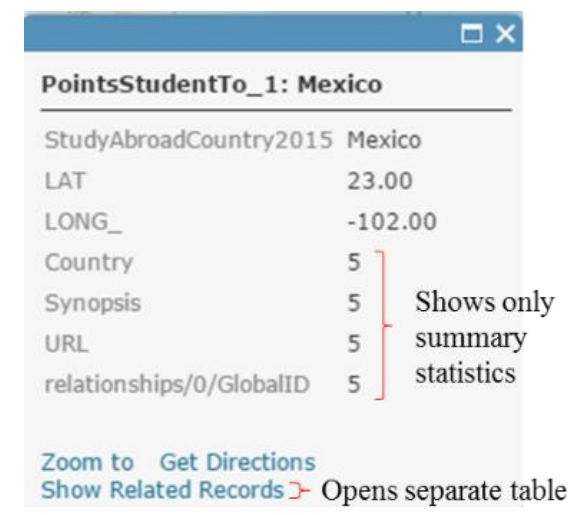

Figure 5-20: Return from Relationship Class 


\subsubsection{Search Widget Implementation}

During project development the dataset for faculty research and teaching was taken from the faculty survey. Not all the faculty responded to the survey, so the dataset was incomplete and sparsely populated. It was anticipated that in future, the client will populate the complete dataset. When that occurred, there would be a lot of data on the map, making panning and zooming to specific data more time consuming. A search widget was implemented for the project to facilitate the finding of data. A widget is a reusable component or tool that enables a user to perform a function access or service. The search widget was created by Esri. Since the JavaScript API is based on the Dojo Toolkit, the reusable user interface component was built using Dijit, which is the user interface library of the Dojo Toolkit. The widget was enabled for the Faculty Research and Faculty Teaching panes and disabled for the rest of panes.

The search widget searched only the tables and feature classes related to the content pane topic. For example, in the faculty research pane the search widget searched only within the faculty research dataset. The widget provided hints, telling the user what search terms could be used. It was set to search by faculty first name, last name, country name, and region name. In addition, it also provided search suggestions for the user when they typed in search terms. When not in use, the search window collapsed to an unobtrusive icon in the top left corner of the map viewer. An example is shown in Figure 5-21 below.

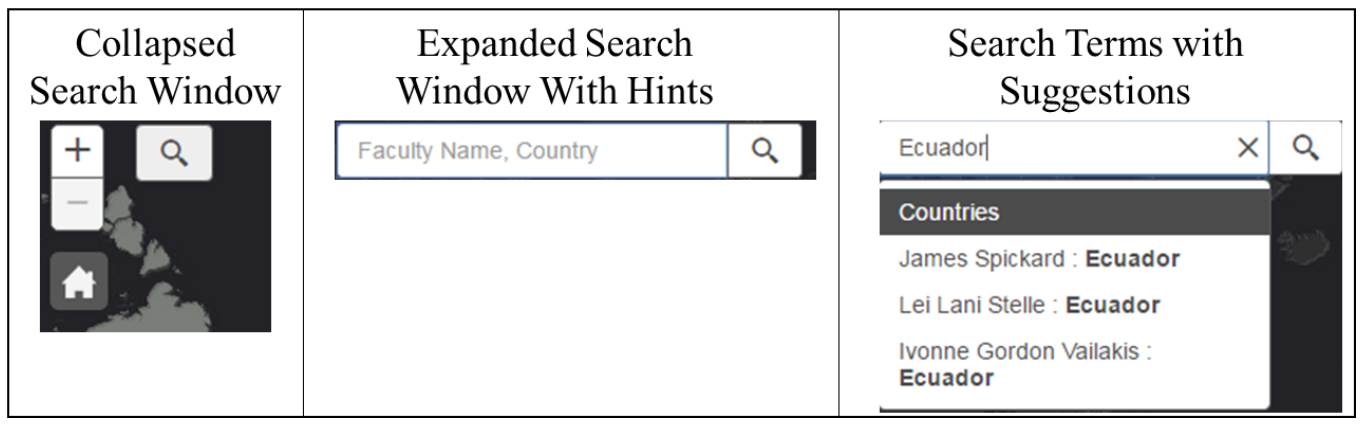

\section{Figure 5-21: Search Widget}

Search results were formatted and displayed in the side content pane. If the user selected one of the search suggestions, only the specific result was displayed. Otherwise, all results pertaining to the search term were displayed. This is shown in Figure 5-22. The team considered centering the map on the items returned during the user's search; however, this was impractical when the user was searching for faculty names since the results might cover several countries and regions. 


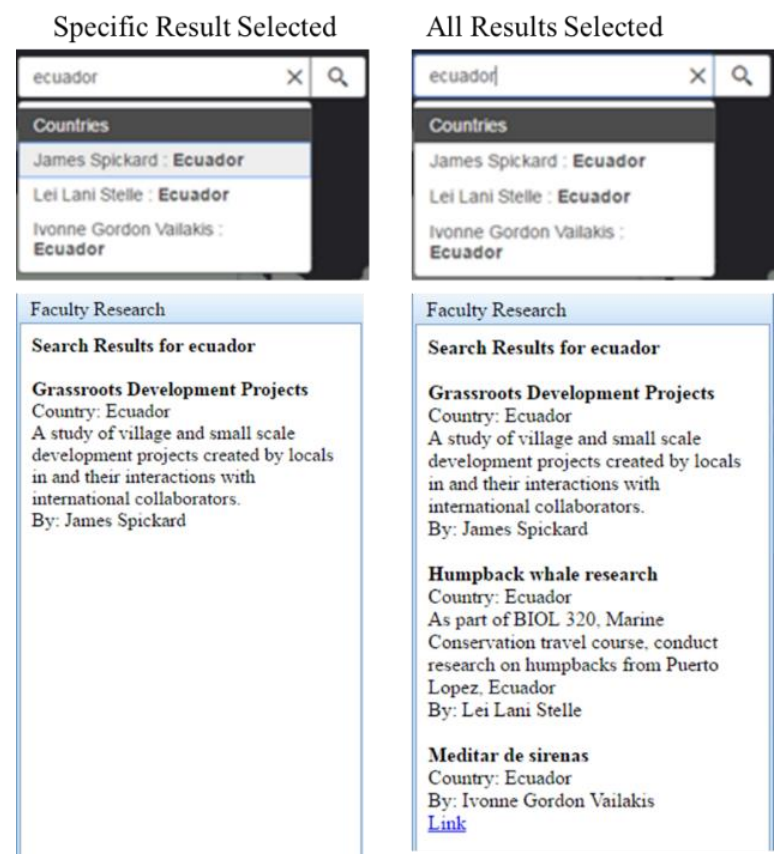

Figure 5-22: Specific Result and All Results

To implement the search widget, a div element was first created in the map viewer for the search bar using HTML. An instance of the search widget was then created and the widget properties were set. The settings included whether to show suggestions for search terms, to zoom to results and to display search hints.

Next, a list of sources was created and the settings for each source were configured. These included the fields to be searched, the information to be returned, and the number of suggestions and results returned. By default, the Esri Geocoder service was included in the list of sources. However, for this project it was removed from the list of sources because the project team wanted the search to be based on the team's country and region master list instead of Esri's list.

The application then decided which pane the user was on to turn on the search widget and set the sources accordingly. For example, if the user was on the faculty teaching pane, the faculty teaching feature service is assigned instead of the faculty research feature service.

Next, the application awaited user input of the search term. The widget provided suggestions based on faculty first name, last name, country name or region name. However, the search widget has issues when both the first and last names were entered. The widget is only able to search in one of the fields at a time. Once the term was entered, the feature service in ArcGIS Online was searched.

Finally, when the search results were returned the application initiated a function to handle the results, configuring it into a presentable format for the user and displaying it on the content pane in the accordion container. Figure 5-23 presents the workflow needed to set the search widget for project. 


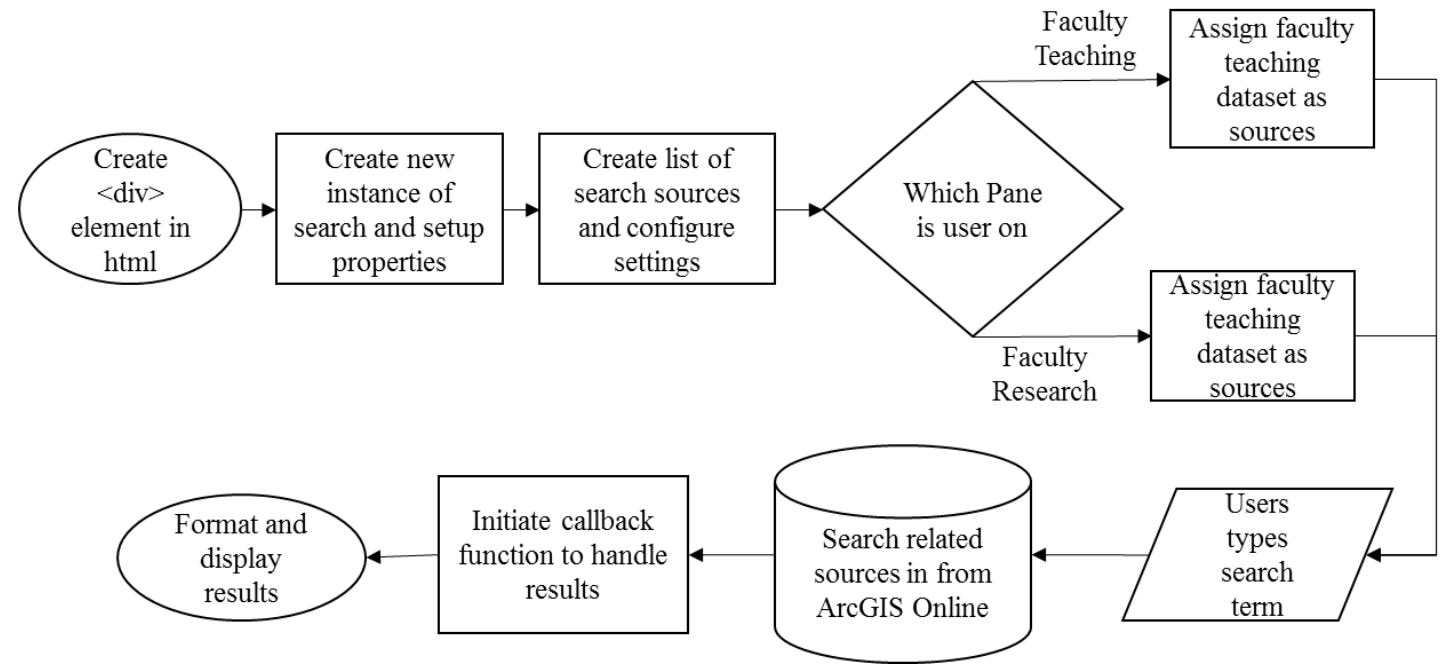

Figure 5-23: Search Widget Workflow

The main difficulty in implementing the search widget was handling the inconsistent results that were returned since the results were returned as objects in varying formats. The number of objects returned corresponded to the number of sources successfully searched. For example if the faculty name was searched and the faculty member was researching in both countries and regions, two objects were returned, one from the country layer and another from the regions layer. Each returned object contained another array of objects depending on the search results. For example if there were three countries, there would have been three objects. The team also had to handle null cases when there were no records returned from a layer in which case there were undefined objects that the server skipped over. These cases are illustrated in Figure 5-24. 


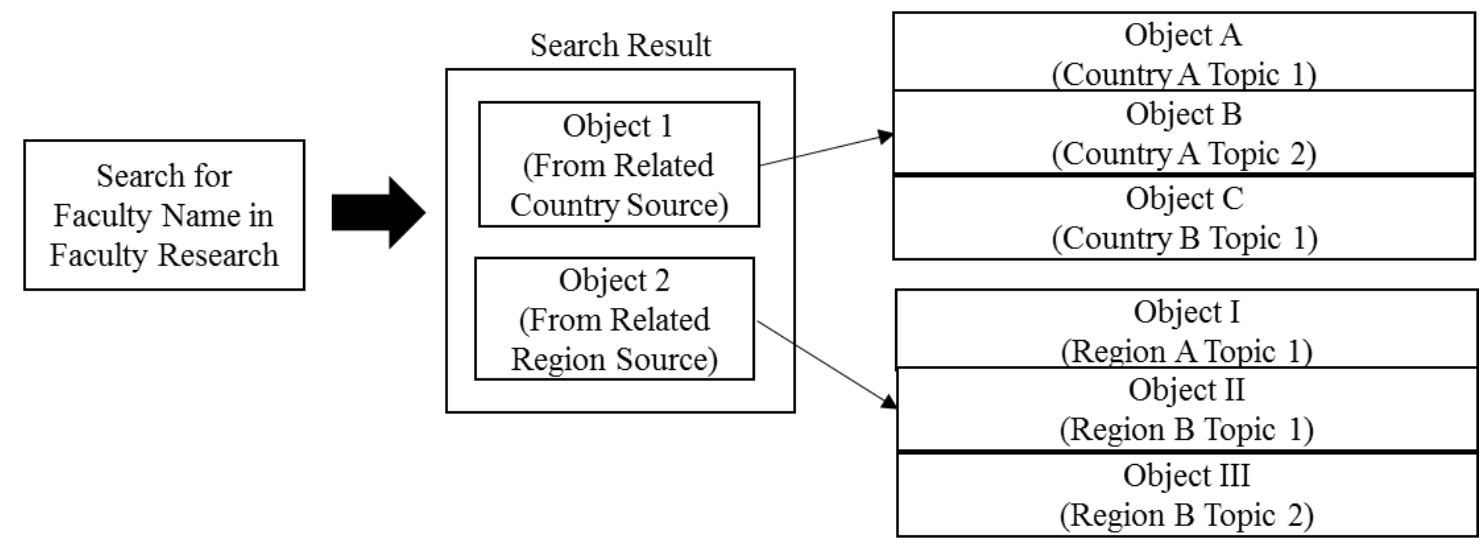

Valid Search With Undefined Objects

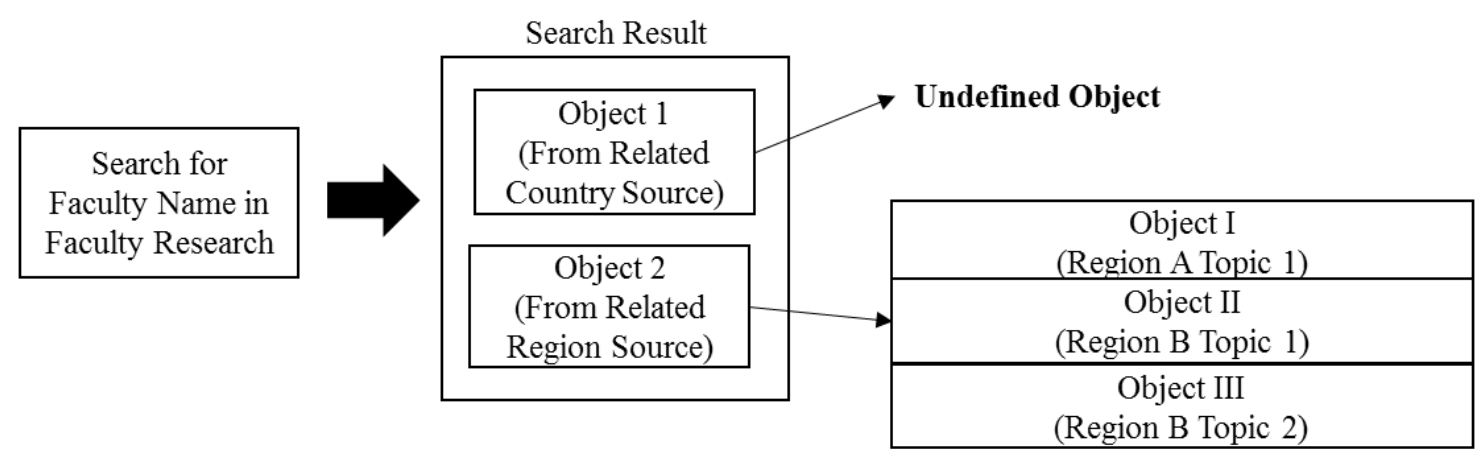

Figure 5-24: Search Results Returned

\subsection{Summary}

This chapter covered the tasks, tools and processes used in the development of the web application. It described the publication of feature services from Arc Desktop to ArcGIS Online and discussed the considerations behind publishing multiple feature services instead of one feature service with all the feature layers. The chapter also described the creation of the web application, beginning with the overall layout, the various panes, and their associated functions. The chapter then detailed the creation of the map viewer and graphic visualization, the symbolization of the feature services, the creation of the content panes, the navigation tools and user interaction, and finally the implementation of the search widget. 



\section{Chapter 6 - Use Cases}

This project was implemented to consolidate the existing datasets of internationalization into a streamlined interface that allows a user to query these datasets according to their respective needs. The CCI needed the query results displayed in a more useful format to aid decision making. This chapter focuses on the potential use cases of this application for decision making for three major groups of people, which are students, faculty and planners. Section 6.1 covers the use cases for student, both prospective and current. Section 6.2 covers the use case for faculty and Section 6.3 covers the use case for planners. Section 6.4 provides a summary to this chapter.

\subsection{Use Case: Students Planning to Come to the University and Looking for Courses}

In this scenario, a prospective student is thinking of coming to the University of Redlands. They want to better understand the study climate at the university before deciding; are any other students from his/her country at the University, how many are there, what type of study abroad opportunities are provided and what other courses are offered.

Upon loading the application, the first thing the student sees is that the University of Redlands is well-connected internationally. The information on the pane invites him to explore the various aspects of internationalization at the university. The student, wanting to see how many countries are represented at the university, uses the mouse to click the pane labelled "International Students" on the accordion container shown in Figure 6-1 below. This hides the Internationalization at Redlands pane and slides up the International Students pane.

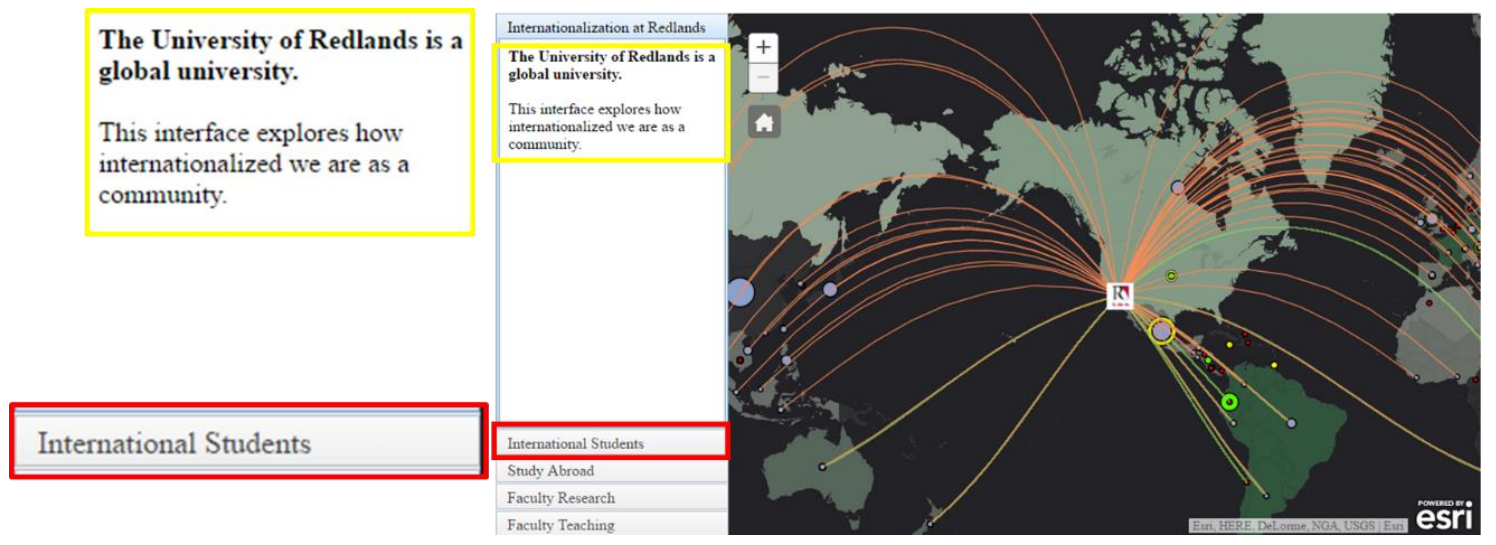

\section{Figure 6-1: Internationalization at the University of Redlands}

The three layers associated with international students are displayed in Figure 6-2 below. A summary statement in the content pane, highlighted in green, tells the student that there are students from 54 countries studying at the University of Redlands. If for example, he was from the United Kingdom, the student would use the mouse to pan to 
the United Kingdom, whereupon he can either use the mouse scroll wheel or the zoom buttons, highlighted in red, to zoom to the country.

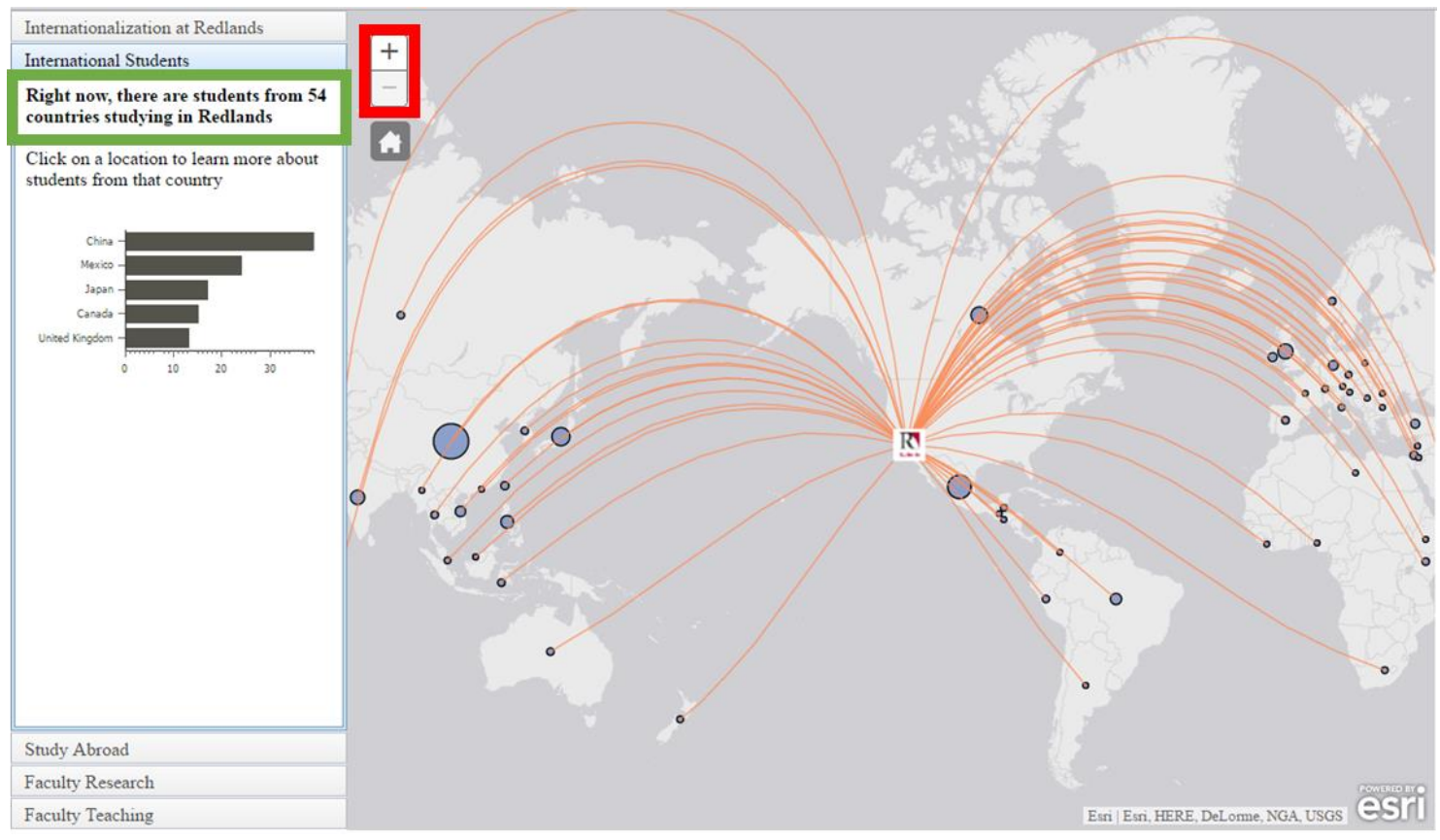

\section{Figure 6-2: International Students Pane}

Once there, clicking on the point representing the United Kingdom will enable a popup, highlighted in red in Figure 6-3 below, telling him that there are 13 students from his country currently studying there. This information might make him decide to study there because of existing social links. The student can return to the original extent via the home button on the top left of the map viewer, highlighted in yellow.

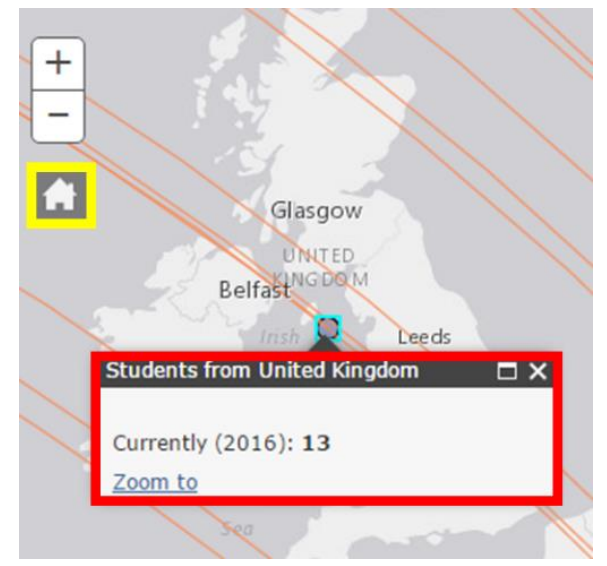

\section{Figure 6-3: Popups and Home Button}

The student is also interested in opportunities that the university provides to study abroad. He clicks on the Study Abroad pane which slides up, hiding the International 
Student pane. This also changes the layers displayed in the Map Viewer, showing him the layers associated with study abroad programs. The content pane informs him that the University sent students to 44 countries for semester-long and May Term study abroad programs. The student decides that he is interested in the programs in China, pans the map to the country using the mouse, and clicks on the country point. The application retrieves information regarding study abroad programs in China and displays the information. The three programs offered by the university are displayed on the content pane. The program names, a short description of the programs and a link to the program's website are displayed. This is shown in Figure 6-4 below.

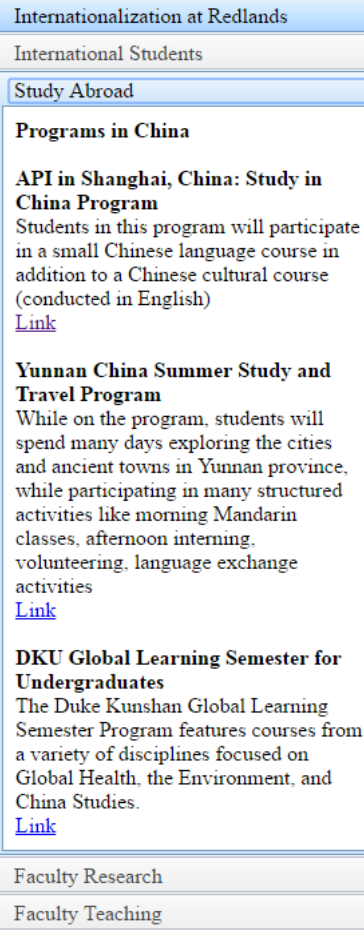

\section{Figure 6-4: Study Abroad Programs Offered Related to China}

To further understand the study climate at the university and find if there are courses that can prepare him to study abroad, the student clicks on the faculty teaching content pane. The map viewer displays the countries and regions that are taught by the faculty. The yellow point in China indicates that there are courses there, and its size indicates the number of courses relative to the rest of the courses in other countries. Clicking on the point, highlighted in cyan in Figure 6-5 below, brings up the list of courses available concerning China on the content pane. The information, highlighted in red, shows that there are two courses available. At the time of writing, the database has yet to be fully populated. The information provided are the course title, course ID, a synopsis of the course, the faculty conducting the course and - if available- a link to the course page. This helps the student decide whether to attend the course. If the student decides to enquire further, he can contact the faculty conducting the course. 


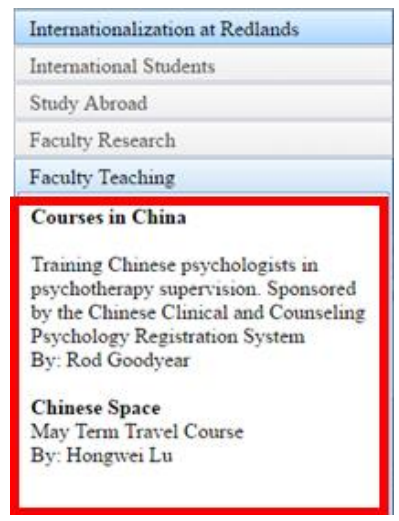

\section{Figure 6-5: Courses Taught With Relation to China}

Once the student has gone through some of the aspects of internationalization, he would gain a better understanding of the study climate at the University of Redlands and what is offered there in terms of educational opportunities and chances for interaction with students from other countries. The student now knows that he can find compatriots at the university, that the university offers travel programs to countries that the student is interested in, and also the necessary courses to attend to take up those opportunities. Hopefully, this will greatly influence his decision to study at the university. Additionally, this would aid not only prospective international students but also current students who want to look for study abroad opportunities, as well as courses to broaden their horizons.

\subsection{Use Case: Faculty Looking for Resources and Collaboration}

The second use case deals with a faculty member who is accessing the application to look for resources and potential collaboration on teaching and research. She might be looking for resources to enhance her own teaching and improve student learning by first inviting students who come from a particular country to share about their country or by recommending that students in their class attend other lectures that are connected with their international topic to gain better insight on peripheral or related topics. There might also be faculty from this or other universities who are looking to collaborate over research.

For the faculty looking for resources, similar to the first use case, she starts at the Internationalization at Redlands pane. Supposing she had to lead a group of students for a study abroad program in Salzburg, Austria, she will first go to the "International Students" pane zoom in and click on the point in Austria. There she would find that there is one student from Austria at the university whom she might invite to share insights, experience and advice. She can then get that student information from the Enrollments Office. This is shown in Figure 6-6 below. 


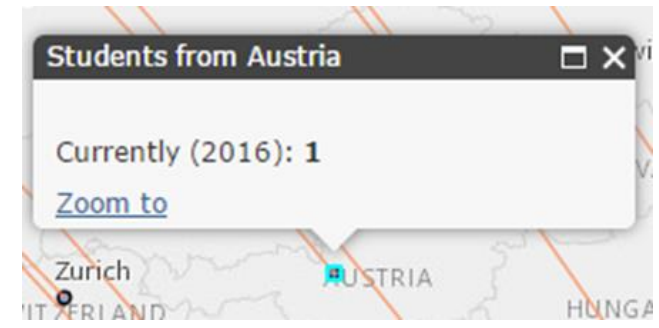

Figure 6-6: Number of Students from Austria

To enhance her teaching and improve student learning, she might also want her students to attend some lectures conducted by other faculty. This gives the students a more holistic understanding of a country and provides peripheral information for them to build on. Obviously, not all the lectures in a series are pertinent, so she should be selective in recommending which ones the students attend. She clicks on the Faculty Teaching pane to locate resources, layers that are related to faculty teaching are displayed in the map viewer.

She might have difficulty locating Austria on the map, so she will use the search widget located in the top left corner of the map viewer. It is usually collapsed to an icon, shown in Figure 6-7(A). Clicking it expands the search box. Its initial state provides hints to her that she can either search by faculty name or by country shown in Figure 6-7(B). By typing in "Austria," the widget searches through both the related faculty teaching country and faculty teaching region layers and provides suggestions via a drop down list in the form of "Faculty name: Country" shown in Figure 6-7(C). In this case, it shows that Baber and Spee teach on Austria and this information is extracted from the countries layer.

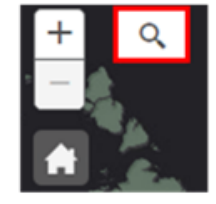

(A)

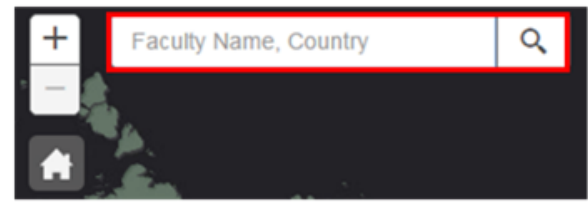

(B)

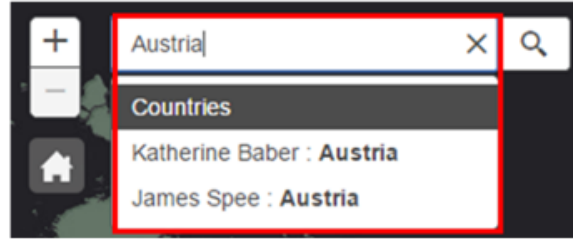

(C)

\section{Figure 6-7: The Search Tool in Various Forms (A) Collapsed (B) Expanded with Hints (C) Showing Search Suggestions}

If the user is unsure of specifically what topic that each faculty teaches about, she can hit the enter key or click on the magnifying glass on the widget. This will return an entire listing of the courses related to Austria on the content pane. If she knows specifically what the faculty does, she can select one of the suggestions, in which case only the specific record will be displayed on the content pane. Figure 6-8 below compares the cases where she searches by country and selects "James Spee: Austria" as a specific result. The results provide the course title, the course ID number, the country or region of interest that it is related to, a synopsis of the course, the faculty that is conducting it, and where there is a link to a course page, it will show up as a hyperlink 
for her to click. She is now able to contact her colleague on the topic that they teach to see if there are suitable lectures for students to attend.

\begin{tabular}{|l|}
\hline Faculty Teaching \\
\hline Search Result for Austria \\
MUS 404 \\
Course ID: Classic Music History and \\
Literature \\
Country: Austria \\
Study of the performance of classical \\
music as a component of Austro- \\
Hungarian history and modern Austrian \\
identity making. \\
By: Katherine Baber \\
Business in Europe \\
Course ID: JNST \\
Country: Austria \\
Compared an industry in Europe with \\
one in US based on personal \\
observations. \\
By: James Spee \\
\hline
\end{tabular}

(A)

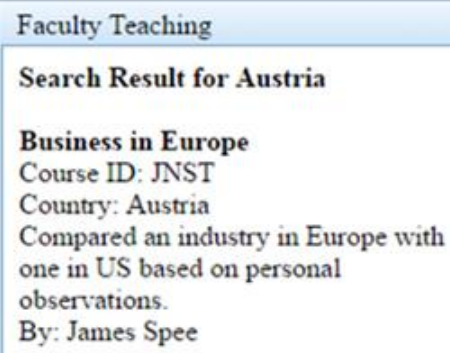

Faculty Teaching

Search Result for Austria

Business in Europe

Course ID: JNST

Country: Austria

Compared an industry in Europe with

one in US based on personal

observations.

By: James Spee

\section{Figure 6-8: Comparison Between (A) General and (B) Specific Search Results}

Lastly, if she is looking to collaborate with other faculty members in areas of international research, she will utilize the faculty research pane which functions similarly to the faculty teaching pane. When it comes to selecting features in the map viewer, the application detects whether the user has selected a region polygon or a country point, and retrieves the records from the appropriate related layer. In Figure 6-9, Northern Africa, which is highlighted in cyan, is selected as a region. The results are configured and output to the content pane. In this case, the faculty would find that Lilian Larsen does research on Northern African Early Monastic Education and so might want to collaborate with her on other topics.

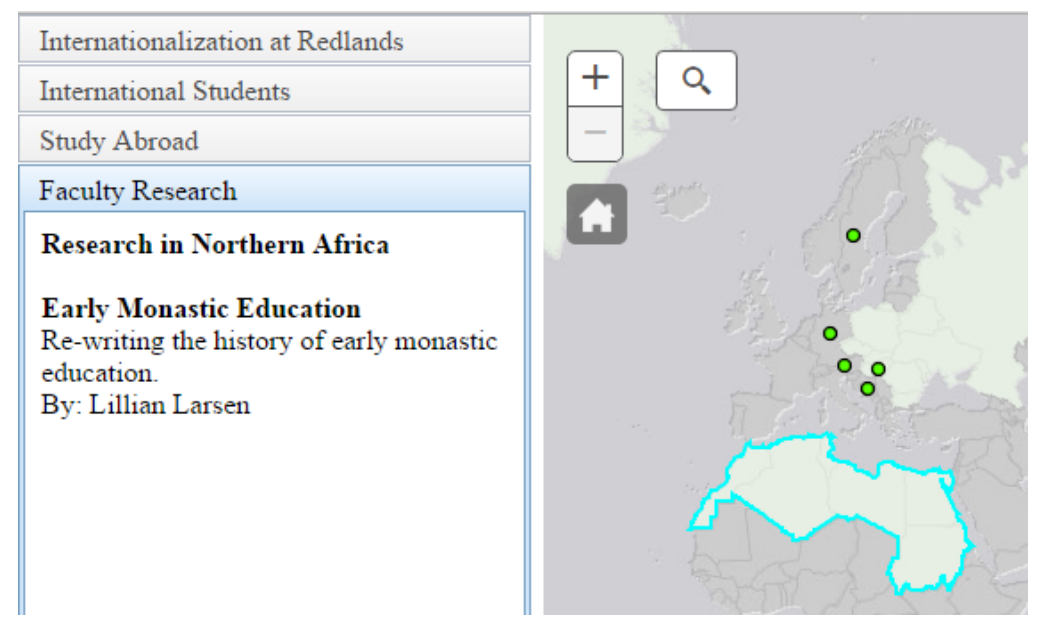

Figure 6-9: Select By Region in Faculty Research 
The web application aids faculty members in locating instructional resources for international education particularly in searching for students to share experiences with or in locating courses where the topics covered may have relevance to a topic that the faculty is teaching. The faculty member can then collaborate with other faculty in terms of teaching to make education more holistic or may collaborate with them in research to enhance knowledge.

\subsection{Use Case: Planning for Students, Faculty and Programs}

The final use case looks at planners at the university and how they might employ the application functions for planning purposes such as marketing the university to attract students, streamlining or expansion of university programs, hiring of staff to meet university needs.

A planner might want to know how many students from each country are at the university and the top countries where students come from. He might use the data to decide whether to strengthen marketing efforts in a country or as a comparison with previous years to determine the level of internationalization. Clicking on the International Student tab, causes the pane to slide up. The opening statement in the pane tells the planner how different countries are represented at the university this year, highlighted in green in below. These data are extracted from a count of the number of country points on the map. Below this, a horizontal bar chart, highlighted in red on the pane shows the top five countries that international students come from in order of number of students. The data are also extracted from the layers on the map, sorted and displayed. This shown in Figure 6-10 below. This information enables the planner to know that the university has a larger community from China, Mexico, Japan, Canada, and the United Kingdom, which they can leverage in future marketing or recruitment plans.

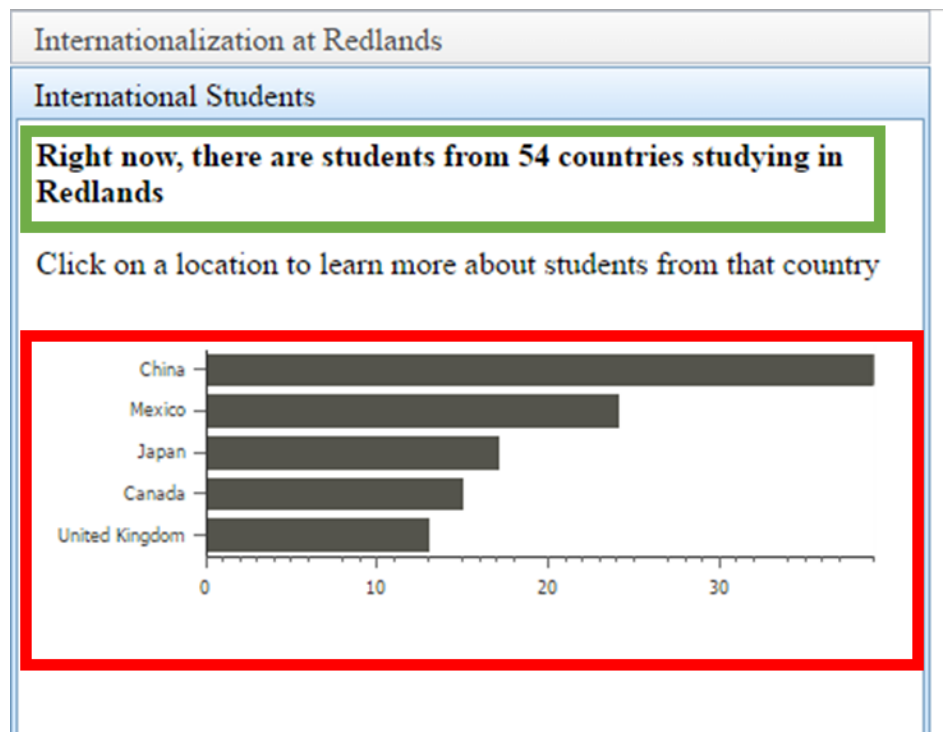

Figure 6-10: Using Country Count and Charts 
Another area that the planner might want to consider will be university study abroad programs. They might wish to strengthen and expand some programs, collaborate with other universities, or cut back and streamline other programs. For example, they might have heard that Austria is a popular choice for students. Clicking on the study abroad pane and selecting Austria, they might see that the only program there is the Salzburg program shown in Figure 6-11, hence they might decide to expand more programs in Austria.

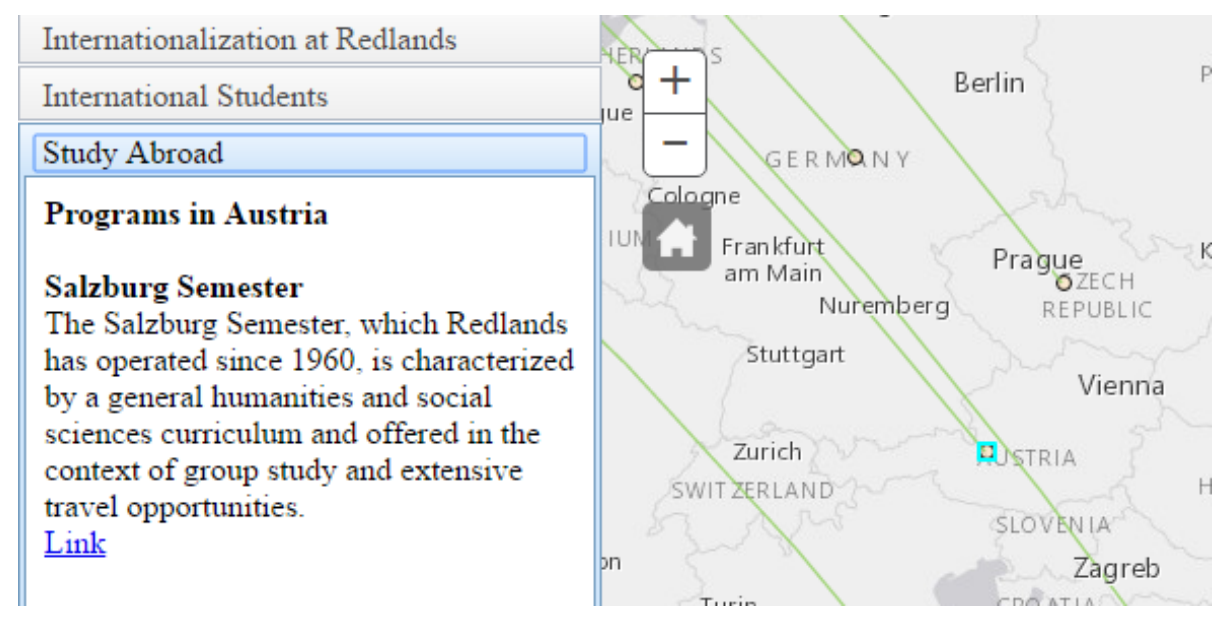

Figure 6-11: Planning for Study Abroad

With regard to staff hiring, if staff go on sabbatical or if they retire, the university planners can make use of the system to see what expertise they would need to replace. They would click the Faculty Teaching tab and bring up the Faculty Teaching pane. Shown in Figure 6-12, using the search widget, they would type in the faculty's name. This would show them, highlighted in blue, a list of suggestions about the faculty and the countries or regions that he/she teaches, sorted by layers. Hitting enter without selecting a particular suggestion brings out all the related records, highlighted in red. From this example it can be seen that if James Spickard were to go on sabbatical, the university would need to either hire or redistribute faculty to cover Australia, Nicaragua and Western Europe topics. A current limitation of the search widget is that it can only search in one field each time and is unable to search multiple fields at once, hence users are unable to type in both first and last names at once. 


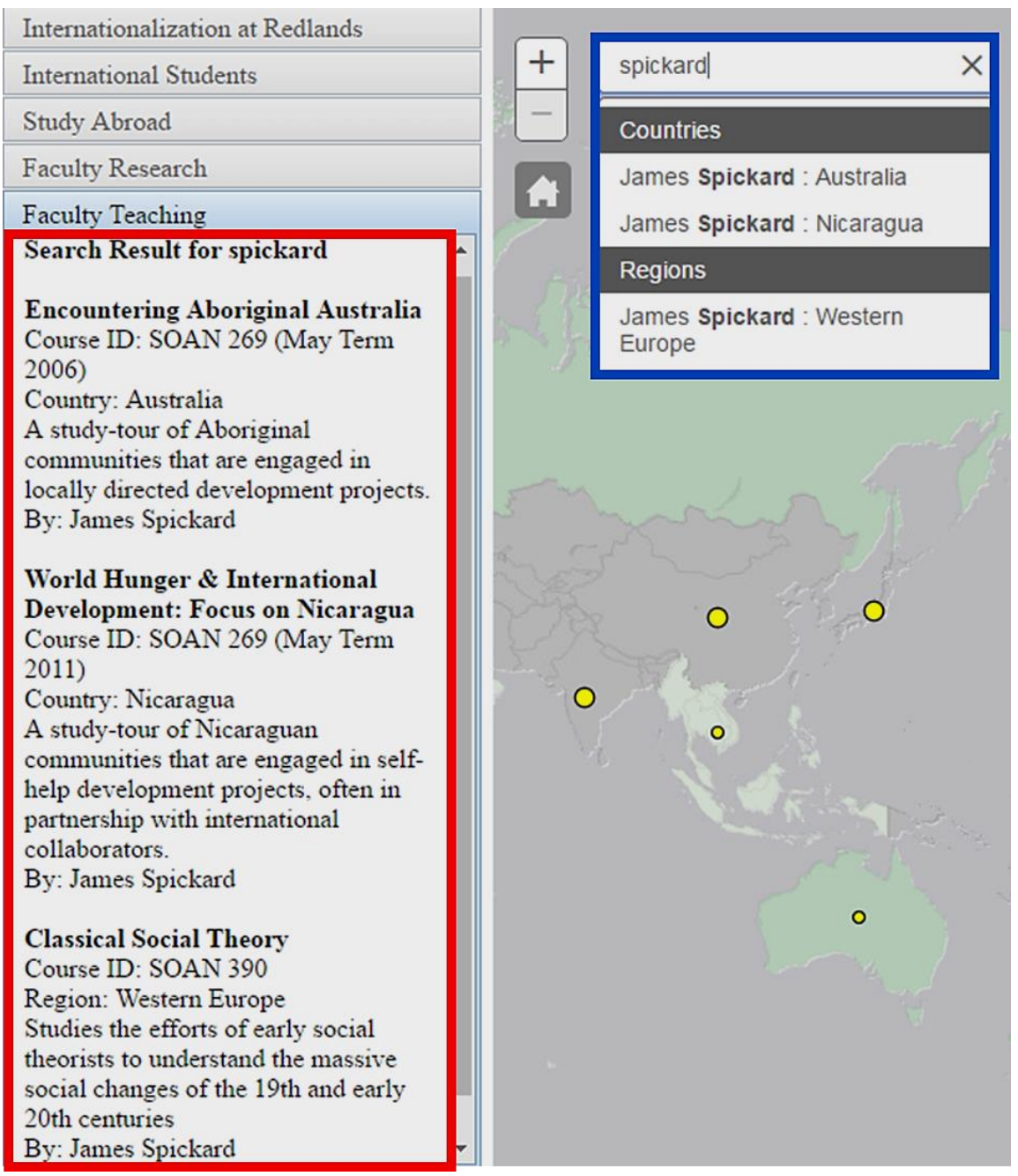

\section{Figure 6-12: Planning for Faculty Hiring}

By making use of the color ramps for visualization, planners are also able to identify at a glance areas that they might want to strengthen. For example in Figure 6-13 below, the planners are able to tell that, the university is considerably stronger concerning topics covering North America, South America and Western Europe, weaker about topics in Western Asia, Western Africa, Northern Europe and South-Eastern Asia, and has no courses concerning Africa and Central Asia topics. Hence, they might decide that they might want to strengthen the university's position in those areas by hiring faculty that have expertise lecturing on Africa and Central Asia. 


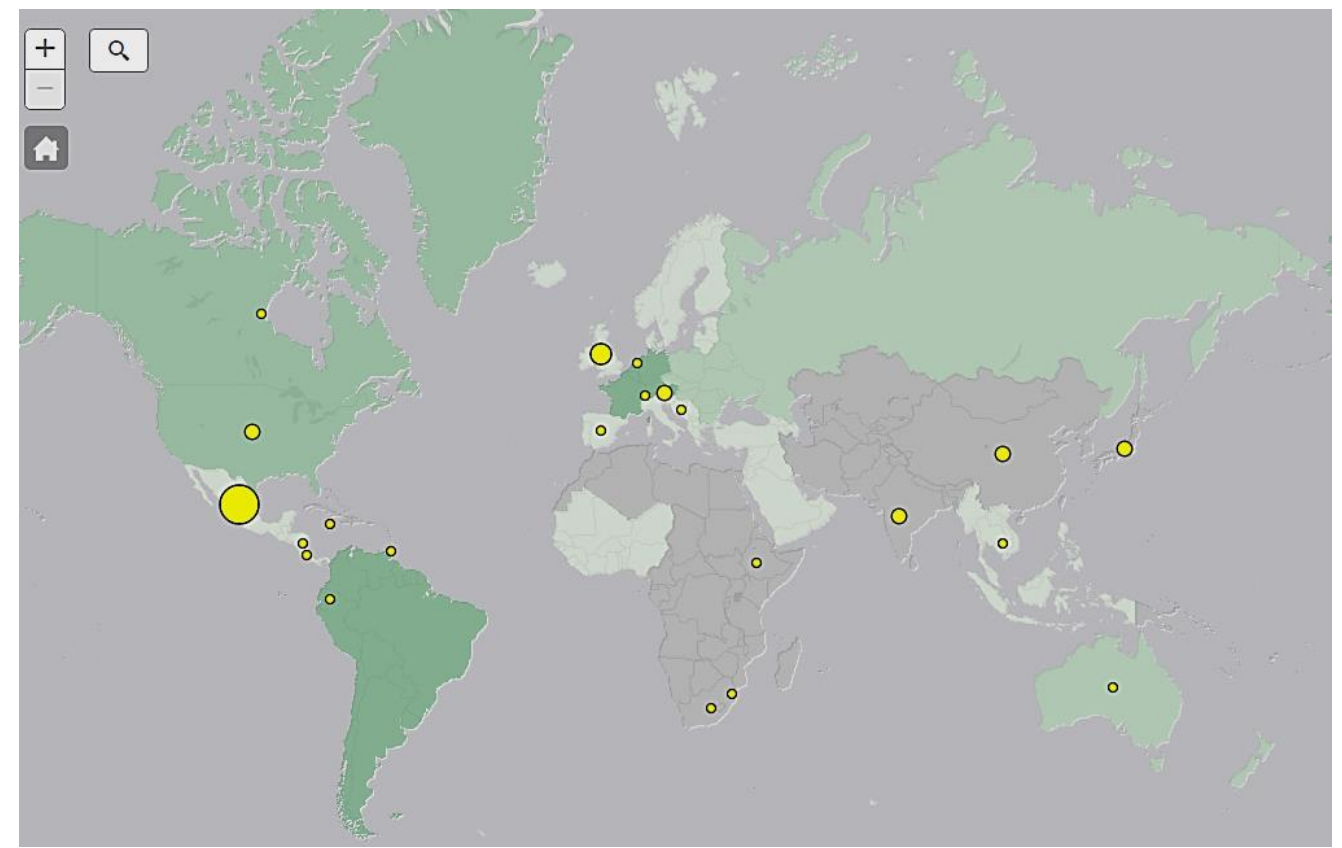

Figure 6-13: Color Ramps and Number of Points in an Area Help in Understanding the Overall Situation

\subsection{Summary}

The project initially sought to develop an application that was useful to students, faculty, and planners in the various university departments. This chapter demonstrates that the application's versatility stems from the fact that the data have been represented in an easy to understand manner and that the provided functionality is user-friendly and aids students, faculty and planners in making decisions according to their needs. 


\section{Chapter 7 - Conclusions and Future Work}

The goal of this project was to develop a proof-of-concept web application for the Council of Comprehensive Internationalization at the University of Redlands that consolidated the existing datasets of internationalization into a streamlined interface that allows a user to access and use these datasets according to their needs. The aspects of internationalization at the university were made up of international students, the various study abroad programs, faculty teaching, and faculty research. This web application was targeted toward four key groups: prospective students, current students, faculty members, and university planners.

The project met these goals and delivered on the various functional and nonfunctional requirements outlined in Chapter 3. The project consolidated the various datasets from the various offices and imported them into a geodatabase using ArcMap 10.3. These datasets were published as multiple feature services within the university's ArcGIS Online portal. An intuitive web application was developed using JavaScript, HTML, and CSS. It made use of ArcGIS JavaScript API and the Dojo Toolkit for added functionality. The various feature services were grouped according to the topics of international students, study abroad programs, faculty research, and faculty teaching and these layers were displayed according to the content pane that the user was on. Additional functionality was added allowing popups of additional information and display of related information in the content pane. Users were given search functionality for faculty research and faculty teaching and charts were added to show the top countries from where international students came.

Now that the project functionality and utility has been demonstrated, the project will need the data to be fully populated to make it a viable tool. Faculty research and teaching data were gathered from the faculty survey, so it is recommended that the faculty continue to populate that dataset. Study abroad program data should be added as they become available from the Study Abroad Office. Currently the level of detail is kept at the sub-region and country level. To make this tool more useful for decision making, future improvements can go into finer data resolution at state and city level, and these should be shown dynamically as the users adjust the zoom scale. For more utility as a planning tool, charts can be added to the popups to show the trends of international students from a country over the years. Graduated circles can be implemented to study abroad programs to show the popularity of each program. Other areas of internationalization can be explored such as student's thesis projects or community projects overseas.

The web application is a useful tool for measuring and mapping internationalization at campuses and other institutes could implement their own version of it. This project increases the knowledge of prospective students about internationalization efforts at te university, and informs current students of study abroad programs and courses that they might attend. It aids faculty members in locating teaching resources, publicizes their work, and helps them collaborate on areas of research and teaching. It provides university planners an overview of internationalization at the university and helps to focus marketing efforts as well as make recruitment of staff and students more effective. 



\section{Works Cited}

Akella, M. (2011, September 6). Creating radial flow maps with ArcGIS. Retrieved from ArcGIS Blog: https://blogs.esri.com/esri/arcgis/2011/09/06/creating-radial-flowmaps-with-arcgis/

ASIC News. (2015, January 15). Student Mobility in South East Asia to Accelerate Due to ASEAN Initiatives. Accreditation Service for International Schools, Colleges \& Universities. Retrieved from http://www.asicuk.com/news/student-mobilitysouth-east-asia-accelerate-due-asean-initiatives/

Brandenburg, U., Berghoff, S., Taboadela, O., Bischof, L., Gajowniczek, J., Gehlke, A., . . others. (2014). The ERASMUS Impact Study. Effects of mobility on the skills and employability of students and the internationalisation of higher education institutions. Publications Office of the European Union, Luxembourg.

Center for Internationalization and Global Engagement. (2012). Mapping Internationalization on US Campuses 2012. Washington,DC: American Council on Education. Retrieved from https://www.acenet.edu/newsroom/Documents/Mapping-Internationalizationon-US-Campuses-2012-full.pdf

De Wit, H. (1999). Changing rationales for the internationalization of higher education. International Higher Education(15), 2-3.

De Wit, H. (2010). Internationalisation of Higher Education in Europe and its assessment, trends and issues. Accreditation Organisation of The Netherlands and Flanders. NVAO, The Hague.

Dempsey, C. (2013, March 10). Map of Cardinals. Retrieved from GIS Lounge: https://www.gislounge.com/map-of-cardinals/

Environmental Systems Research Institute, Inc. (Esri). (2015). Symbolizing graphics with renderers. ArcGIS API for JavaScript 3.16. Retrieved from https://developers.arcgis.com/javascript/3/jshelp/inside_graphics.html

George R. Muirhead Center for International Education. (2012). Countries Represented by Connecticut International Students. Retrieved from International Education Resources in Connecticut: http://www.ierconn.net/countries.htm

Gopal, A. (2011). Internationalization of Higher Education: Preparing Faculty to Teach Cross-Culturally. International Journal of Teaching and Learning in Higher Education, 23(3), 373-381. Retrieved from http://files.eric.ed.gov/fulltext/EJ946163.pdf

Green, M. F. (2012). Measuring and assessing internationalization. NAFSA: Association of International Educators, 1, 1-26.

Grove, J. (2014, November 13). Germany aims to send 50 per cent of students abroad by 2020. Retrieved from The Times Higher Education World University Rankings: https://www.timeshighereducation.com/news/germany-aims-to-send-50-per-centof-students-abroad-by-2020/2016853.article

Heberlie, L., Powell, J., \& Svensson , B. (2016, May 3). It's here! ArcGIS API for JavaScript 4.0 Released. Retrieved from ArcGIS Blog: https://blogs.esri.com/esri/arcgis/2016/05/03/arcgis-api-for-javascript-4-0released/

Hudzik, J. K., \& Stohl, M. (2009). Modelling Assessment of the Outcomes and Impacts of Internationalization. Measuring Success in the Internationalisation of Higher 
Education(22), 9-21. Retrieved from

https://www.researchgate.net/publication/232219994_Modeling_Assessment_of_

Outcomes_and_Impacts_from_Internationalization

Knight, J. (2003). Updated definition of internationalization. International higher education(33), 2.

Knight, J. (2015). Updated definition of internationalization. International higher education (33), 2-3.

Luo, J., \& Jamieson-Drake, D. (2013). Examining the Educational Benefits of Interacting with International Students. Journal of International Students, 3(2), 85-101.

Mazzarol, T., \& Soutar, G. N. (2002). "Push-pull" factors influencing international student destination choice. The International Journal of Educational Management, 16(2), 82-90. Retrieved from http://0search.proquest.com.books.redlands.edu/docview/62287998? accountid=14729

Muehlenhaus, I. (2013). Web cartography: map design for interactive and mobile devices. Florida: CRC Press.

Olson, C. L., Green, M. F., \& Hill, B. A. (2005). Building a strategic framework for comprehensive internationalization (Vol. 1). Washington, DC: American Council on Education.

Organisation for Economic Co-operation and Development (OECD). (2013). How is international student mobility shaping up. Education Indicators In Focus(5), 1-4.

The College at Brockport. (n.d.). Map Search. Retrieved July 11, 2016, from The College at Brockport Study Abroad:

https://brockport.studioabroad.com/index.cfm?FuseAction=Programs.MapSearch

Tremblay, K., Lalancette, D., \& Roseveare, D. (2013). AHELO. Feasibility Study Report. Tyner, J. A. (2010). Principles of Map Design. New York: The Guilford Press.

UNC Eshelman School of Pharmacy. (2016). Global Pharmacy Scholars Program. Retrieved from UNC Eshelman School of Pharmacy: https://pharmacy.unc.edu/academics/the-pharmd/about/global-pharmacy-scholarsprogram/

UNESCO Institute for Statistics. (2016, March 2). Global Flow of Tertiary-Level Students. Retrieved from http://www.uis.unesco.org/Education/Pages/international-student-flow-viz.aspx

University of Oxford. (2015). International Trends in Higher Education. International Strategy Office. Oxford, UK: University of Oxford. Retrieved 7 6, 2016, from https://www.ox.ac.uk/sites/files/oxford/International\%20Trends\%20in\%20Higher \%20Education\%202015.pdf

Wingenbach, E., Dyerly, K., Wuhs, S., MacQueen, M., MadhavaRau, L., \& Falkenstein, S. (2014). Report of the Council on Comprehensive Internationalization. Redlands, CA: University of Redlands. 


\section{Appendix A. HTML Code}

HTML Code for Application

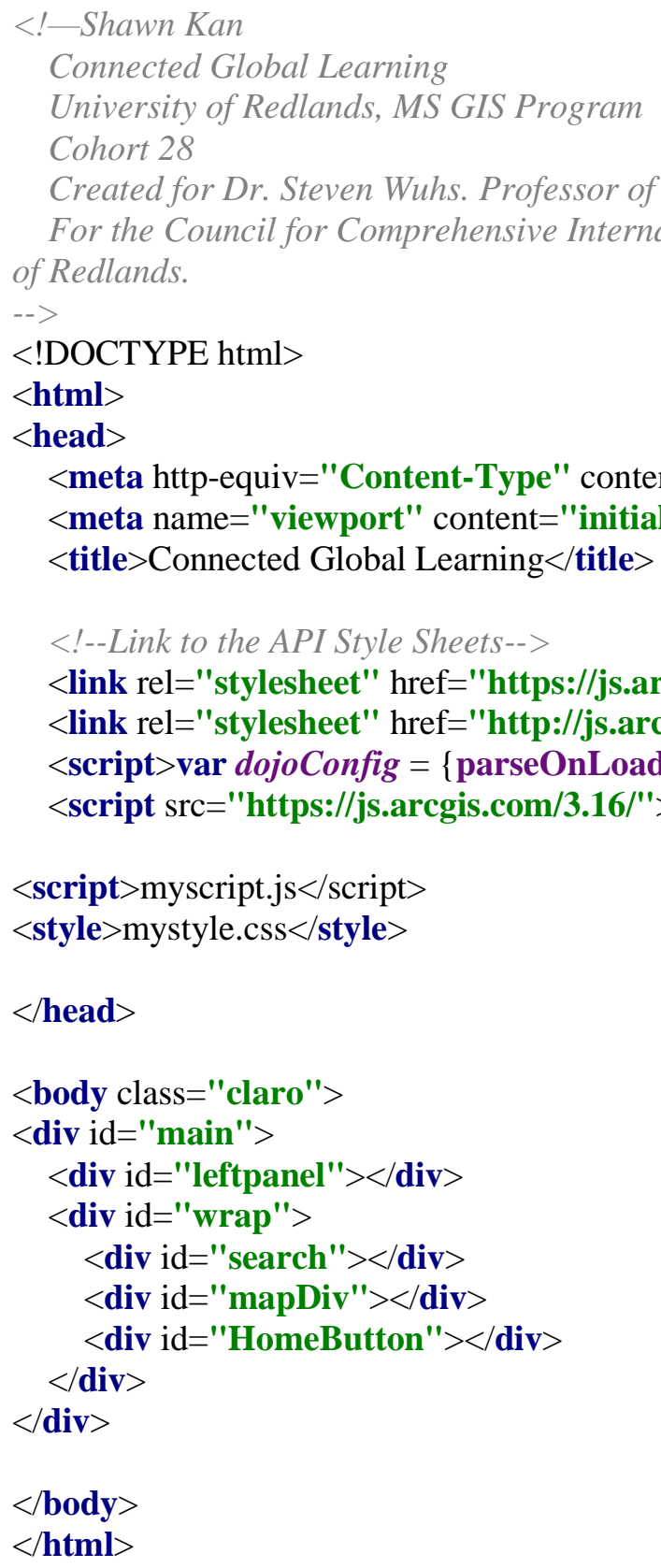




\section{Appendix B. JavaScript Code}

JavaScript Code for the Application

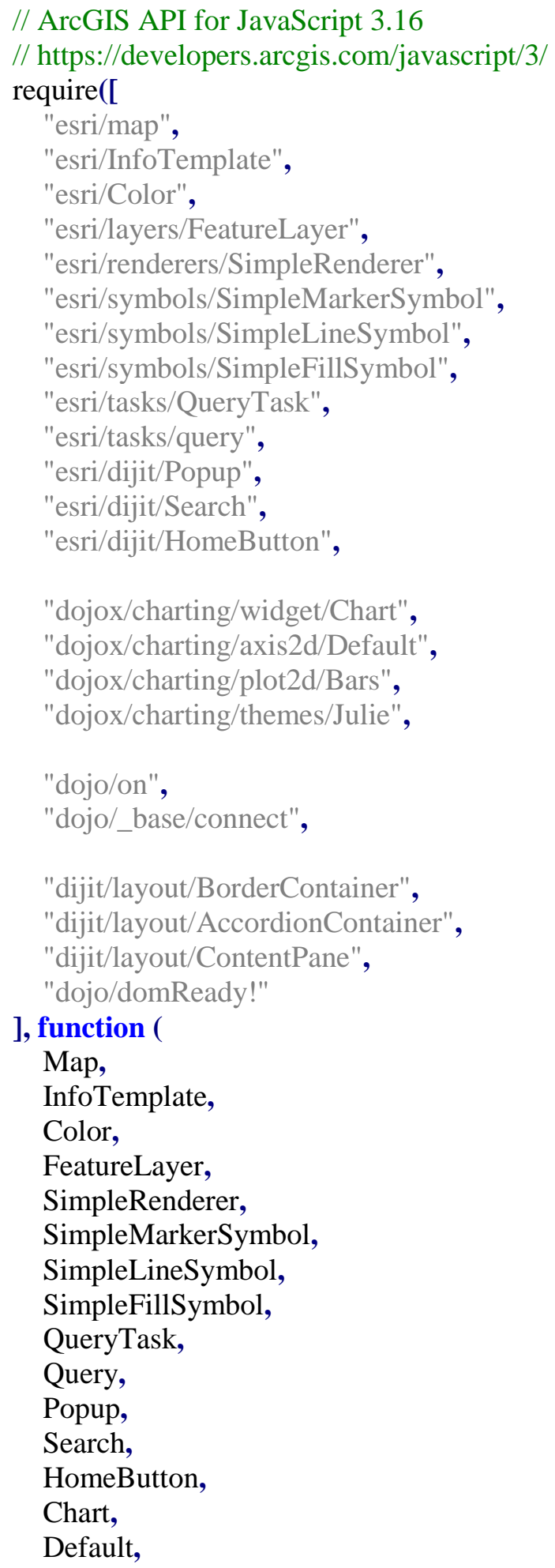




\begin{abstract}
Bars,
Julie,

on,

connect,

BorderContainer,

AccordionContainer,

ContentPane) \{
\end{abstract}

| $* * * * * * * * * * * * * * * * * * * * * * * * * * * * * * * * * * * /$

// Declare and Configure New Map

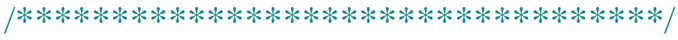

map = new Map("mapDiv", \{

center: $[-122.68,40]$,

zoom: 2,

basemap: "dark-gray",

minZoom: 2,

maxZoom: 8,

\}); // end of map

//********************************/

// declare layer

//******************************/

//declare layers and pushes them into a list

var layerlist $=[]$;

var sources;

var switchvalue $=1$; // used to decide the sources for fac research and teaching

var search $=$ setupsearch () ;

/***************************************************

* layer string variable declarations

* grouped by feature servers

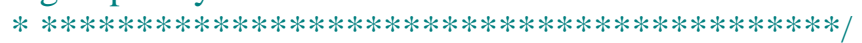

// International Students

var redlandslogo $=$

"http://services.arcgis.com/o6oETlrWetREI1A2/ArcGIS/rest/services/InternationalStudents 1 60517/FeatureServer/0";

var StuFr2015Points =

"http://services.arcgis.com/o6oETlrWetREI1A2/ArcGIS/rest/services/InternationalStudents1 60517/FeatureServer/1";

var StuFr2015Line =

"http://services.arcgis.com/o6oETlrWetREI1A2/ArcGIS/rest/services/InternationalStudents 1 60517/FeatureServer/2";

//Study Abroad

var StuTo2015Points $=$

"http://services.arcgis.com/o6oETlrWetREI1A2/ArcGIS/rest/services/StudyAbroad160517/

FeatureServer/0";

var StuTo2015Line =

"http://services.arcgis.com/o6oETlrWetREI1A2/ArcGIS/rest/services/StudyAbroad160517/ 
FeatureServer/1";

var StuTo2015Table $=$

"http://services.arcgis.com/o6oETlrWetREI1 A2/ArcGIS/rest/services/StudyAbroad160517/

FeatureServer/2";

//Fac Research

var RC_Points =

"http://services.arcgis.com/o6oETlrWetREI1A2/ArcGIS/rest/services/FacRsh160517/Featur

eServer/0";

var RC_Region =

"http://services.arcgis.com/o6oETlrWetREI1 A2/ArcGIS/rest/services/FacRsh160517/Featur

eServer/1";

var RC_CountryTable =

"http://services.arcgis.com/o6oETlrWetREI1A2/ArcGIS/rest/services/FacRsh160517/Featur

eServer/3";

var RC_RegionTable =

"http://services.arcgis.com/o6oETlrWetREI1A2/ArcGIS/rest/services/FacRsh160517/Featur

eServer/2";

//Fac Teaching

var TC_Points =

"http://services.arcgis.com/o6oETlrWetREI1A2/ArcGIS/rest/services/FacTeach160517/Feat

ureServer/0";

var TC_Region =

"http://services.arcgis.com/o6oETlrWetREI1A2/ArcGIS/rest/services/FacTeach160517/Feat ureServer/1";

var TC_CountryTable =

"http://services.arcgis.com/o6oETlrWetREI1A2/ArcGIS/rest/services/FacTeach160517/Feat ureServer/3";

var TC_RegionTable =

"http://services.arcgis.com/o6oETlrWetREI1A2/ArcGIS/rest/services/FacTeach160517/Feat ureServer/2";

//create the necessary info templates for popups and for side panel

var StuFr2015Template = new InfoTemplate("Students from $\$\{$ Country $\} "$, "<br $>$ Currently

(2016): <b>\$\{Total $\}</ b>")$;

var StuTo2015Template = new InfoTemplate("Student from $\$\{$ StudyAbroadCountry2015 $\} "$,

"<br>Currently (2016)");

var RC_PointTemplate $=$ new InfoTemplate () ;

var RC_RegionTemplate = new InfoTemplate () ;

var TC_PointTemplate $=$ new InfoTemplate () ;

var TC_RegionTemplate $=$ new InfoTemplate () ;

// create the new feature layers using the string variables

var layer0 = new FeatureLayer(redlandslogo);

var layer1 = new FeatureLayer(StuFr2015Points,

\{

mode: FeatureLayer.MODE_ONDEMAND,

outFields: ["Total", "Country"],

infoTemplate: StuFr2015Template

\}); 


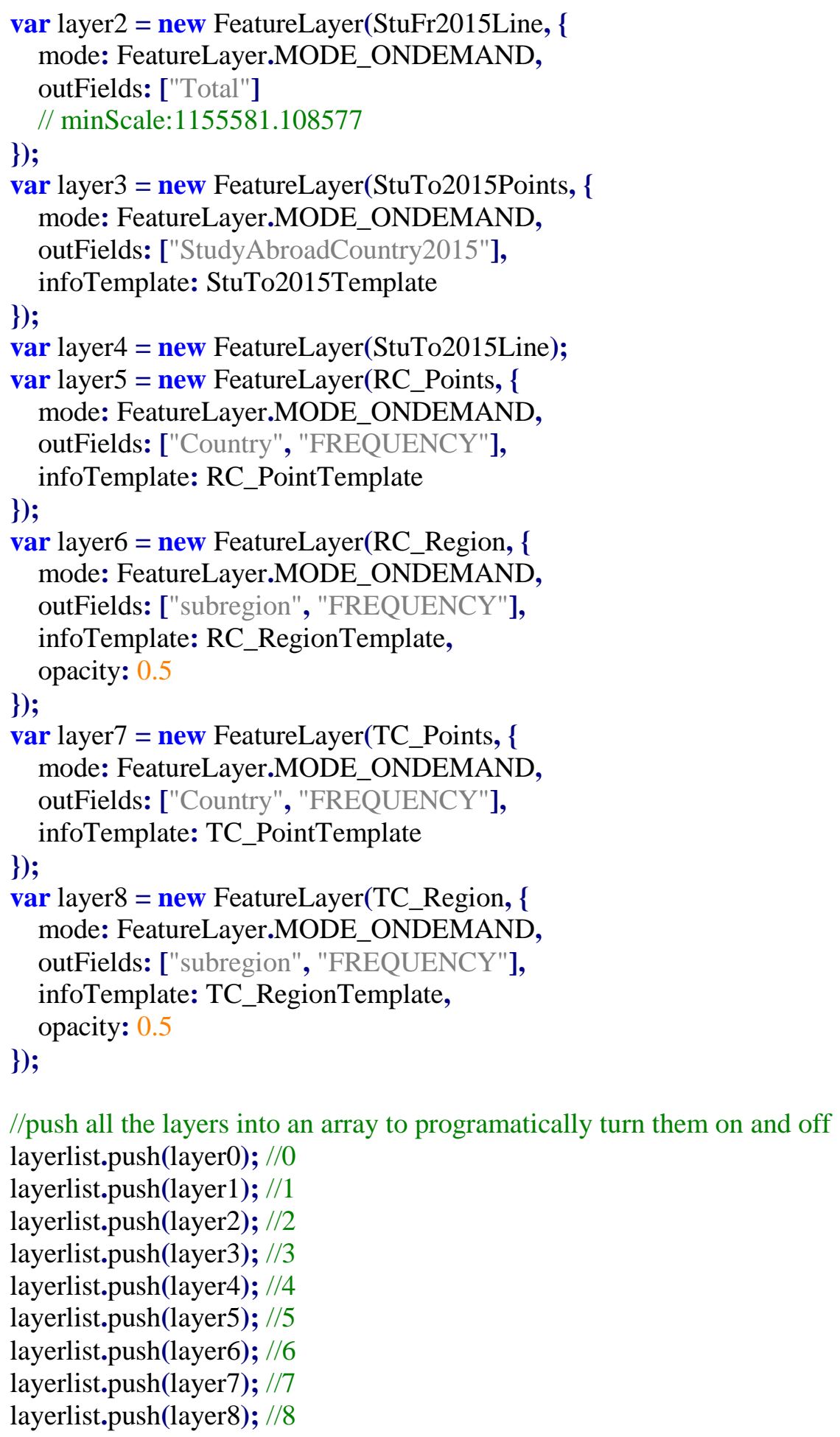




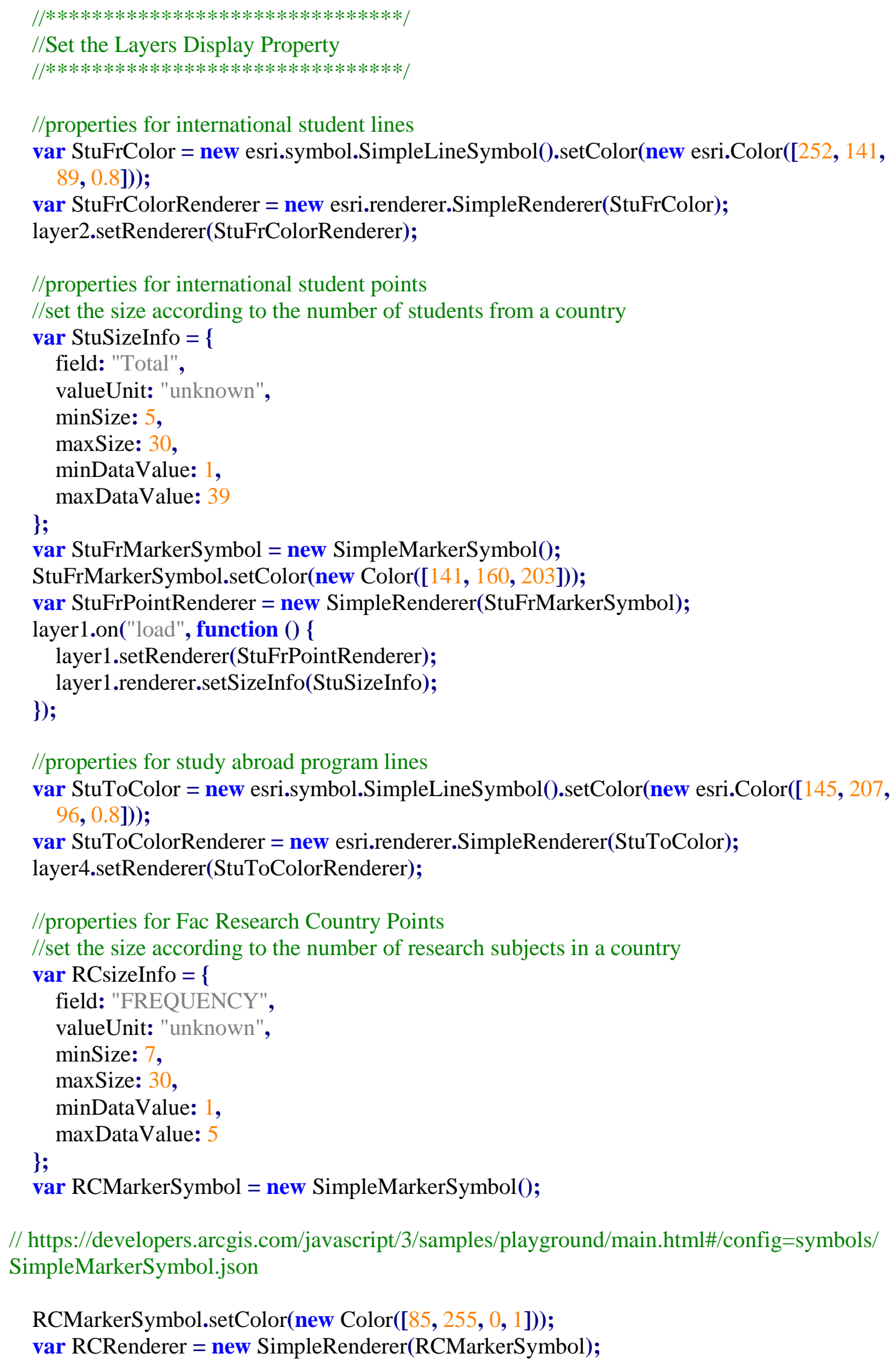

RCMarkerSymbol.setColor(new Color([85, 255, 0, 1]));

var RCRenderer = new SimpleRenderer(RCMarkerSymbol); 


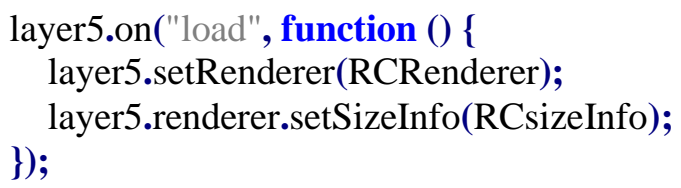

//properties for Fac Teach Country Points

// Examples taken from https://developers.arcgis.com/javascript/3/jssamples/ renderer_proportional_points.html

// Style selected from https://developers.arcgis.com/javascript/3/samples/playground/ main.html\#/config=symbols/SimpleMarkerSymbol.json

//set the size according to the number of teaching subjects in a country

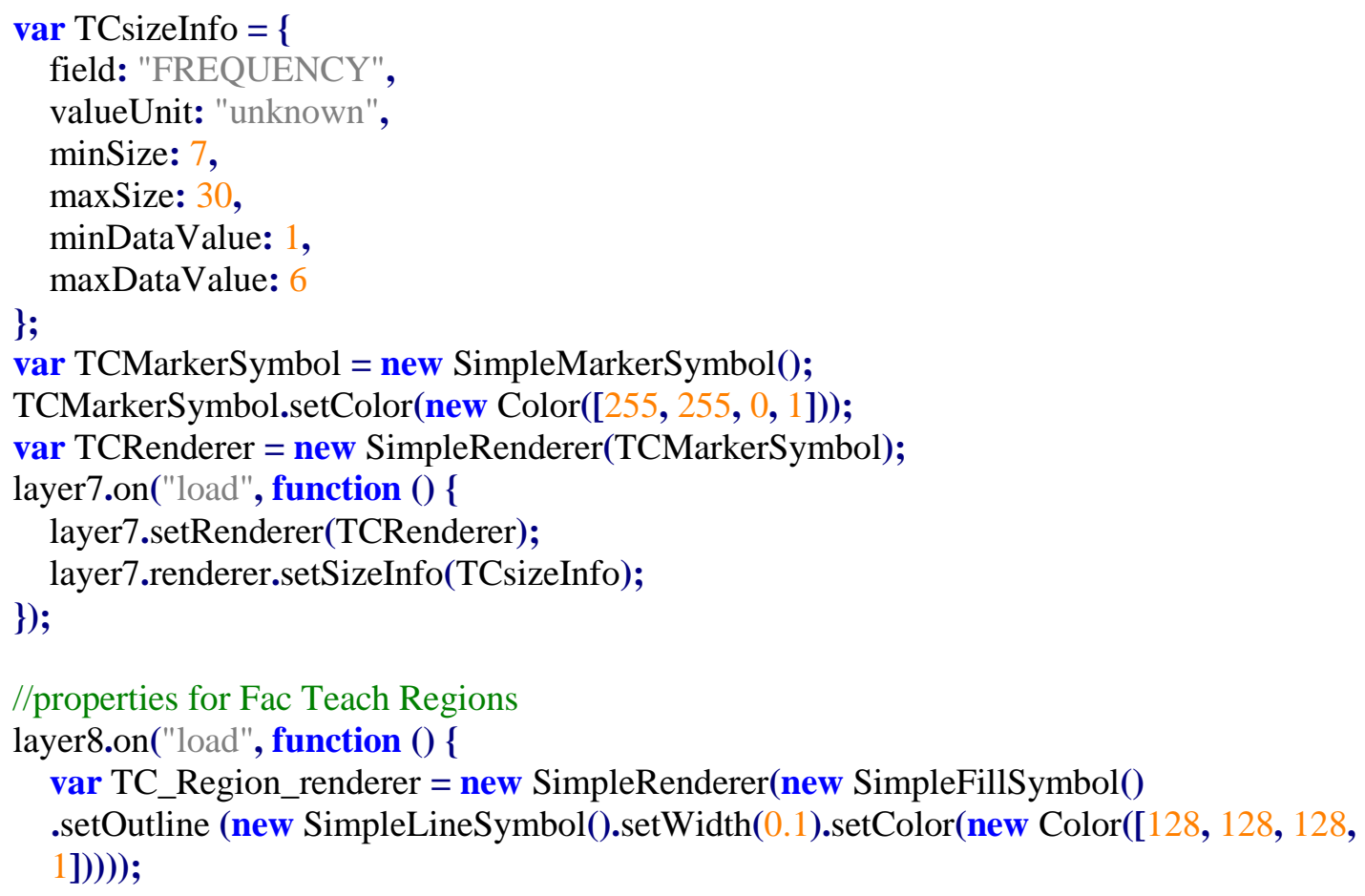




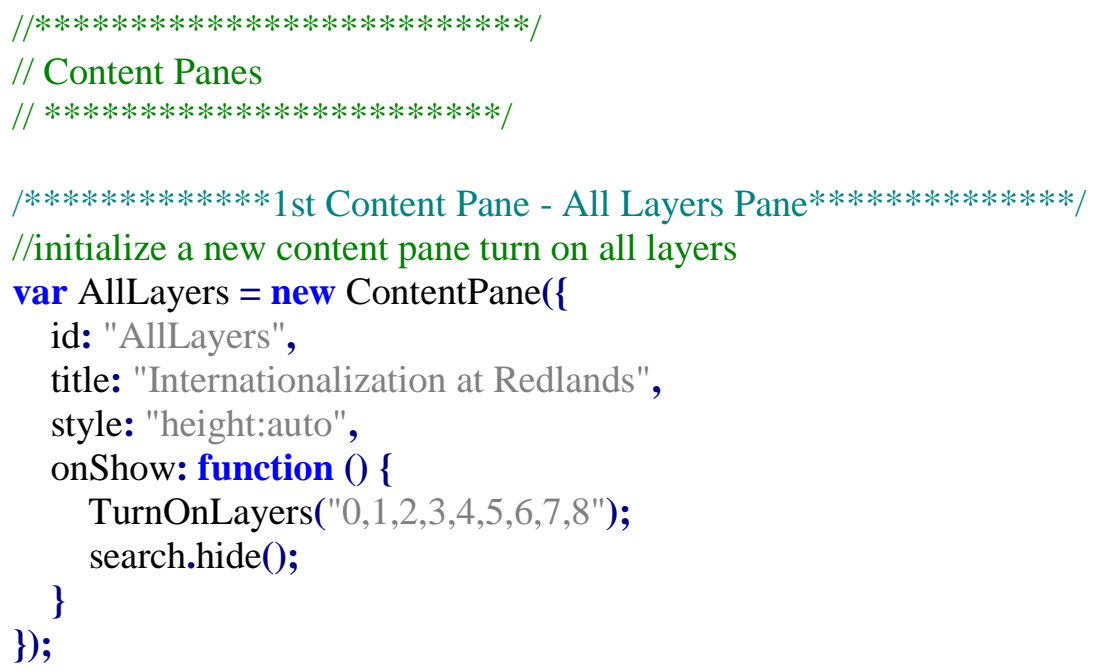

//set the text to appear in the content pane

var AllLayersTextString $="\langle\mathrm{~b}\rangle$ The University of Redlands is a global university. $</ \mathrm{b}\rangle$ $\langle$ br $\rangle\langle$ br $\rangle "$ + "This interface explores how internationalized we are as a community."; AllLayers.set('content', AllLayersTextString);

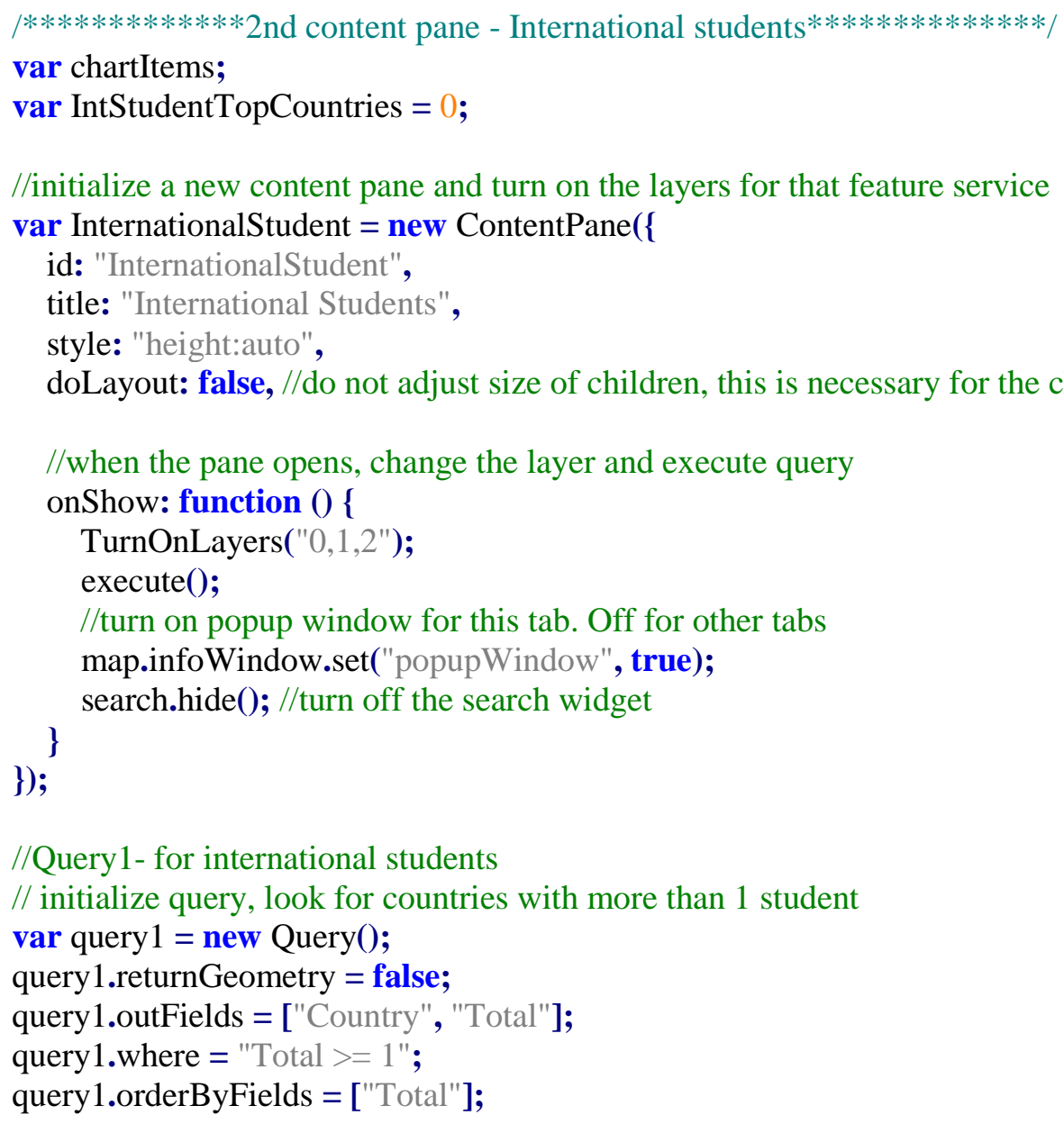

//Query1- for international students

// initialize query, look for countries with more than 1 student

var query 1 = new Query();

query1.returnGeometry = false;

query1.outFields = ["Country", "Total"];

query 1. where $=$ "Total $>=1 "$;

query1.orderByFields = ["Total"]; 
//execute the query tasks on the layer of StuFrLine, run showResults function after that

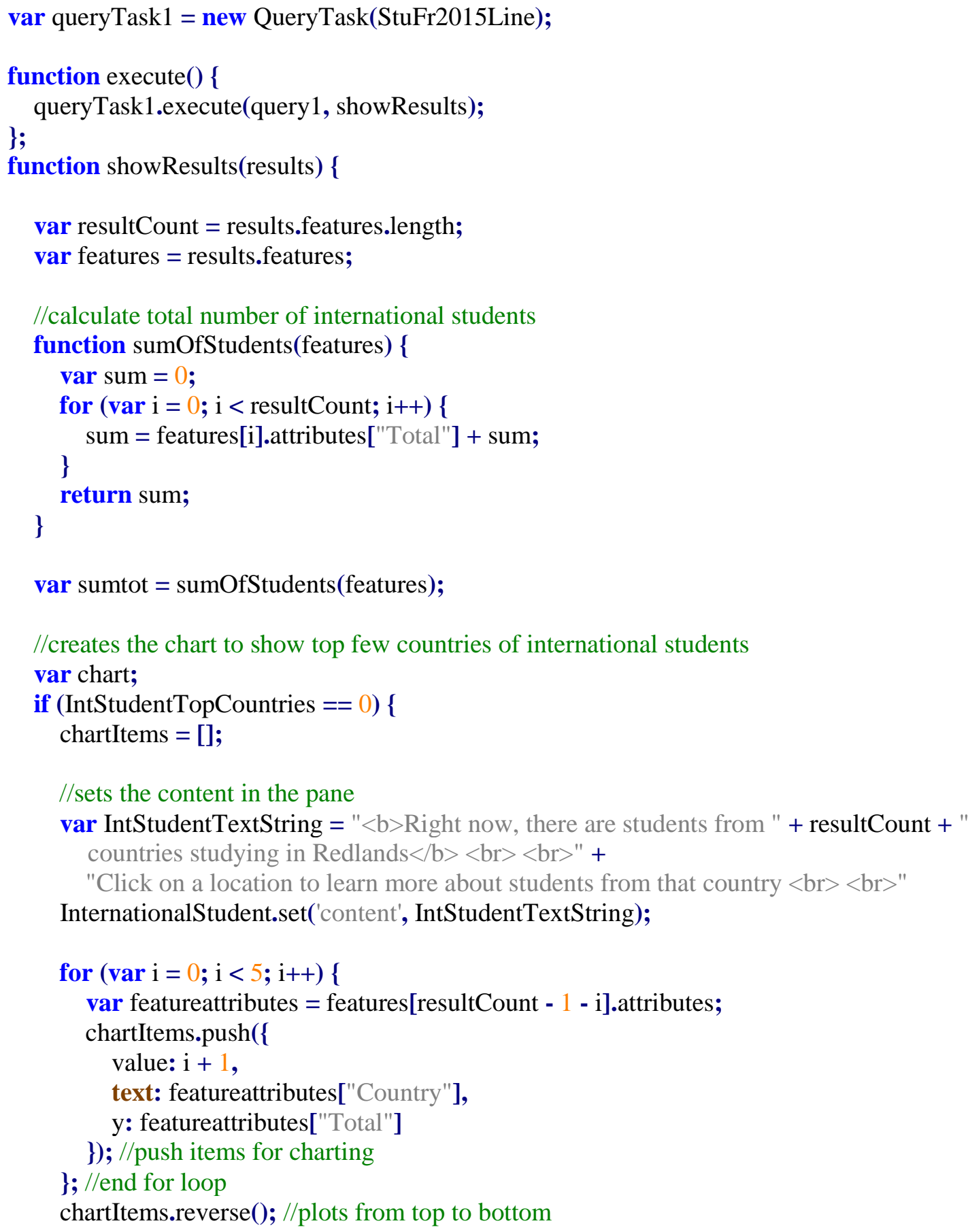




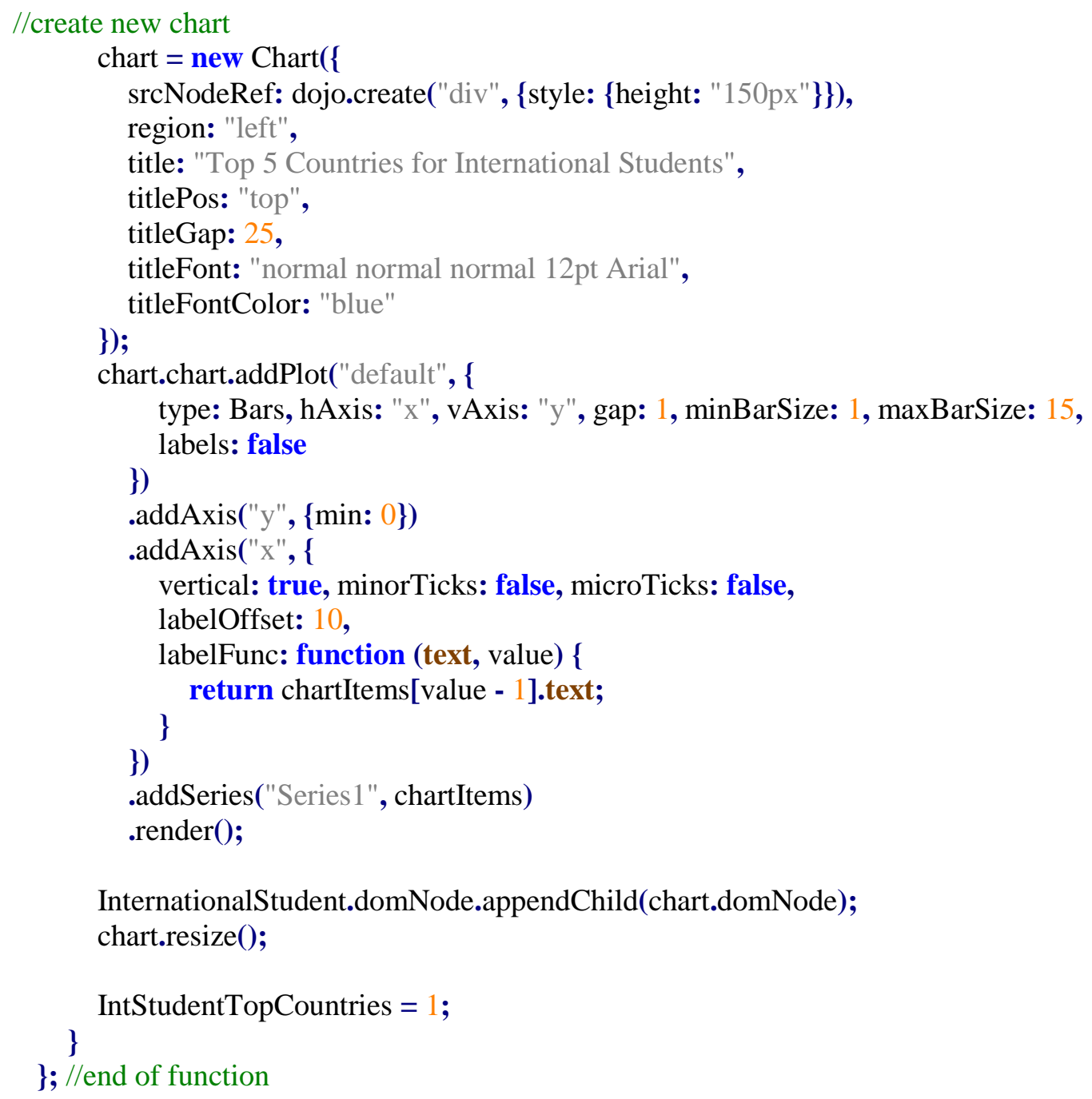

//initialize what to show on the study abroad pane

function InitializeSideDisplay_StudyAbroad() \{

var StudyAbroadTextString = " $<\mathrm{b}>$ This year, Redlands students went to 39 different countries on semester-long and May Term study abroad programs $\langle/ \mathrm{b}\rangle\langle$ br $\rangle\langle$ br $\rangle "+$ "Click on a site to find out more about programs our students choose $<$ br $><b r\rangle$; 
StudyAbroadTab.destroyDescendants(true);

StudyAbroadTab.set('content', StudyAbroadTextString);

//code snippets from https://developers.arcgis.com/javascript/jssamples/

popup_sidepanel.html

//turn off popup windows for this tab.

map.infoWindow.set("popupWindow", false);

var popup = map.infoWindow;

//when the selection change, update side panel to display the info for currently selected feature

connect.connect(popup, "onSelectionChange", function () \{

displayContentInSidebar_StudyAbroad(popup.getSelectedFeature());

\});

//Sets what to show on Content Pane when features are cleared

connect.connect(popup, "onClearFeatures", function () \{

StudyAbroadTextString $="<\mathrm{b}>$ This year, Redlands students went to 39 different countries on semester-long and May Term study abroad programs $\langle/ \mathrm{b}\rangle\langle$ br $\rangle\langle$ br $\rangle "+$

"Click on a site to find out more about programs our students choose $\langle$ br $\rangle\langle$ br $\rangle$ ";

StudyAbroadTab.destroyDescendants(true);

StudyAbroadTab.set('content', StudyAbroadTextString);

\}$)$

//when features are associated with the map's info window, update the sidebar with new content connect.connect(popup, "onSetFeatures", function () \{ displayContentInSidebar_StudyAbroad(popup.getSelectedFeature()); \}$)$;

\}; //end of function

\section{function displayContentInSidebar_StudyAbroad(feature) \{} if (feature) \{

//search the table for programs from a country

$/ /$ where country $=$ country

//return program name, synopsis and URL

$/ /$ no need to return geometry

var queryTask2 = new QueryTask(StuTo2015Table); //teaching table

var query 2 = new Query () ;

query2.returnGeometry = false;

query2.outFields = ["Program_Name", "Synopsis", "URL"];

query2. where $=$ "Country $=$ "' + feature.attributes.StudyAbroadCountry2015 + "'";

//execute the query, showResults as the callback function

queryTask2.execute(query2, showResults);

function showResults(results) \{

var ReturnedFeatures = results.features;

var numResults = ReturnedFeatures.length; 


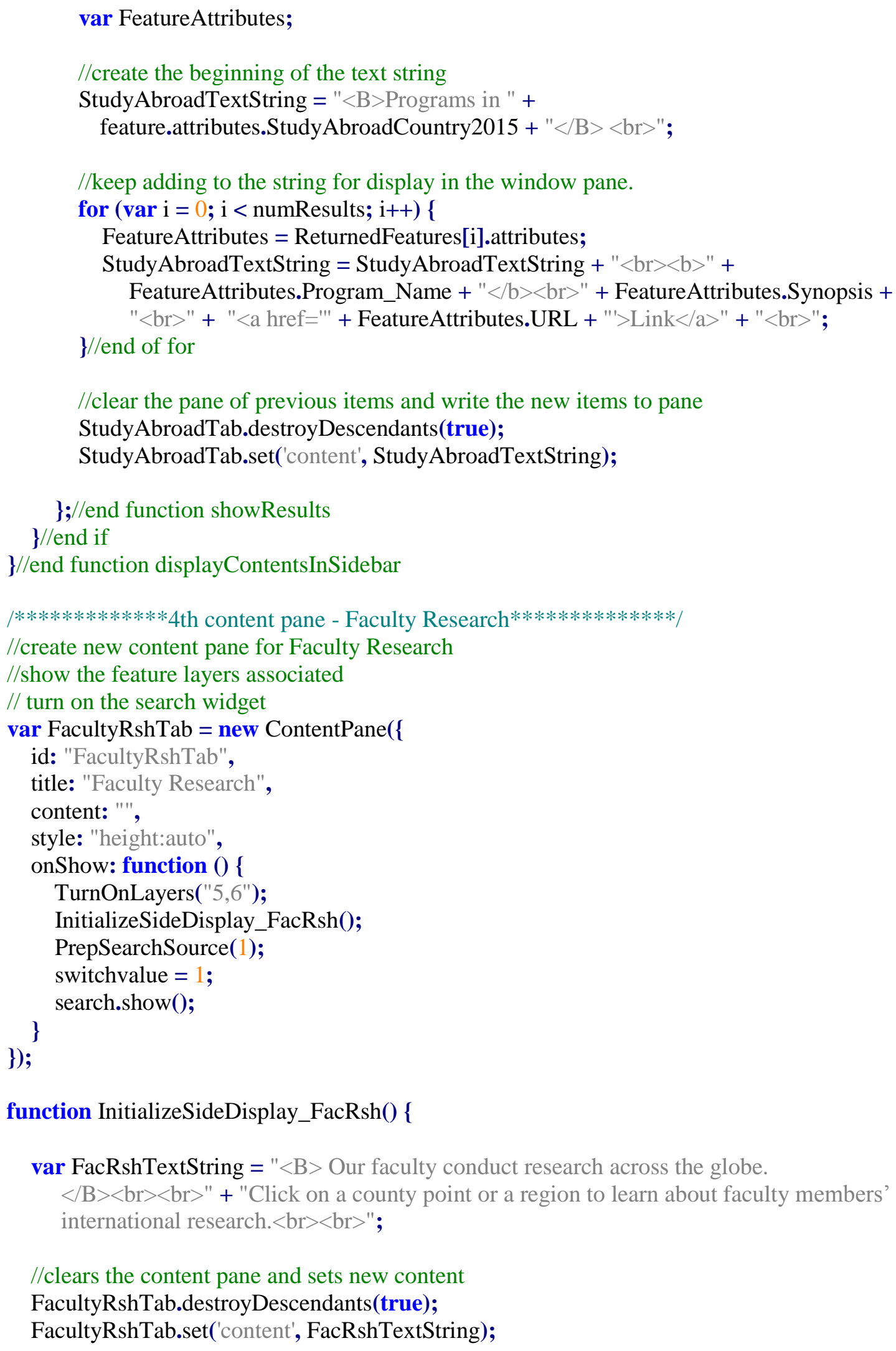


//code snippets from https://developers.arcgis.com/javascript/jssamples/ popup_sidepanel.html

//turn off popup windows for this tab.

map.infoWindow.set("popupWindow", false);

var popup = map.infoWindow;

//set what to display in the content pane when features are cleared

connect.connect(popup, "onClearFeatures", function () \{

FacRshTextString $="\langle\mathrm{~B}\rangle$ Our faculty conduct research across the globe. $\langle/ \mathrm{B}\rangle\langle$ br $\rangle\langle$ br $\rangle "$

+ "Click on a county point or a region to learn about faculty members' international

research. $\langle$ br $><$ br $>$;

FacultyRshTab.destroyDescendants(true);

FacultyRshTab.set('content', FacRshTextString);

\}$)$

//when features are associated with the map's info window, update the sidebar with new

content

connect.connect(popup, "onSetFeatures", function () \{

displayContentInSidebar_FacRsh(popup.getSelectedFeature());

\});

\}; //end function

\section{function displayContentInSidebar_FacRsh(feature) \{}

//check if user selected country point or region polygon and execute accordingly

if (feature.geometry.type $==$ "point") \{

//search the table for programs from a country

$/ /$ where country $=$ country

//return program name, synopsis and URL

$/ /$ no need to return geometry

var queryTask3 = new QueryTask(RC_CountryTable); //Research_Country

var query3 = new Query();

query3.returnGeometry = false;

query3.outFields = ["FacultyName", "FacLastName", "ResearchTitle", "Synopsis",

"URL_If_any_"];

query3. where $=$ "Country $=$ "' + feature.attributes.Country + "'";

//execute the query, showResults as the callback function

queryTask3.execute(query3, showResults);

function showResults(results) \{

var ReturnedFeatures = results.features;

var numResults = ReturnedFeatures.length;

var FeatureAttributes;

//create the beginning of the text string

var FacRshTextString $="<\mathrm{B}>$ Research in " + feature.attributes.Country +

"</B $><$ br $><$ br $>$;

//keep adding to the string for display in the window pane. 


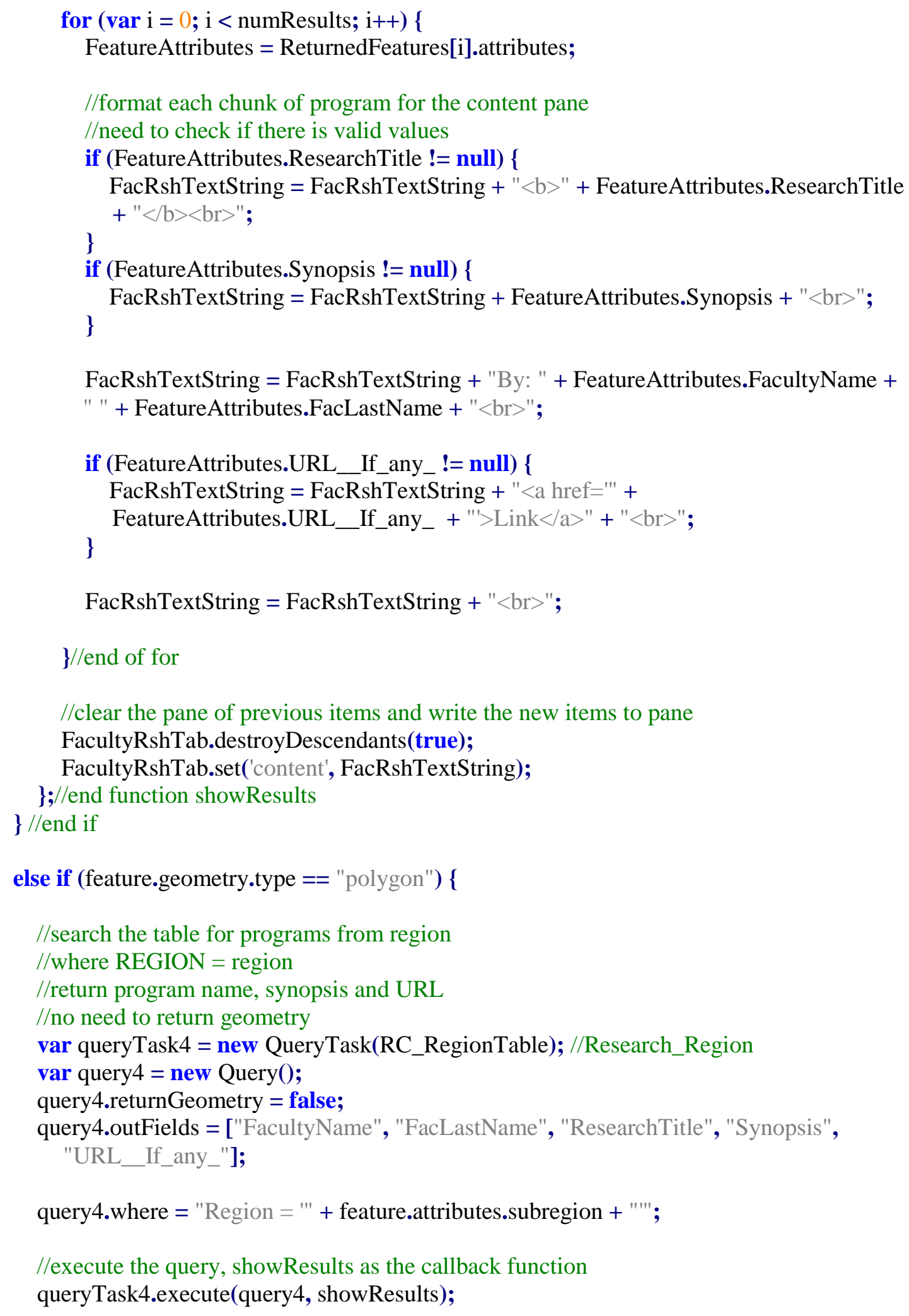




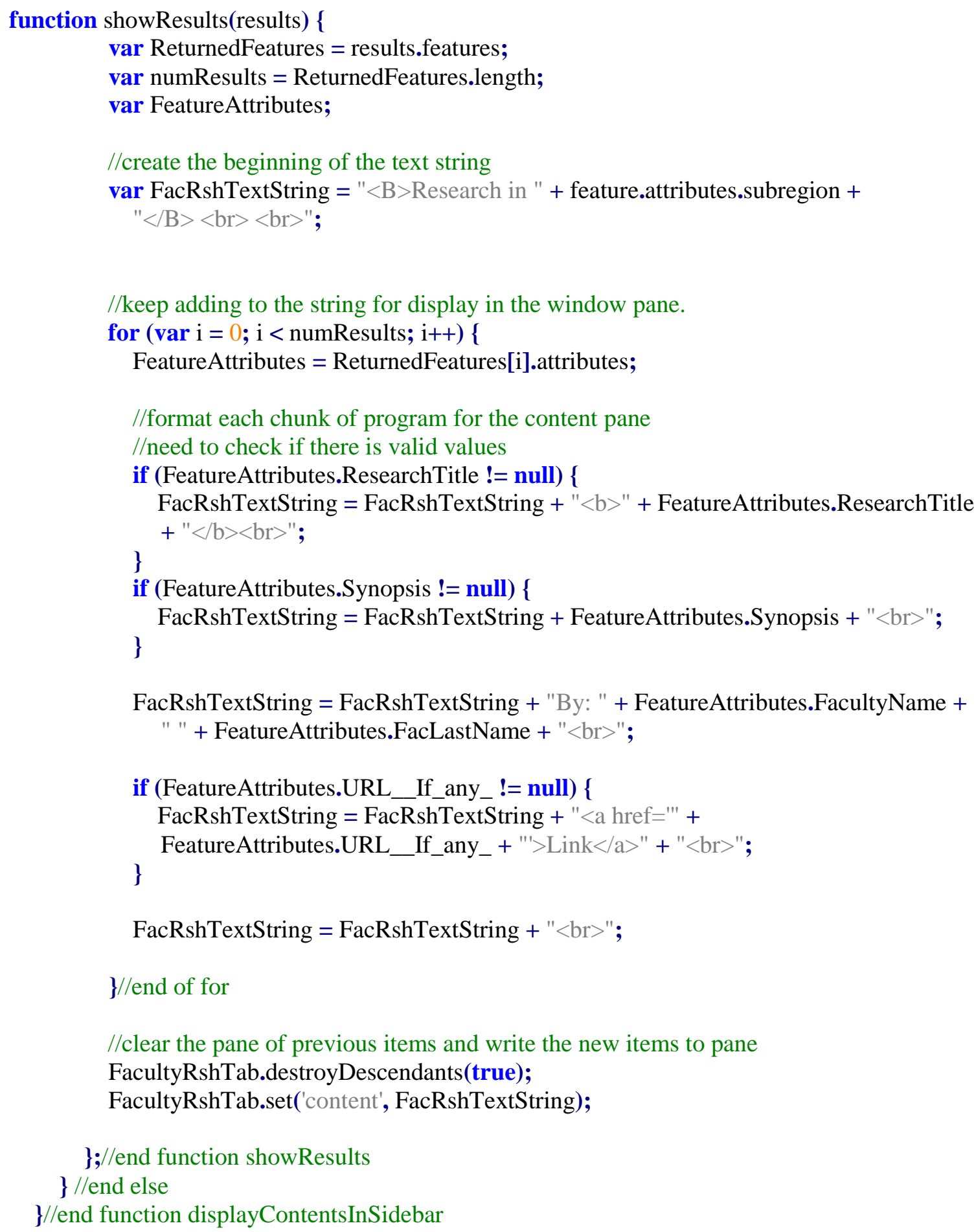




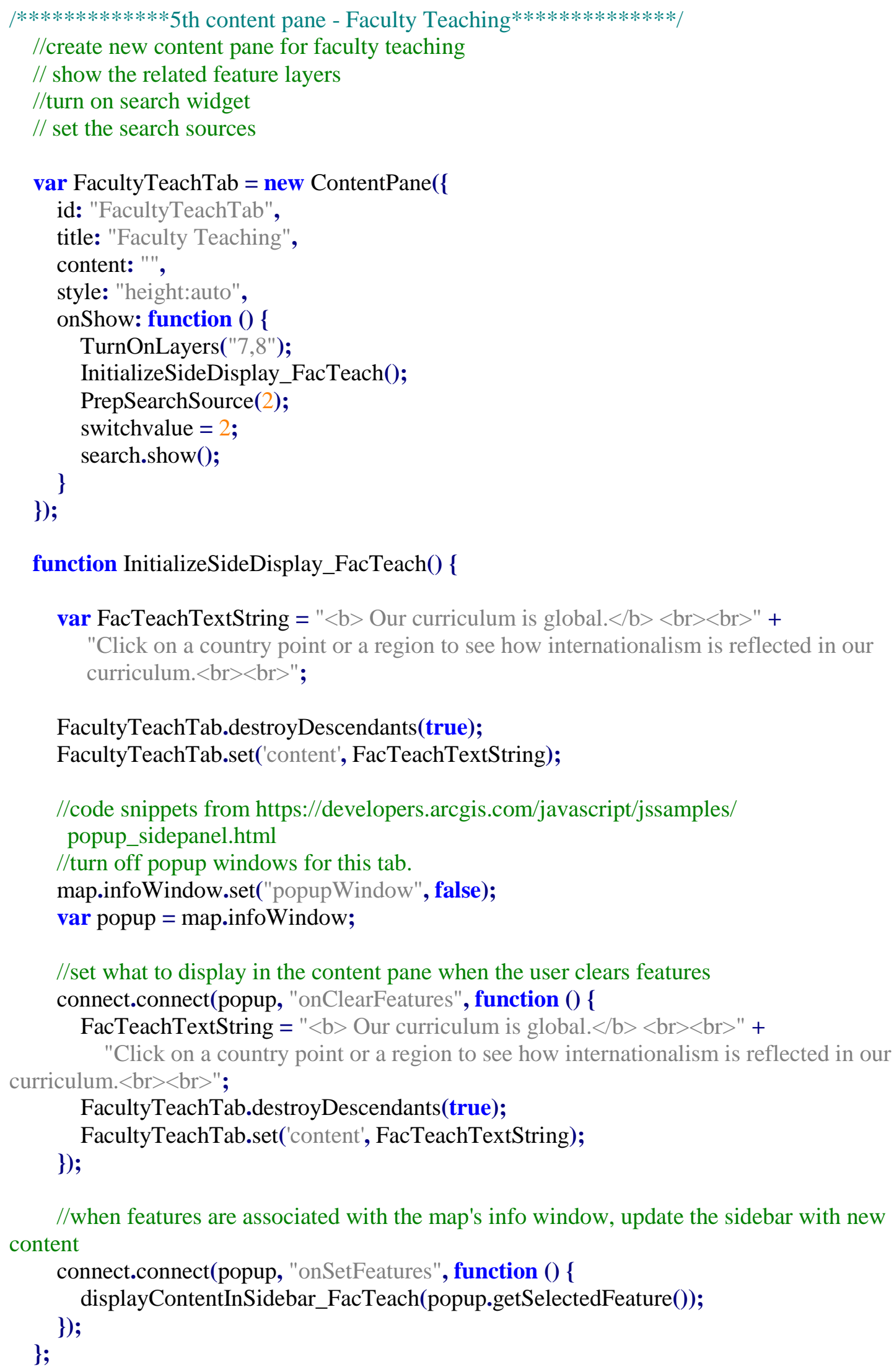

//set what to display in the content pane when the user clears features connect.connect(popup, "onClearFeatures", function () \{ 
function displayContentInSidebar_FacTeach(feature) \{

//check if the user selected a country point or a region polygon

if (feature.geometry.type $==$ "point") \{

//search the table for programs from a country

$/ /$ where country $=$ country

//return program name, synopsis and URL

$/ /$ no need to return geometry

var queryTask5 = new QueryTask(TC_CountryTable); //Teaching_Country

var query5 = new Query();

query5.returnGeometry = false;

query5.outFields = ["Instructor", "InstrLastName", "Course_Name", "Course_ID",

"Synopsis", "URL"];

query5.where $=$ "Country $=$ "' + feature.attributes.Country + "'";

//execute the query, showResults as the callback function

queryTask5.execute(query5, showResults);

function showResults(results) \{

var ReturnedFeatures = results.features;

var numResults = ReturnedFeatures.length;

var FeatureAttributes;

//create the beginning of the text string

var FacTeachTextString $="<\mathrm{B}>$ Courses in " + feature.attributes.Country +

"</B $><$ br $><$ br $>$;

//keep adding to the string for display in the window pane.

for (var $i=0$; $i$ < numResults; $i++$ ) \{

FeatureAttributes $=$ ReturnedFeatures[i].attributes;

//format each chunk of program for the content pane

//need to check if there is valid values

if (FeatureAttributes.Course_Name $!=$ null) \{

FacTeachTextString = FacTeachTextString $+"\langle\mathrm{~b}\rangle "+$

\}

FeatureAttributes.Course_Name + "</b $>\langle b r\rangle "$;

if (FeatureAttributes.Course_ID != null) \{

FacTeachTextString = FacTeachTextString + "Course ID: " +

\}

FeatureAttributes.Course_ID + "<br $>$;

if (FeatureAttributes.Synopsis != null) \{

FacTeachTextString $=$ FacTeachTextString + FeatureAttributes.Synopsis +

"<br>";

\} 
FacTeachTextString = FacTeachTextString + "By: " + FeatureAttributes.Instructor +

" " + FeatureAttributes.InstrLastName + "<br $>$ ";

if (FeatureAttributes.URL != null) \{

FacTeachTextString = FacTeachTextString + "<a href="" + FeatureAttributes.URL

+ "'>Link $</ a>"$ + "<br $>$ ";

\}

FacTeachTextString = FacTeachTextString + "<br $>$;

y//end of for

//clear the pane of previous items and write the new items to pane

FacultyTeachTab.destroyDescendants(true);

FacultyTeachTab.set('content', FacTeachTextString);

return;

\};//end function showResults

y//end if

else if (feature.geometry.type == "polygon") \{

//search the table for programs from a region

$/ /$ where region $=$ REGION

//return program name, synopsis and URL

$/ /$ no need to return geometry

var queryTask6 = new QueryTask(TC_RegionTable); //Teaching_Region

var query6 = new Query () ;

query6.returnGeometry = false;

query6.outFields = ["Instructor", "InstrLastName", "Course_Name", "Course_ID",

"Synopsis", "URL_If_any_"];

query6. where $=$ "Region $=$ "' + feature.attributes.subregion + "'";

//execute the query, show Results as the callback function

queryTask6.execute(query6, showResults);

function showResults(results) \{

var ReturnedFeatures = results.features;

var numResults = ReturnedFeatures.length;

var FeatureAttributes;

//create the beginning of the text string

var FacTeachTextString $="\langle\mathrm{~B}\rangle$ Courses in " + feature.attributes.subregion + $"</ \mathrm{B}>\langle\mathrm{br}><\mathrm{br}>$;

//keep adding to the string for display in the window pane.

for (var $i=0$; $i$ < numResults; $i++)\{$

FeatureAttributes $=$ ReturnedFeatures[i].attributes;

//format each chunk of program for the content pane

$/ /$ need to check if there is valid values returned

if (FeatureAttributes.Course_Name $!=$ null) \{

FacTeachTextString $=$ FacTeachTextString $+"\langle b\rangle "+$

FeatureAttributes.Course_Name $+"\langle/ \mathrm{b}\rangle\langle\langle\mathrm{br}\rangle "$; \} 


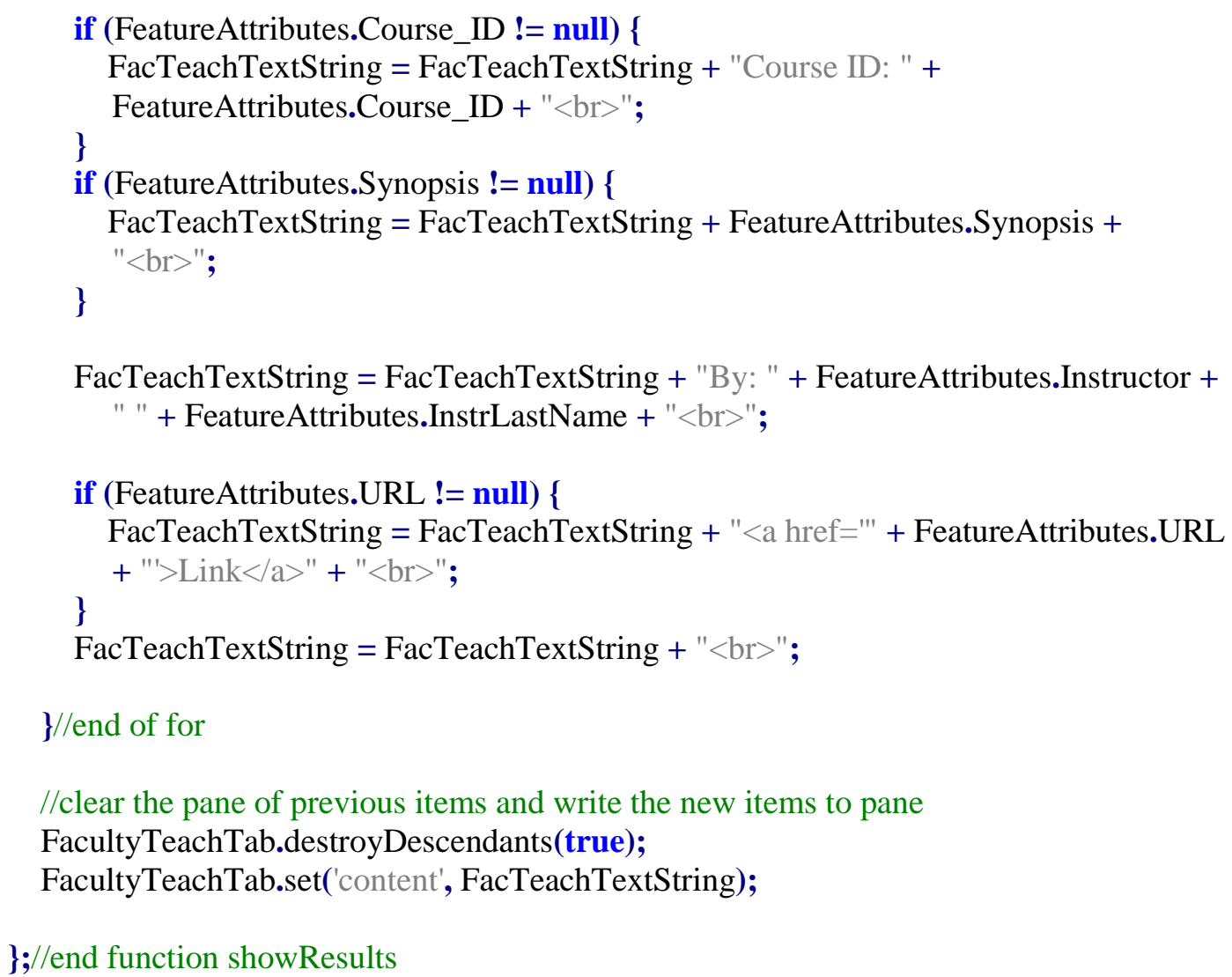




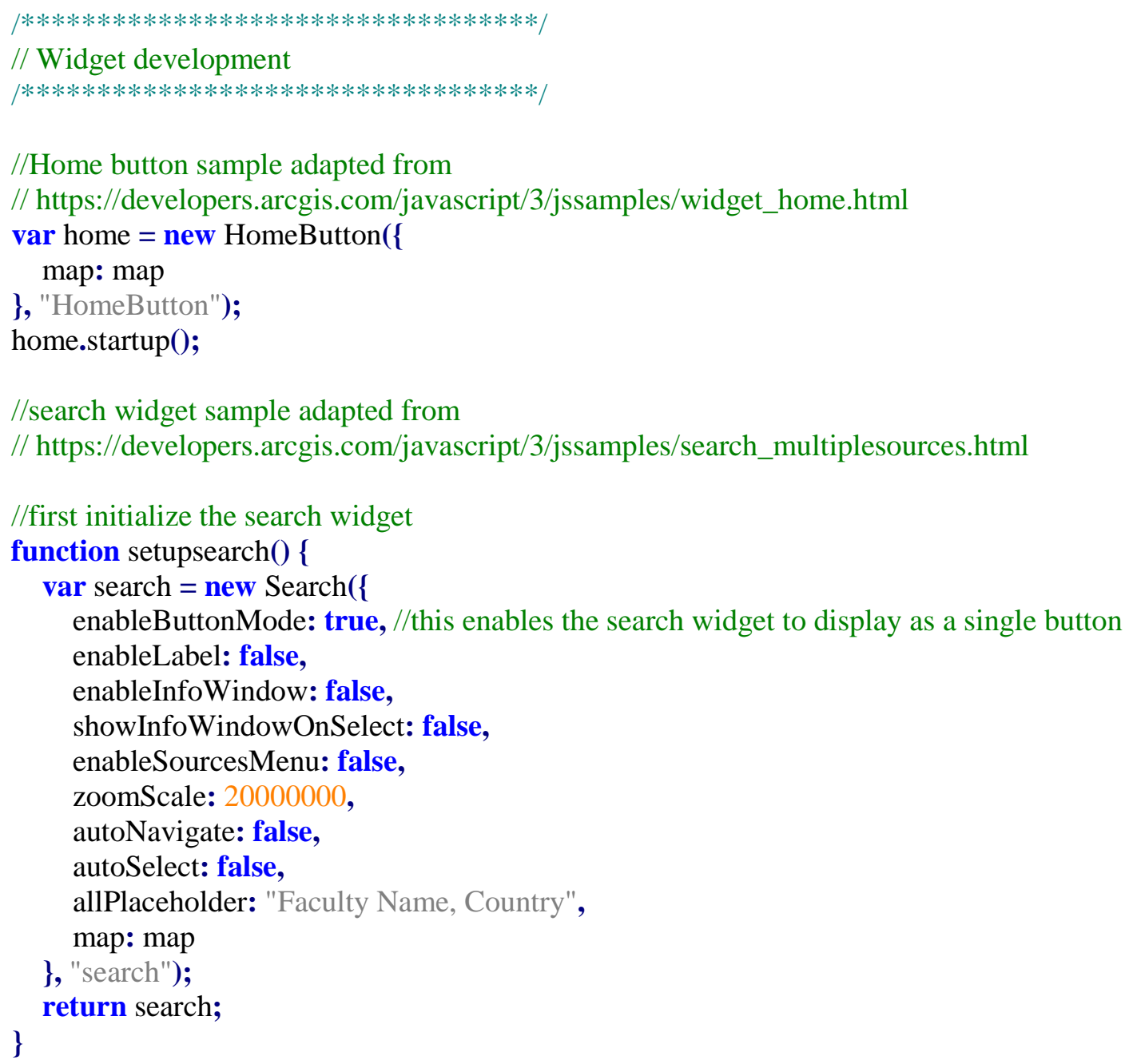

//get the initial list of sources, remove Esri geo coder from the list sources = search.get("sources"); sources.shift();

//setup the sources needed for the search according to which pane the user is on

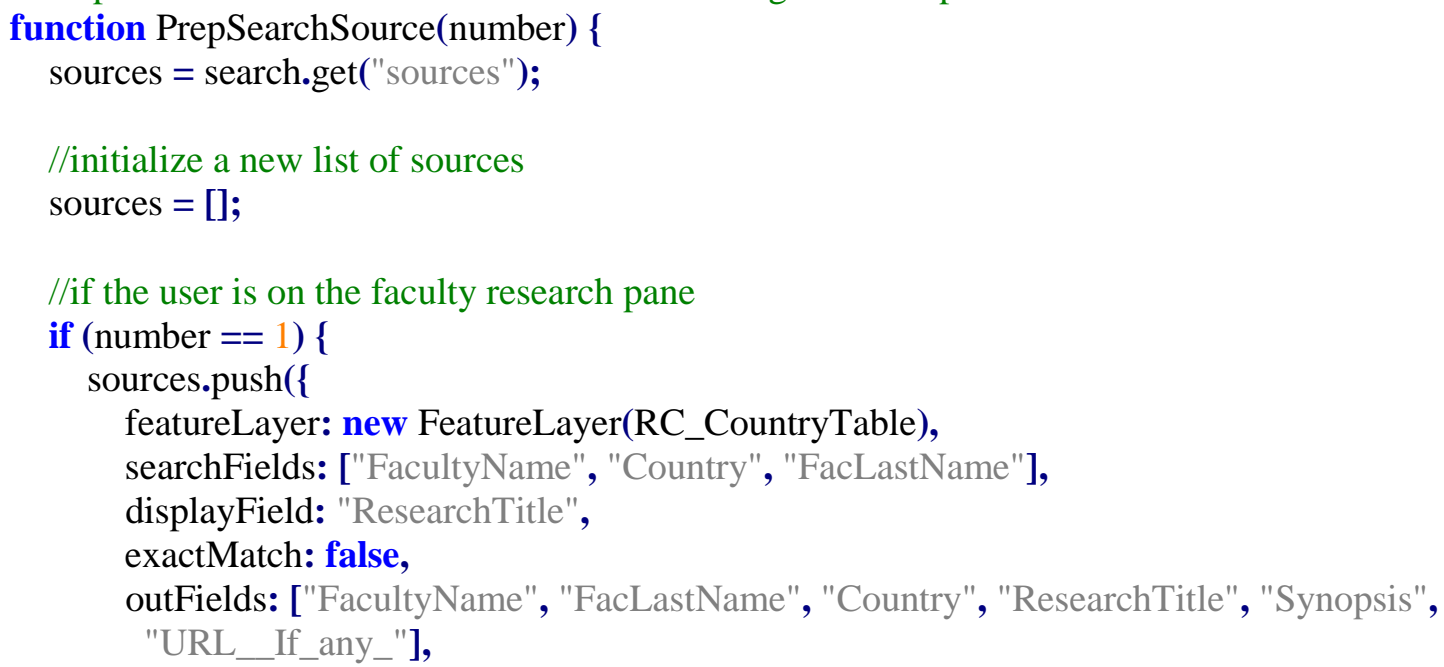




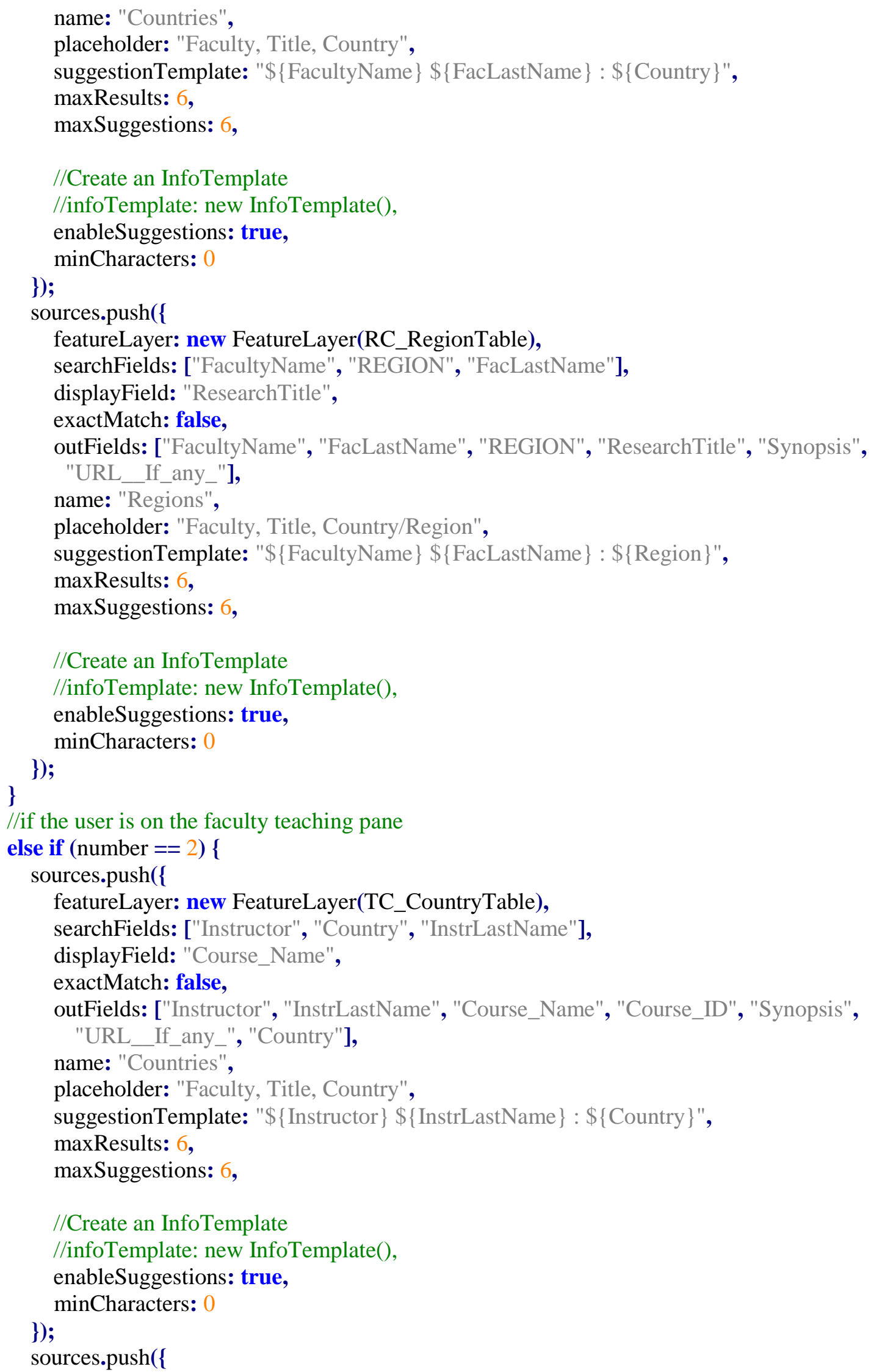




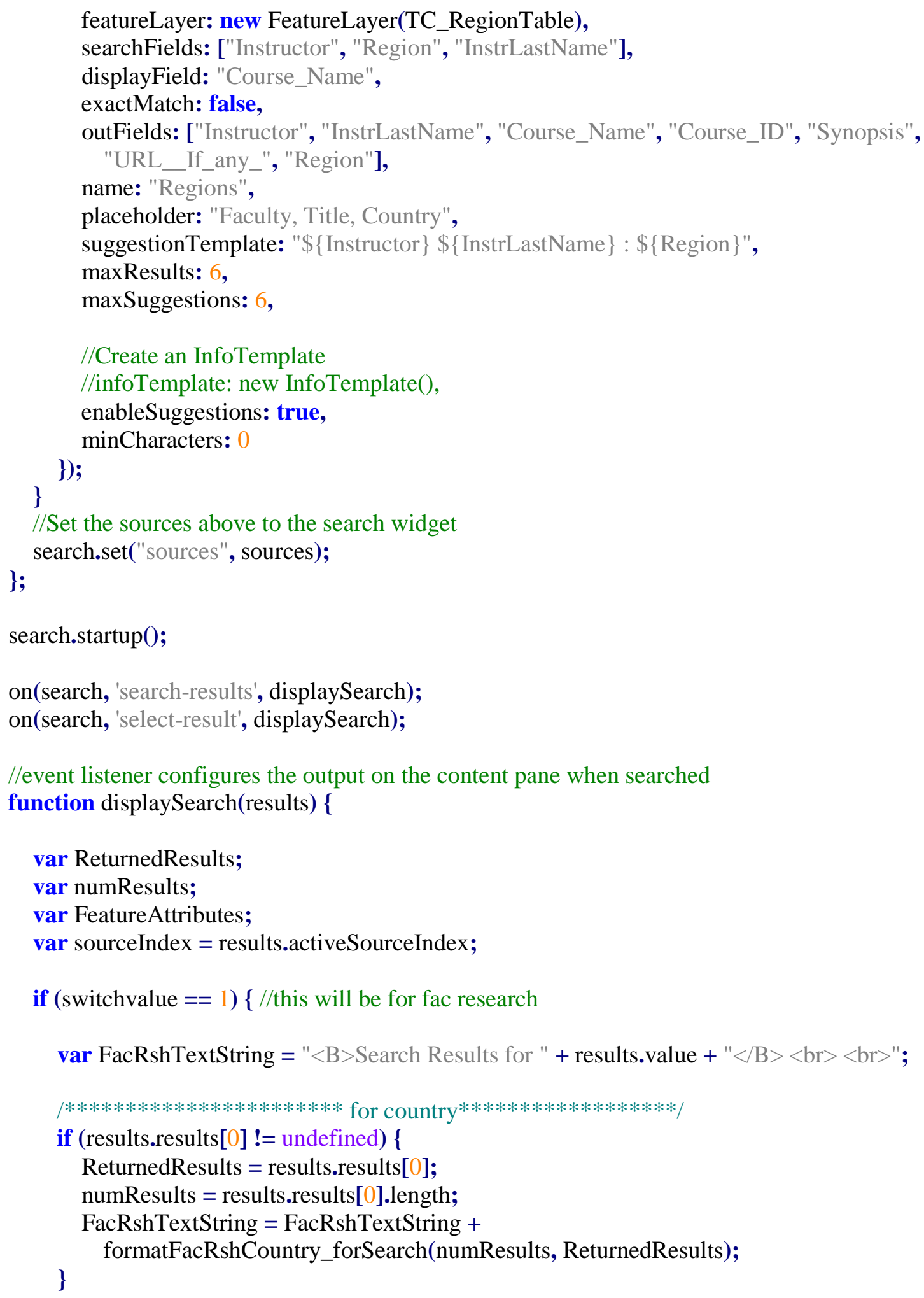




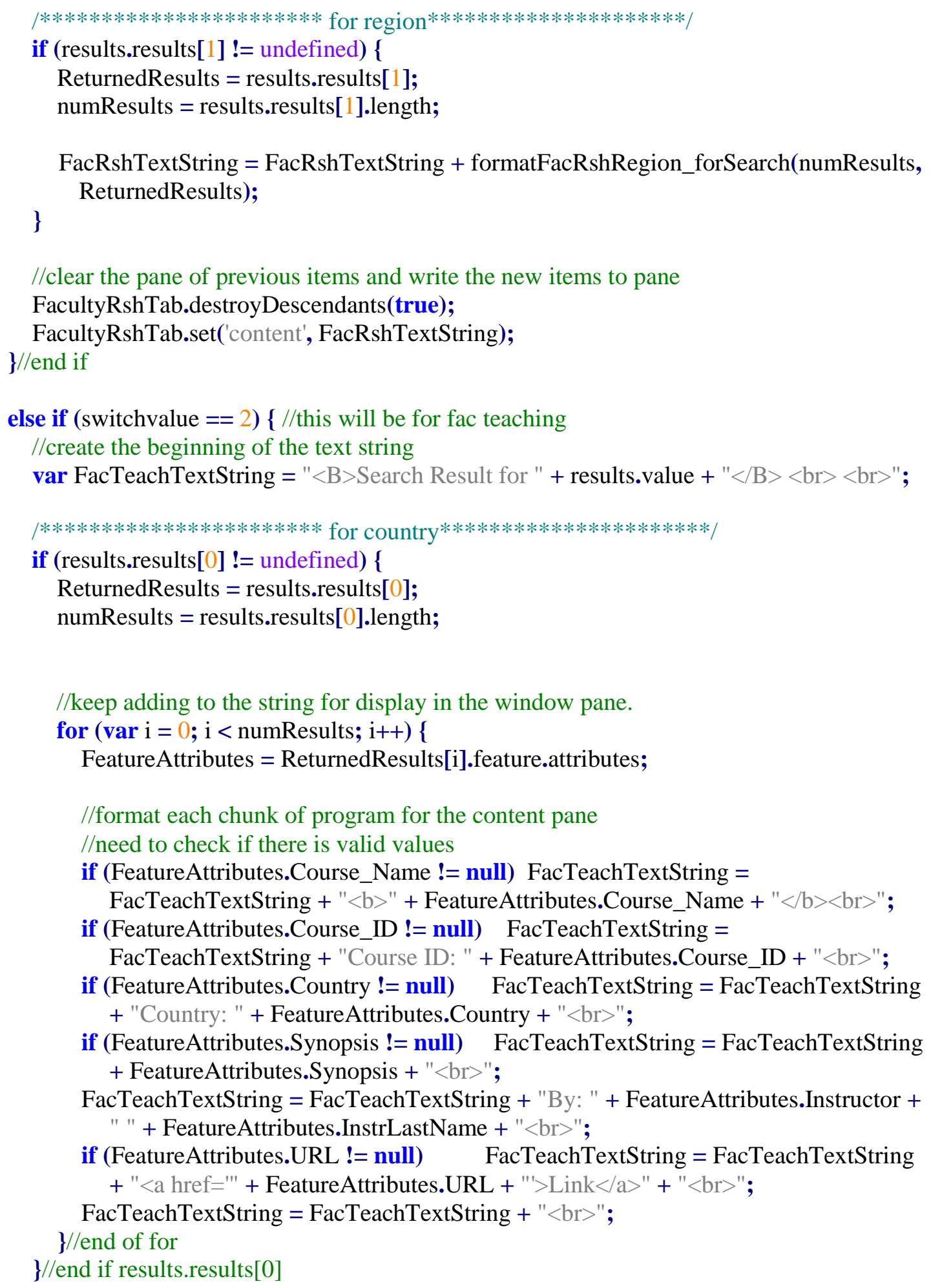




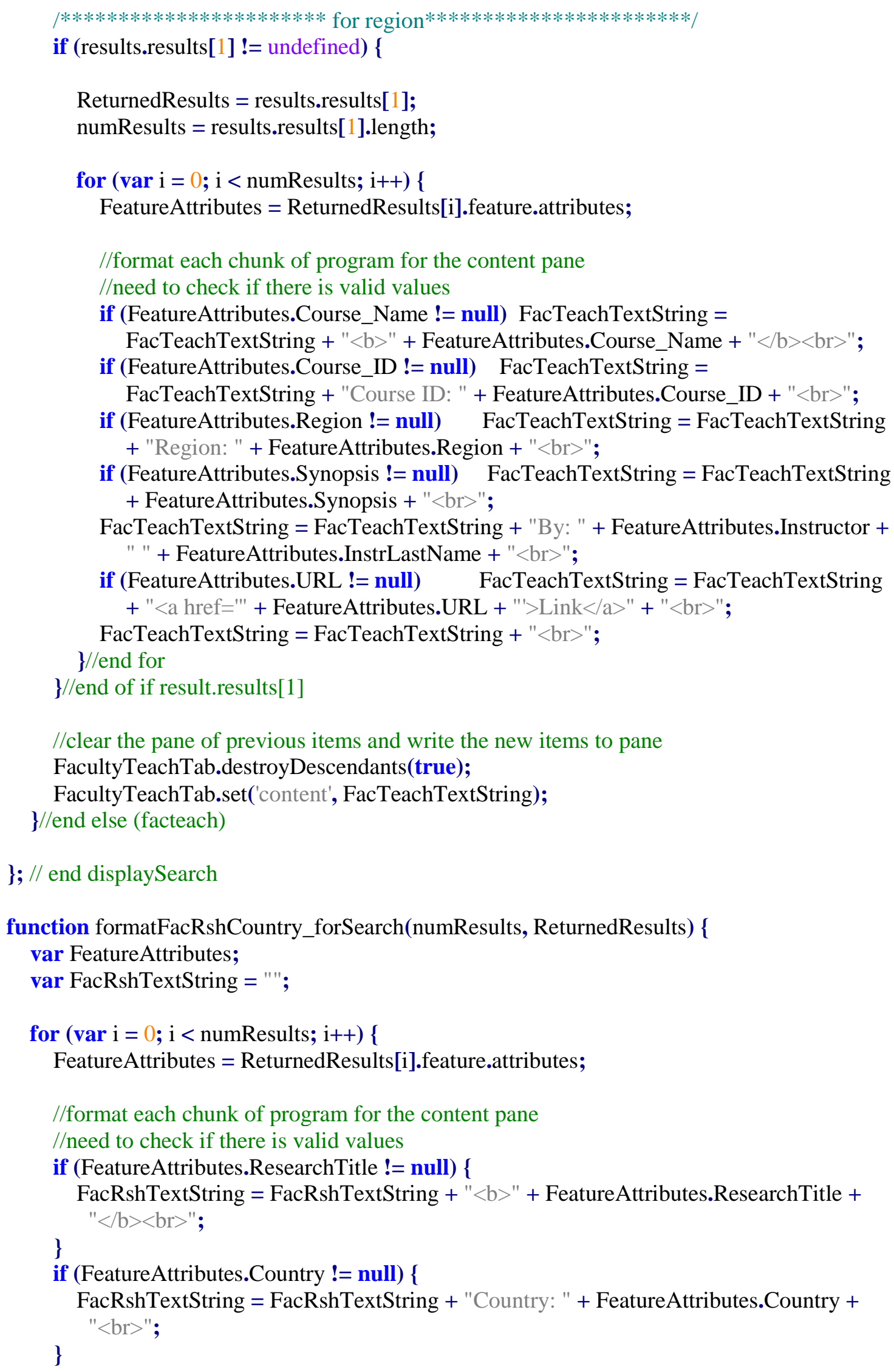




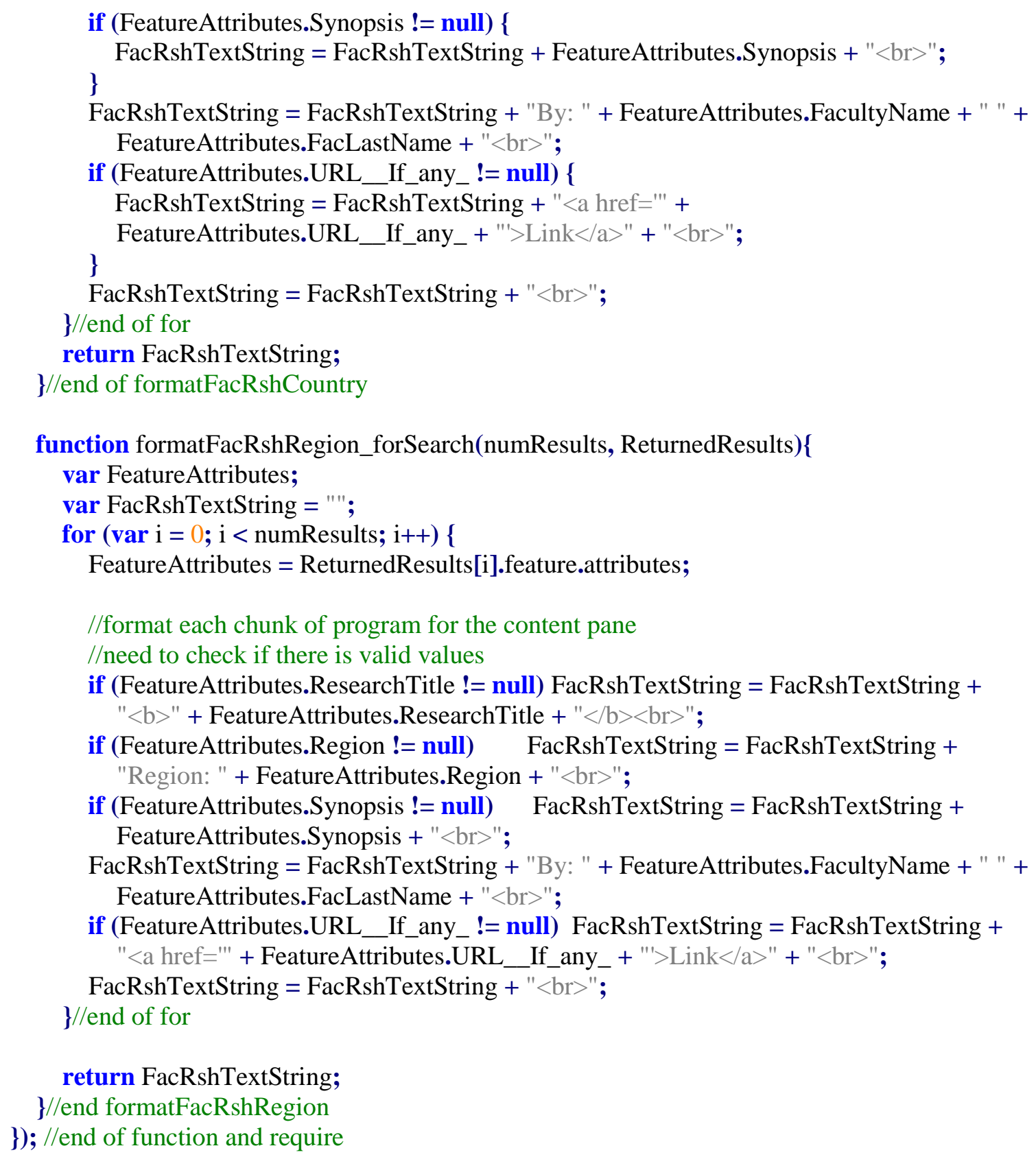




\section{Appendix C. CSS Code}

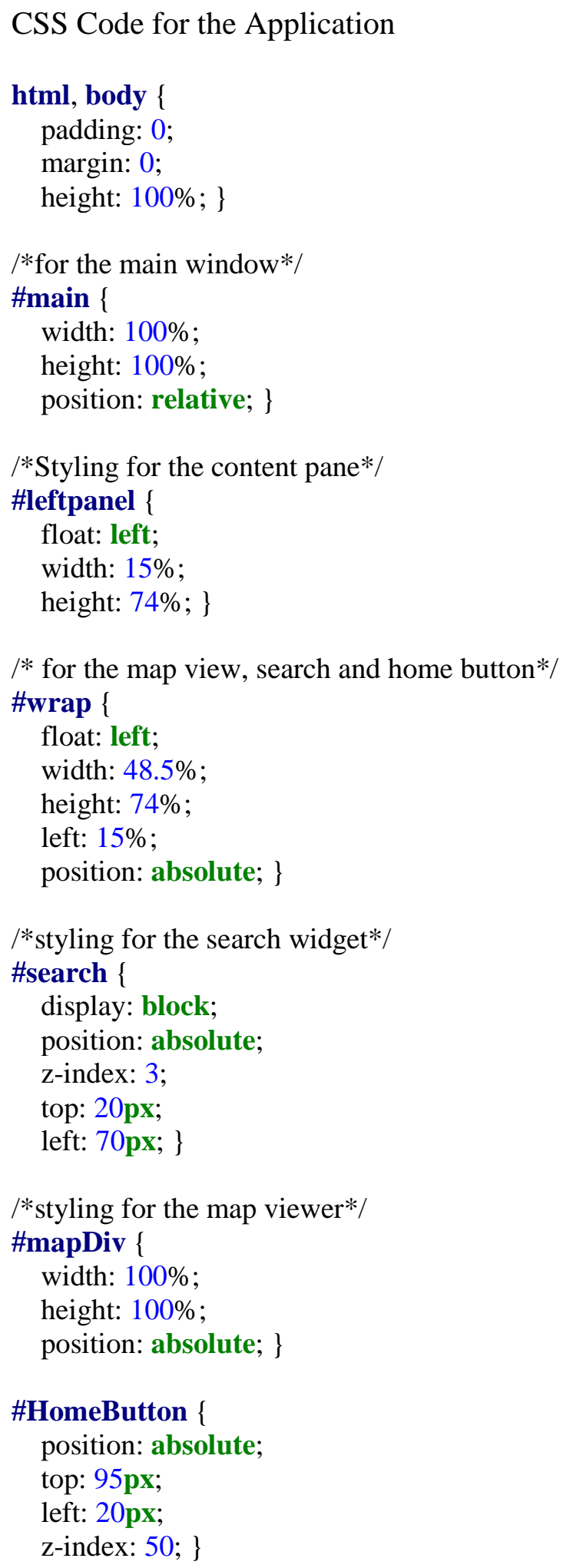

